
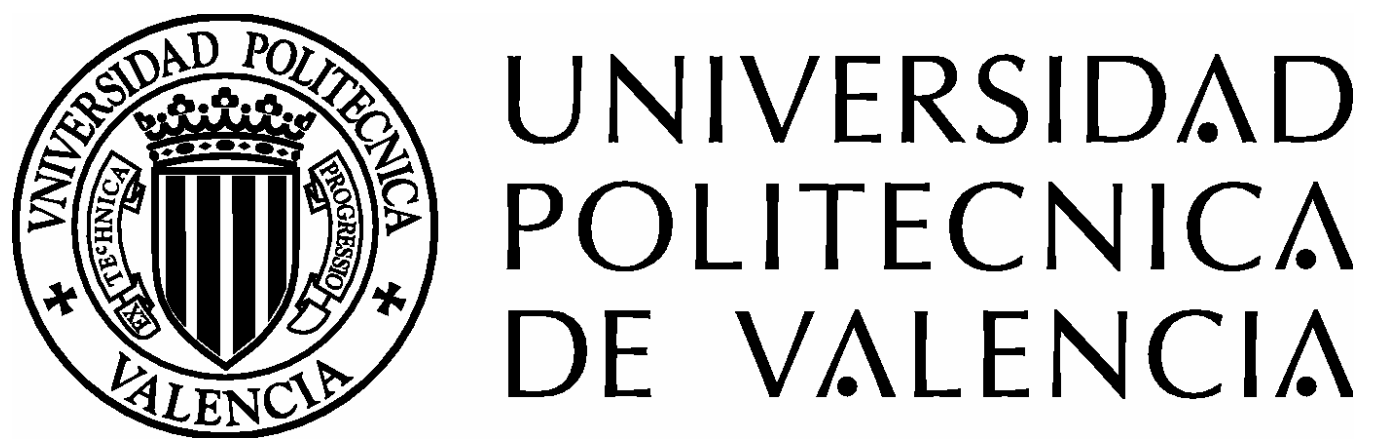

DEPARTAMENTO DE TECNOLOGÍA DE ALIMENTOS

\title{
SUCEDÁNEO DEL CAFÉ A PARTIR DE ALGARROBA (Prosopis alba Griseb)
}

TESIS DOCTORAL

Presentada por:

DANTE BASILIO PROKOPIUK

Directores:

Doctora Amparo Chiralt Boix

Doctor Gastón Cruz Alcedo

Valencia, 2004 


\section{UNIVERSIDAD \\ POLITECNICA \\ DE VALENCIA}

DEPARTAMENTO DE TECNOLOGÍA DE ALIMENTOS

DRA. AMPARO CHIRALT BOIX, CATEDRÁTICA DEL DEPARTAMENTO DE TECNOLOGÍA DE ALIMENTOS DE LA UNIVERSIDAD POLITÉCNICA DE VALENCIA.

CONSIDERA: que la memoria titulada "SUCEDÁNEO DEL CAFÉ A PARTIR DE ALGARROBA (Prosopis alba Griseb)" para aspirar al grado de Doctor en Ciencia y Tecnología de Alimentos, presenta Dante Basilio Prokopiuk, realizada bajo mi dirección en el Departamento de Tecnología de Alimentos de la Universidad Politécnica de Valencia, reúne las condiciones adecuadas como Tesis Doctoral, por lo que AUTORIZO al interesado su presentación en ese doctorado.

Valencia, Octubre de 2004

Dra. Amparo Chiralt Boix Directora de la Tesis Doctoral 
A mi esposa Mirta y a mis hijos Pablo, Estefanía, Carolina y Fernando 


\section{AGRADECIMIENTOS}

A la Directora de Tesis, Doctora Amparo Chiralt Boix, del Departamento de Tecnología de Alimentos de la Universidad Politécnica de Valencia, por su excelente guía, revisión crítica y corrección de la Tesis.

Al Co-Director de Tesis, Doctor Gastón Cruz Alcedo, de la Unidad de Proyectos Ambientales y Desarrollo Integral de la Universidad de Piura, Piura, Perú, quién en el año 2000 durante una pasantía en la Universidad de Piura valoró mi entusiasmo para el estudio del fruto de Prosopis y me permitió: trabajar en su laboratorio y en la planta piloto; acceder a su importante base de datos; discutir procedimientos y resultados; y publicar en conjunto. Después, con su experiencia en Prosopis me orientó en el proyecto de Tesis, y efectuó una excelente revisión crítica y corrección de la misma.

Al Doctor Oscar Garro, de la Facultad de Agroindustrias de la Universidad Nacional del Nordeste, Presidencia Roque Sáenz Peña, Chaco, Argentina, por su aporte en la discusión de las técnicas y resultados de los análisis de laboratorio, y la revisión crítica de la Tesis.

Al Ingeniero Hugo Sánchez, que puso a mi disposición el Instituto de Tecnología de Alimentos de la Universidad Nacional del Litoral, Santa Fe de la Veracruz, Argentina, y con quién realicé en la planta piloto los ensayos de tostado, molienda y tamizado de las algarrobas.

A la Doctora Nora Sabbag, del Instituto de Tecnología de Alimentos de la Universidad Nacional del Litoral, con quién hice la evaluación sensorial de las harinas.

A la Ingeniera Claudia Lesa, de la Facultad de Ciencias de la Alimentación de la Universidad Nacional de Entre Ríos, Concordia, Argentina, con quien analicé fibra dietética y efectué las mediciones de color de las harinas.

A la Bioquímica Gisela Fabiani, de la Facultad de Agronomía y Agroindustrias de la Universidad Nacional de Santiago del Estero, Argentina, con quien realicé la identificación y cuantificación por cromatografía de los azúcares en las harinas.

Al Profesor José Schrdeter, del Instituto Don Orione, de Presidencia Roque Sáenz Peña, por la revisión lingüística de la Tesis.

Al Señor Hugo Domínguez, de Envaril Plastic Packaging S.R.L., Buenos Aires, Argentina, por el suministro de los envases para las muestras.

Al Psicólogo Roberto Curín, de Presidencia Roque Sáenz Peña, por permitirme trabajar con los frutos de su rodal puro de Prosopis alba Griseb.

Al personal de la Cátedra de Fisicoquímica de la Facultad de Agroindustrias de la U.N.N.E., por su permanente colaboración.

Al Arquitecto Oscar Valdés, Rector de la Universidad Nacional del Nordeste, Corrientes, Argentina, por su firme apoyo.

Al Ingeniero Federico Kaenel, Decano de la Facultad de Agroindustrias de la Universidad Nacional del Nordeste, por su constante apoyo.

Al Doctor Ramón Avanza, Secretario General de Ciencia y Técnica de la Universidad Nacional del Nordeste, por el soporte financiero, sin el cual no hubiera sido posible la realización de este trabajo. 


\section{ÍNDICE}

$\begin{array}{ll}\text { I. INTRODUCCIÓN } & 1\end{array}$

1. LA ALGARROBA COMO ALIMENTO 2

1.1 Descripción general 2

1.2 Producción y cosecha de algarrobas 5

1.3 Productos tradicionales derivados de la algarroba 5

1.4 Composición de la algarroba 9

1.4.1 PULPA 9

$\begin{array}{ll}1.4 .2 \text { ENDOCARPIO } & 11\end{array}$

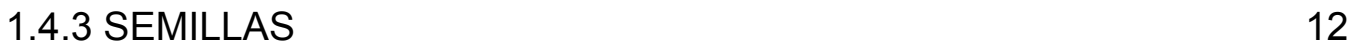

1.4.4 FACTORES ANTINUTRICIONALES 13

1.5 Procesamiento para obtener nuevos productos 14

2. SUCEDÁNEOS DEL CAFÉ 17

$\begin{array}{lr}2.1 \text { Antecedentes } & 17\end{array}$

3. CAFÉ GENUINO 20

3.1 Generalidades $\quad 20$

3.2 El fruto del café $\quad 21$

3.3 Procesamiento del fruto del café 21

3.4 Composición química $\quad 22$

3.5 Composición lipídica 23

3.6 Componentes aromáticos $\quad 24$

3.7 Componentes ácidos 25

$\begin{array}{ll}\text { II. OBJETIVOS } & 26\end{array}$

1. OBJETIVOS 27

1.1 Objetivo general $\quad 27$

$\begin{array}{ll}1.2 \text { Objetivos específicos } & 27\end{array}$

III. MATERIALES Y MÉTODOS 28

1. PREPARACIÓN DE LAS MUESTRAS 29

1.1 Recolección 29

1.2 Selección 29

1.3 Limpieza $\quad 29$

1.4 Secado $\quad 29$

1.5 Tostado $\quad 29$

$\begin{array}{ll}1.6 \text { Molienda } & 29\end{array}$ 
1.7 Tamizado 30

1.8 Envasado 30

2. CARACTERIZACIÓN FÍSICA Y QUÍMICA DE LA ALGARROBA 31 CRUDA Y TOSTADA

2.1 Caracterización del grado de tueste 31

2.2 Distribución del tamaño de partícula 32

2.2.1 NIVEL Y GRADO DE FINEZA 32

2.3 Determinación de las isotermas de sorción de agua 33

2.3.1 AJUSTE DEL MODELO DE BET 35

2.3.2 AJUSTE DEL MODELO DE GAB 35

2.3.3 EFECTO DE LA TEMPERATURA. CALOR ISOSTÉRICO DE
SORCIÓN

2.4 Cuantificación de sólidos solubles 37

2.5 Humedad 37

2.6 Proteínas totales 38

2.7 Lípidos totales 38

2.8 Cenizas 38

2.9 Minerales 38

2.10 Fibra cruda 38

2.11 Carbohidratos totales 38

2.12 Valor energético 39

2.13 Taninos condensados 39

2.14 Polifenoles solubles totales 39

2.15 Cafeína 39

2.16 Fibra dietética 40

2.17 Lisina 40

2.18 Azúcares 40

2.18.1 AZÚCARES TOTALES 40

2.18.2 AZÚCARES REDUCTORES 40

2.18.3 TIPOS DE AZÚCARES POR HPLC 41

3. EVALUACIÓN SENSORIAL 41

3.1 Preparación de la infusión 41

3.2 Selección del panel de catadores 41

3.3 Organización de las sesiones de cata 42

3.3.1 ANÁLISIS DESCRIPTIVOS 42

3.3.2 ACEPTABILIDAD SENSORIAL 42

3.3.3 ANÁLISIS ESTADÍSTICO DE LOS RESULTADOS 43

IV. RESULTADOS Y DISCUSIÓN

1. CARACTERIZACIÓN FÍSICA Y QUÍMICA DE LA ALGARROBA CRUDA Y TOSTADA 45

1.1 Selección 45 
1.2 Secado

1.3 Caracterización del grado de tueste 45

1.4 Distribución del tamaño de partículas 53

1.5 Isoterma de sorción de agua de la algarroba cruda 54

1.5.1 AJUSTE DEL MODELO DE BET 56

1.5.2 AJUSTE DEL MODELO DE GAB 57

1.5.3 EFECTO DE LA TEMPERATURA. CALOR ISOSTÉRICO DE SORCIÓN

1.6 Isoterma de sorción de agua de la algarroba tostada 60

1.6.1 AJUSTE DEL MODELO DE BET 61

1.6.2 AJUSTE DEL MODELO DE GAB 62

1.6.3 EFECTO DE LA TEMPERATURA. CALOR ISOSTÉRICO DE SORCIÓN

1.6.4 EFECTO DEL TOSTADO

1.7 Sólidos solubles $\quad 67$

1.8 Composición química 68

1.9 Azúcares 71

1.9.1 AZÚCARES TOTALES

1.9.2 AZÚCARES REDUCTORES

1.9.3 TIPOS DE AZÚCARES POR HPLC

2. EVALUACIÓN SENSORIAL 75

2.1 Análisis descriptivos 75

2.2 Aceptabilidad sensorial 83

V. CONCLUSIONES

$\begin{array}{ll}\text { VI. BIBLIOGRAFÍA } & 87\end{array}$ 


\section{RESUMEN}

Prosopis alba Griseb (algarrobo blanco) es una leguminosa arbórea que crece naturalmente en el Chaco argentino. Los frutos o algarrobas son dulces y tienen un apreciable valor proteico, por ello son utilizadas en la alimentación humana y animal, principalmente secas y molidas o en forma de extractos acuosos.

El objetivo de este trabajo de tesis doctoral fue desarrollar un sucedáneo de café a partir de la algarroba de Prosopis alba Griseb. Para ello, se tostaron las algarrobas a seis temperaturas $(100,115,130,145,160$ y $\left.175^{\circ} \mathrm{C}\right)$ y a tres tiempos (30, 45 y $\left.60 \mathrm{~min}\right)$. Sobre las fracciones de algarroba tostada molida retenidas sobre el tamiz de $0,25 \mathrm{~mm}$ se realizaron las siguientes determinaciones: caracterización del grado de tueste (color), distribución del tamaño de partículas, determinación de las isotermas de sorción de agua, cuantificación de sólidos solubles, propiedades químiconutricionales (humedad, proteína, cenizas, lípidos, minerales, fibra cruda, carbohidratos totales, valor energético, taninos, polifenoles, cafeína, fibra dietética, lisina, y azúcares) y evaluación sensorial de las infusiones.

El estudio de la influencia del tostado sobre las características del producto final reveló que los valores de la energía aparente de activación $\left(E_{a}\right)$ fueron muy similares para las funciones de color: luminosidad $\left(L^{*}\right)$ y croma métrico $\left(\mathrm{C}^{*} \mathrm{ab}\right)$, lo cual muestra que son indicadores equivalentes de la evolución del pardeamiento durante el proceso de tostado. En las muestras tostadas a 160 y $175^{\circ} \mathrm{C}$ fue posible obtener valores del tono, croma y luminosidad del producto en el intervalo de los encontrados para café tostado. El tostado modificó el comportamiento de la adsorción del agua en la algarroba, disminuyendo la tendencia a la humectación y la capacidad de retención de agua. El contenido de sacarosa disminuyó con el tiempo y temperatura de tostado. El aroma de las infusiones ensayadas, presentó matices de tostado, miel, hierba, y chocolate. La muestra tostada a $160^{\circ} \mathrm{C}$ durante 60 min es la que desarrolló aroma más parecido al de café genuino, y tuvo mayor aceptación entre los consumidores consultados.

Se concluye que en este trabajo se logró desarrollar un nuevo producto con tecnología simple, con variables definidas de control de proceso (color, temperatura y tiempo), totalmente natural, sin cafeína, y de sabor y aroma agradable. 


\section{RESUM}

Prosopis alba Griseb és una lleguminosa arbórea que creix naturalment en el Chaco argentí. Els fruits o garrofes són dolços i tenen un apreciable valor proteic, per això són utilitzades en l'alimentació humana i animal, principalment seques i mòltes o en forma d'extractes aquosos.

L'objectiu d'este treball de tesi doctoral va ser desenrotllar un succedani de café a partir de la garrofa de Prosopis alba Griseb. Per a això, es van torrar les garrofes a sis temperatures $\left(100,115,130,145,160 \mathrm{i} 175^{\circ} \mathrm{C}\right)$ i a tres temps (30, 45 i $60 \mathrm{~min})$. Sobre les fraccions de garrofa torrada mòlta retingudes sobre el tamís de $0,25 \mathrm{~mm}$ es van caracteritzar: el grau de torre (color), distribució del tamany de partícules, determinació de les isotermes de sorción d'aigua, quantificació de sòlids solubles, propietats químicnutricionals (humitat, proteïna, cendres, lípids, minerals, fibra crua, carbohidratos totals, valor energètic, taninos, polifenoles, cafeïna, fibra dietètica, lliseta, i sucres) i avaluació sensorial de les infusions.

L'estudi de la influència del torrat sobre les característiques del producte final va revelar que els valors de l'energia aparent d'activació $\left(E_{a}\right)$ van ser molt semblants per a les funcions de color: lluminositat $\left(L^{*}\right)$ i croma mètric $\left(C^{*}{ }_{a b}\right)$, la qual cosa mostra que són indicadors equivalents de l'evolució del obscuriment durant el procés de torrat. En les mostres torrades a $160 \mathrm{i}$ $175^{\circ} \mathrm{C}$ va ser possible obtindre valors del to, croma i lluminositat del producte en d'interval dels trobats per a café torrat. El torrat va modificar el comportament de l'adsorció de l'aigua en la garrofa, disminuint la tendència a la humectació i la capacitat de retenció d'aigua. El contingut de sacarosa va disminuir amb el temps i temperatura de torrat. L'aroma de les infusions assajades, va presentar matisos de torrat, mel, herba, i xocolata. La mostra torrada a $160^{\circ} \mathrm{C}$ durant $60 \mathrm{~min}$ és la que va desenrotllar aroma més paregutal cafè genuïna, i va tindre major acceptació entre els consumidors consultats.

Es conclou que en este treball es va aconseguir desenrotllar un nou producte amb tecnologia simple, amb variables definides de control de procés (color, temperatura i temps), totalment natural, sense cafeïna, i de sabor i aroma agradable. 


\section{ABSTRACT}

Prosopis alba Griseb is a leguminous tree that grows naturally in the Argentinean Chaco. Its fruits (pods) are sweet and have significant protein content. They have been used for human and animal feeding, especially dried and milled, and also as an aqueous extract.

The objective of the present work was to develop a coffee substitute from the pods of Prosopis alba Griseb. The pods were roasted at six different temperatures $\left(100,115,130,145,160\right.$ y $\left.175^{\circ} \mathrm{C}\right)$ and at three different times (30, 45 y $60 \mathrm{~min}$ ). Samples of roasted material retained by $0,25 \mathrm{~mm}$ sieve, were analyzed in order to determine: degree of roasting (colour), particle size distribution, isotherm adsorption curves, soluble solids, chemical-nutritional properties (moisture, protein, lipids, minerals, crude and dietary fibre, total carbohydrates, energy value, tannins, polyphenols, caffeine, lysine, and sugars). Moreover, sensorial properties of infusions prepared from the roasted material were evaluated.

The study of the influence of roasting on the product properties revealed that apparent activation energy $\left(E_{a}\right)$, values were similar to the colour functions: luminosity $\left(\mathrm{L}^{*}\right)$ and metric chroma $\left(\mathrm{C}^{*}{ }_{\mathrm{ab}}\right)$. This fact shows that both parameters are good indicators for the evolution of browning during the roasting process. On the samples roasted at 160 and $175^{\circ} \mathrm{C}$, the resulting values for hue, chroma and luminosity are comparable with those found for roasted coffee. Roasting changed the water adsorption behaviour of pod: roasted pod showed a lower hygroscopicity. Sucrose content decreased when time and temperature of roasting were increased. Taste of assayed infusions was described as roast, honey, herbal and chocolate tones. The sample roasted at $160^{\circ} \mathrm{C}$ during 60 min developed the best aroma (closely related to coffee) and it had the highest acceptability by the surveyed consumers.

In conclusion, this work let to develop a new food product that could be produced with a simple technology. This technology offers defined parameters for the roasting process control such as colour, temperature and time. The product is natural, caffeine-free and has good taste and flavour. 


\section{INTRODUCCIÓN}




\section{LA ALGARROBA COMO ALIMENTO}

\subsection{Descripción general}

Todas las especies de Prosopis son leguminosas arbóreas o arbustivas que presentan gran resistencia a la sequía y a la salinidad, y tienen alta capacidad de fijar nitrógeno. Sus frutos son legumbres con alto contenido de proteínas e hidratos de carbono, que varían en tamaño, color y características químicas, según la especie. Esto hace que su cultivo sea recomendado con una doble finalidad: detener el avance de la desertificación y erosión del suelo en zonas áridas y semiáridas, y utilizar sus frutos para alimentación humana y animal en países en desarrollo (Fagg y Stewart, 1994).

Del género Prosopis se conocen 44 especies en todo el mundo, distribuidas por América (40), sudoeste de Asia (3), y África (1). En la Argentina se encuentran 28 especies de Prosopis: 17 son arbóreas y el resto arbustiva. La mayor concentración de árboles está en el Chaco (Roig, 1993a; Burkart, 1976).

El Chaco ocupa en la Argentina la porción centro-norte, con una superficie de 52 millones de hectáreas; se lo divide en tres regiones principales: Chaco árido, semiárido y subhúmedo. $P$. flexuosa y $P$. chilensis, en el Chaco árido, Prosopis alba y $P$. nigra, en el Chaco semiárido y subhúmedo, son las especies más frecuentes e importantes. Las características generales del Chaco son: latitud sur, 22 a $33^{\circ}$; altura sobre el nivel del mar, 50 a 250 m; precipitación anual, 500 a 1300 mm; temperatura, -6 a $+45^{\circ} \mathrm{C}$; profundidad de napa freática, 4 a $15 \mathrm{~m}$; y suelo, arcilloso (Coirini y Karlín, 1999; Roig, 1993a; Burkart, 1976).

Prosopis alba Griseb tiene como sinónimos vulgares: algarrobo; ibopémorotí, ibopé-pará o igopé-pará (en guaraní) que significa "árbol puesto en el camino para comer"; yurak-tacú, yaná-tacú, takku, taco juraj (en quechua) que significa "el árbol"; patá (en diaguita); maapik y joayuc (en toba); fwayuk (en wichí); malumpé (en vilela); roak (en abipón); y tiwis (en lengua maskoy) (Roig, 1993b).

Algarrobo es el nombre más usado para los árboles de Prosopis en Sudamérica y sus frutos o vainas son llamados algarrobas. El nombre algarrobo es también usado en España para el árbol Ceratonia siliqua, lo cual a veces causa confusión. Los españoles dieron al $P$. pallida el mismo nombre cuando arribaron a Perú en 1532, debido a la semejanza de sus frutos (Cruz, 1999). En Norteamérica las especies de Prosopis son conocidas como mesquite (Simpson, 1977), y sus frutos presentan considerables diferencias en forma y sabor respecto a la algarroba del Chaco.

Prosopis alba es el árbol por antonomasia para los pobladores del Chaco, a los que proporciona sombra, alimento, bebida, madera y combustible. Árbol de hasta $12 \mathrm{~m}$ de altura y $1 \mathrm{~m}$ de diámetro, copa globosa, redondeada, de hasta $10 \mathrm{~m}$ de diámetro; corteza pardo-grisáceo con fisuras oblicuas; ramas tortuosas, con espinas pares en las axilas de las hojas (FIGURA 1). 
Las hojas son caducas, de un verde claro brillante; bipinaticompuestas; eje central $1-8 \mathrm{~cm}$ de longitud, 1 a 3 pares de ejes laterales de $6-10 \mathrm{~cm}$ de longitud, 25 a 36 pares de foliolulos de $0,5-1,5 \mathrm{~cm}$ de longitud por 1-2 $\mathrm{mm}$ de ancho; fasciculadas o alternas; la distancia entre los foliolulos es menor o igual que el ancho de los mismos. Florece entre los meses de septiembre y noviembre. Las flores son perfectas, completas, de 5-7 $\mathrm{mm}$ de longitud, perfumadas; cáliz campanulado, corola con 5 pétalos libres, pubescentes, 10 estambres, ovario súpero; reunidas en racimos cilíndricos amarillo-verdosos, péndulos de 4-12 cm de longitud, reunidos en grupos de hasta 8; protoginas, la polinización es forzosamente cruzada (Zuloaga y Morrone, 1996; Galera et al., 1992; Biloni, 1990; Burkart, 1976) (FIGURA 2). Los frutos son vainas lineares, arqueadas o anulares, de 12 a $25 \mathrm{~cm}$ de largo, 1,2 a 1,8 cm de ancho y 0,5 a $0,6 \mathrm{~cm}$ de espesor, con un peso promedio de $10 \mathrm{~g}$, indehiscentes, amarillo paja cuando están maduras, muy comprimidas, de bordes paralelos, con semillas que se identifican en las caras laterales, y pulpa dulce. Las semillas (15 a 30 por vaina) son de forma ovoidal, de 6 a 7 $\mathrm{mm}$ de largo, 4 a $5 \mathrm{~mm}$ de ancho, $2 \mathrm{~mm}$ de espesor, 40 a $45 \mathrm{mg}$ de peso, muy duras y están constituidas de epispermo (tegumento castaño y muy fino), endospermo, y cotiledón (Prokopiuk et al., 2001; Biloni, 1990; Burkart, 1976). Una algarroba está compuesta de cuatro componentes separables mecánicamente: exocarpio (cáscara fibrosa), endocarpio (carozo fibroso), mesocarpio (pulpa), y semillas (FIGURA 3).

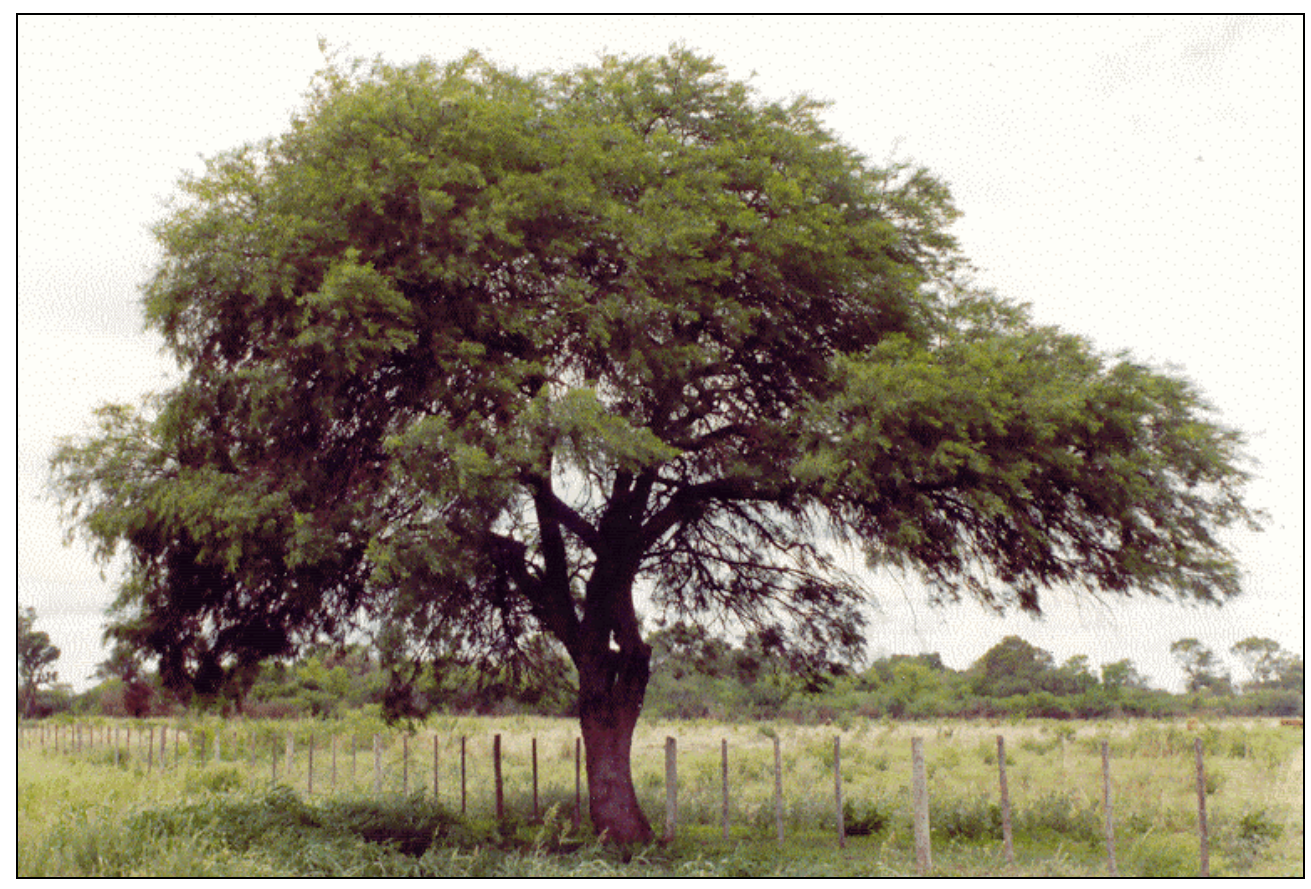

FIGURA 1. Árbol de Prosopis alba, Chaco, Argentina 


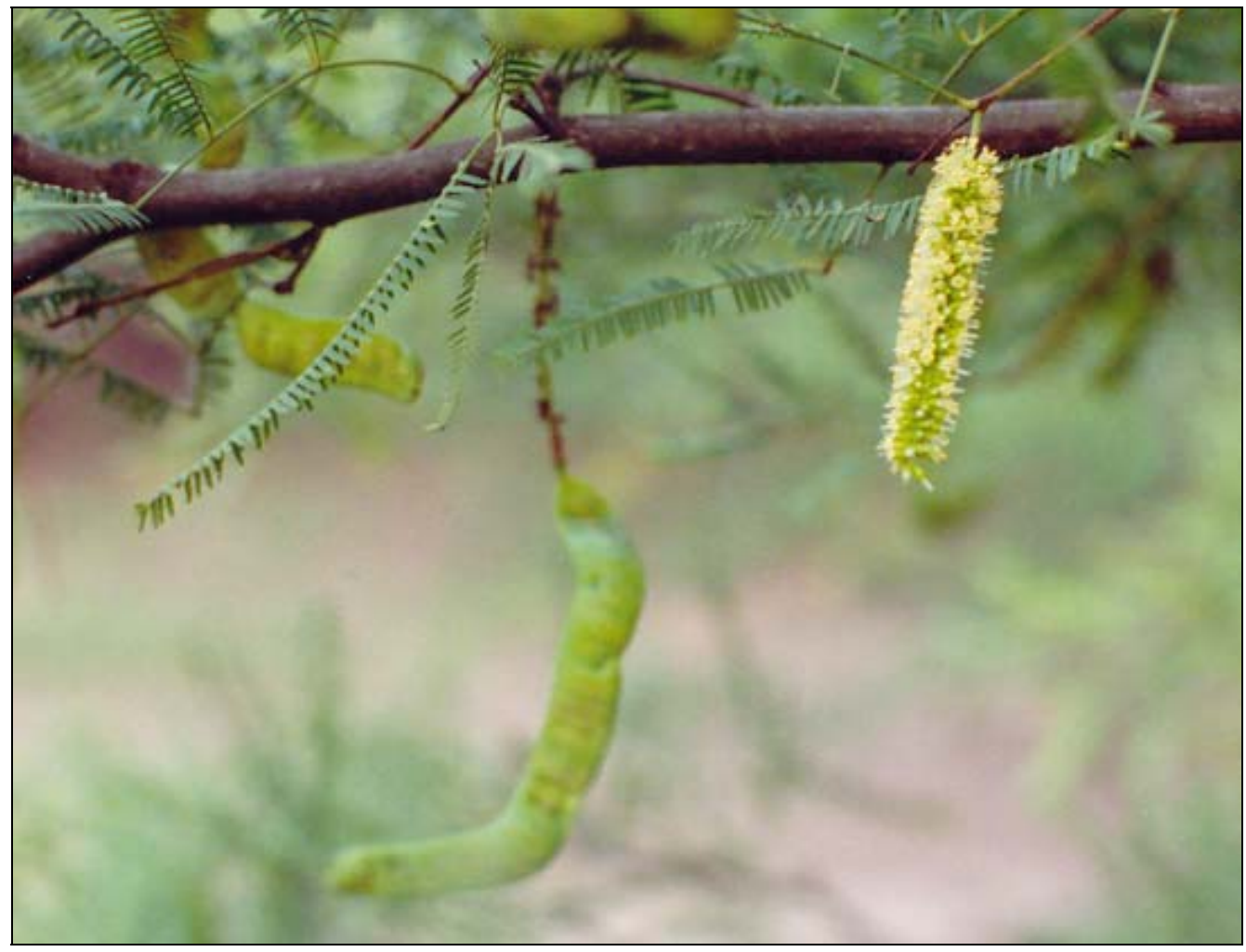

FIGURA 2. Algarrobas en formación, racimo floral, y hojas de Prosopis alba

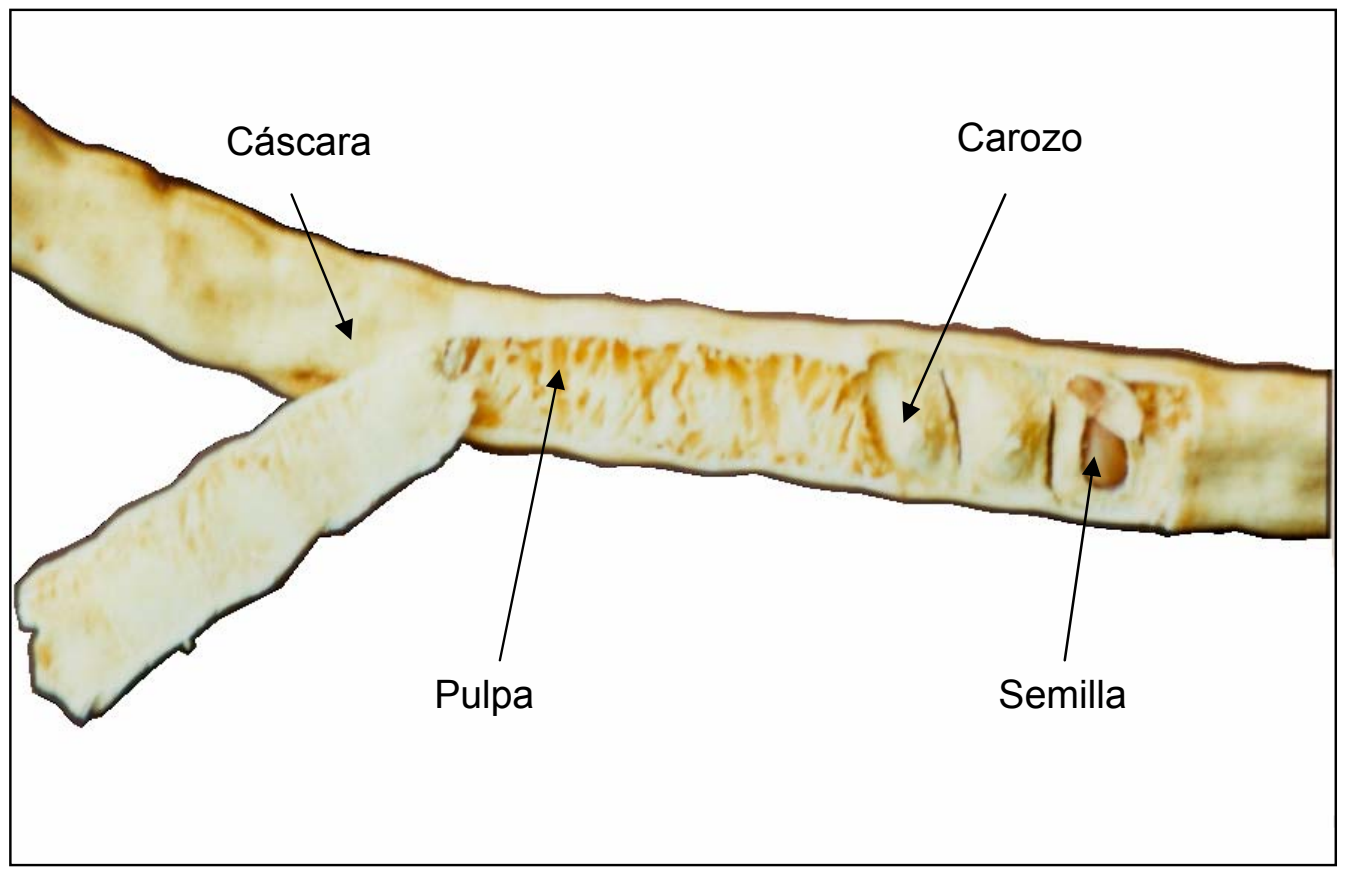

FIGURA 3. Algarroba madura de Prosopis alba (aspecto interno) 


\subsection{Producción y cosecha de algarrobas}

A partir del quinto año de vida, el Prosopis alba produce algarrobas. Fructifica entre los meses de diciembre y febrero. La producción de algarrobas es muy variable de árbol a árbol y de año en año. En buenos años, un árbol chico ( $15 \mathrm{~cm}$ de diámetro en el tronco) puede producir de 5 a $10 \mathrm{~kg}$ de algarrobas, y un árbol grande $(40 \mathrm{~cm}$ de diámetro) $40 \mathrm{~kg}$ de algarrobas (Felker, 1999).

La mayor producción de algarroba en el Chaco proviene de bosques que se han desarrollado de modo silvestre, a los que no se les ha dado ningún cuidado silvicultural, ni un manejo forestal adecuado. No existe ningún inventario forestal donde se pueda estimar la cantidad de Prosopis $s p$.

El Instituto de Investigaciones Forestales y Agropecuarias del Gobierno de la Provincia del Chaco ejecutó un programa de forestación con Prosopis alba Griseb. La forestación en macizo, entre 1993 y 1998, alcanzó las 2184 hectáreas, con una densidad de 400 árboles por hectárea (Subsecretaría de Recursos Naturales y Medio Ambiente, 1999).

Realizan la cosecha, manualmente, chicos y mujeres, y algunas veces toda la familia rural. El momento óptimo para la cosecha, es cuando las algarrobas alcanzan un grado de madurez tal, que el desprendimiento es espontáneo. La cosecha se hace por recolección de las algarrobas caídas en el suelo. Que la cosecha sea buena depende de varios factores, como las heladas tardías que afectan las flores produciéndose pocos frutos, o que estos sean dañados por las lluvias tempranas cuando están madurando en el árbol, o cuando ya maduros, en el suelo, llueve (Saravia, 1995).

\subsection{Productos tradicionales derivados de la algarroba}

Los frutos de Prosopis se han usado como fuente de alimento, en casi todos los lugares donde existen estos árboles o arbustos (Cruz, 1999).

Las vainas de muchas de las especies de Prosopis de América contienen un dulce y pulposo mesocarpio, y se han utilizado como alimento humano desde tiempos prehistóricos (Fagg y Stewart, 1994); de acuerdo con Felker (1981), ha sido la legumbre mucho más usada como fuente alimenticia. Restos de plantas en cuevas en el Valle Tehuacan en México muestran que vainas de mesquite (probablemente $P$. laevigata) fueron masticadas alrededor de 6500 a.C. (Smith, 1967); Felger (1977) cita evidencias de consumo prehistórico de $P$. glandulosa en el sudoeste de Texas y noreste de México (Tamaulipas).

Las vainas de mesquite (Prosopis sp.) jugaron un importante rol en el desierto de Sonora en Norteamérica, donde las tribus indias hacían harina y masa con la pulpa secada o tostada de las vainas maduras. Una clase de torta durable se preparaba secando la masa en forma de bolas (Meyer, 1984; Simpson, 1977). Una pasta fermentada de semillas hervidas de $P$. africana, llamada "okpiye" se prepara en Nigeria (Achi, 1992).

El uso de vainas de Prosopis para consumo humano data de tiempos lejanos. 
Cuando los españoles arribaron a Sudamérica observaron que los indios, especialmente de Perú, Chile y Argentina, incluían vainas de Prosopis en sus dietas (Silva, 1988).

Las algarrobas de mejor calidad se emplean en la alimentación humana, aunque en la Argentina su uso sólo persiste entre las clases pobres. Los indios, sobre todo en Chaco y Formosa, encuentran sin embargo un precioso recurso en los algarrobos (Burkart, 1952). Los indios tobas, con las algarrobas de Prosopis alba y $P$. nigra, preparaban harina dejándolas secar y moliéndolas en un mortero. La consumían disuelta en agua (Martínez Crovetto, 1964).

Falkner (1787, citado por Burkart, 1952) describe los algarrobos en Santiago del Estero (Argentina) y dice que su fruto es el alimento más común de los habitantes, quienes fabrican con él "patay", "aloja" y "añapa".

En general, las algarrobas maduran rápidamente y caen; su período de aprovechamiento es muy corto, de aproximadamente un mes. El "patay", elaborado en ese período, una vez seco o tostado, asegura el mantenimiento del alimento por mucho tiempo. Así lo confirma Alonso de Ovalle en 1646 (trascripto por Rusconi, 1958) al relatar sobre los indios huarpes de Cuyo (Argentina), quienes al no tener trigo, maíz o arroz para hacer pan, lo hacían de algarroba en la época de cosecha y lo guardaban para que no faltara ese ordinario sustento.

Para la elaboración de "patay", los frutos maduros y secos se machacan en un mortero (de piedra o de madera), luego se ciernen para dejar sólo la harina y eliminar el resto, incluidas las semillas. Con esta harina y agua se hace una pasta, se le da forma de panes, se secan al horno o al rescoldo, y puede conservarse bien en climas semiáridos (Roig y Dalmasso, 1986) (FIGURA 4). En Catamarca, San Luis, Santiago del Estero y La Rioja (Argentina), el "patay" es un alimento popular (Burkart, 1952).

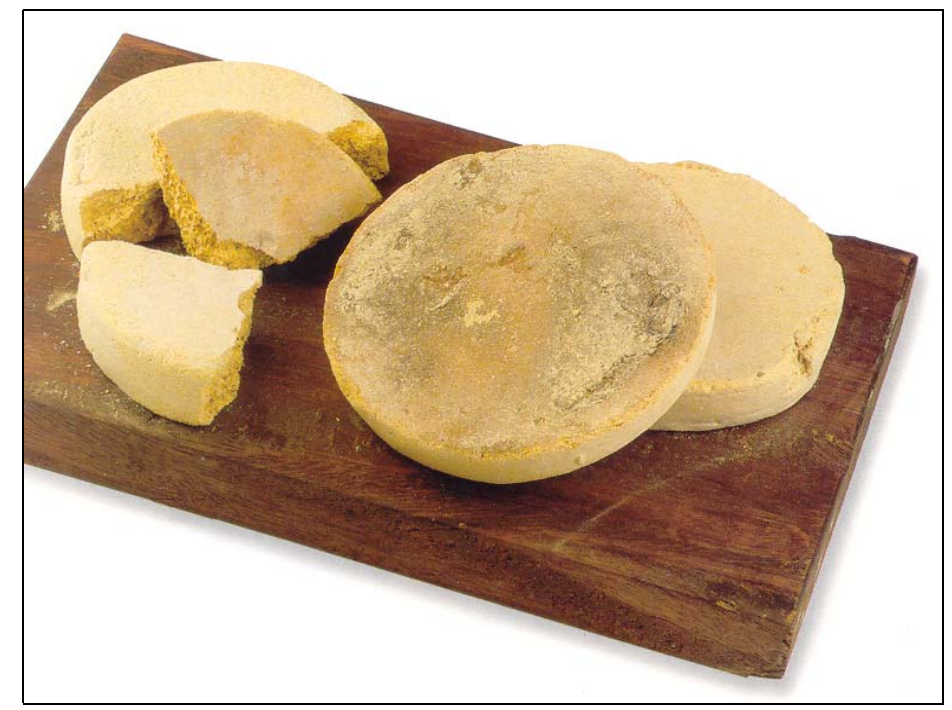

FIGURA 4. Patay de Prosopis alba 
Las especies más utilizadas para la elaboración de "patay" son Prosopis alba, $P$. nigra y $P$. flexuosa, también se usan $P$. elata, $P$. ruscifolia, $P$. vinalillo (Arenas, 1981), y $P$. torquata (Ragonese y Martínez Crovetto, 1947).

"Chuningo" Ilaman en La Rioja a una variedad de "patay", obtenida mojando la masa molida y cernida de algarroba, que se consume sin hornearla. En Santiago del Estero hacen, además, un bollito alimenticio a partir de pasta de mistol (Zizyphus mistol Gris.), rodeada por harina de algarroba, que recibe el nombre de "bolanchao" (Burkart, 1952).

Escudero y Herraiz (1943) encontraron que el patay posee un alto contenido de calcio asimilable $(0,138-0,217 \%)$, e informaron que es una buena fuente de tiamina y riboflavina.

Los frutos de Prosopis se han utilizado en muchos lugares también para preparar bebidas fermentadas (Meyer, 1984; Simpson, 1977).

Bibar (1558, citado por Roig, 1993b) relata que en el valle de Atacama (Chile) hacían una bebida fermentada con algarroba molida cocida en agua. El Abate Americano (1787, citado por Roig, 1993b) describe el uso en Cuyo de $P$. chilensis en la elaboración de una bebida llamada "aloja", a partir de una infusión de las algarrobas en agua, dejada fermentar naturalmente y decantar.

El uso de la "aloja" es común a numerosos pueblos. "Los indios mapuches (Guinnard, 1856, citado por Erize, 1960), recogen gran cantidad de algarrobas que aplastan entre dos piedras y meten en bolsas de cuero llenas de agua a fin de obtener el "soe pülen", bebida que dejan fermentar durante muchos días y sobre la cual se forma una espuma que quitan con cuidado; le añaden otra porción de algarroba hervida y lo mezclan todo agitándolo fuertemente. Esta preparación es bastante agradable y los embriaga completamente".

Métraux (1944) comenta que en el Chaco: "las legumbres de algarroba son machacadas en un mortero y luego mezcladas con agua caliente en un tronco ahuecado del árbol de botella (Choricia sp.) o en un recipiente improvisado de cuero de vaca o cabra encuadrado con los bordes levantados del suelo. A veces, para acelerar la fermentación, se añade un poco de algarroba molida que ha sido mascada por una mujer vieja".

Burkart (1952) explica el proceso de preparación de la "aloja" en Salta (Argentina): "se machacan las algarrobas (Prosopis alba) en un mortero y se colocan en una tinaja agregándole agua. Se tapa y se deja fermentar. A las $24 \mathrm{~h}$, comienza ya la formación de burbujas. A las $48 \mathrm{~h}$, se saca la parte sólida estrujándola entre las manos bien limpias y se agrega una mayor cantidad de algarroba. La proporción definitiva es: algarroba molida, 1 parte; agua, 4 partes. En cuanto a la levadura de la "aloja" es probablemente un Saccharomyces de alta fermentación. Está siempre acompañada por gran cantidad de bacterias, especialmente fermentos lácticos, y por hongos. El inconveniente para la difusión de esta bebida es que no se conserva, sino que debe tomarse enseguida. Por su gusto agradable, acidulado, se compara ventajosamente con otras bebidas alcohólicas similares". 
Las especies más utilizadas en Argentina para la elaboración de "aloja" son Prosopis alba y $P$. chilensis (Burkart, 1952), también se usan $P$. ruscifolia (Martínez Crovetto, 1964), P. hassleri y P. torquata (Ragonese y Martínez Crovetto, 1947), $P$. elata y $P$. vinalillo (Arenas, 1981).

En la Argentina y Chile se obtiene de la algarroba madura molida mezclada con agua fría una bebida dulce y refrescante, la "añapa". Se usan para ello las mismas especies que para la elaboración de la "aloja" (Roig, 1993b; Habit et al., 1981).

Debido a su alto contenido de azúcar, las vainas de mesquite crudas sirven en México y Centroamérica como material para preparación de bebidas no fermentadas como el "mesquitatole" (Allen y Allen, 1981). En Perú, por la extracción acuosa de los azúcares de la pulpa dulce de $P$. pallida se obtiene una bebida no fermentada conocida como "yusipín", que se consume sólo en zonas rurales (Cruz, 1999).

En Bolivia la gente hervía las algarrobas y comía su pulpa (Roig, 1993b). En el Chaco paraguayo se consumen los frutos de $P$. ruscifolia y $P$. vinalillo previamente hervidos (Arenas, 1981).

Las semillas tostadas de Prosopis sp. pueden reemplazar al café (Hieronymus, 1881, citado por Roig, 1993b).

Un almíbar, o extracto concentrado azucarado de algarrobas de $P$. pallida, llamada "algarrobina", se elabora comúnmente en áreas rurales del norte de Perú. Este almíbar se hace de algarrobas maduras enteras o troceadas, las cuales son hervidas en agua durante dos horas y luego prensadas; el jugo resultante es entonces filtrado y concentrado por evaporación. El almíbar marrón oscuro obtenido es más viscoso que la miel y exhibe una peculiar brillantez. El proceso se efectúa en el ámbito casero usando un equipo de cocina muy simple, y la "algarrobina" producida es vendida en botellas de vidrio o en potes de plástico (Cruz, 1999). De manera similar se elabora, en la Argentina, el "arrope" a partir de algarrobas maduras de $P$. nigra (Martínez Crovetto, 1964), P. torquata y P. hassleri (Ragonese y Martínez Crovetto, 1947).

Por mucho tiempo, la "algarrobina" ha sido elaborada como un producto tradicional sin estándares de calidad. Hoy se cuenta con una Norma Técnica Peruana. En Perú la "algarrobina" se consume de diferentes maneras: muchas personas recomiendan tomar una cucharada diaria como alimento saludable o también directamente o agregándola al jugo de frutas o la leche, como agente endulzante y saborizante. Se da a menudo de este modo a niños y a personas de avanzada edad porque se reconocen en la "algarrobina" propiedades fortificantes y revitalizantes. En las zonas urbanas, este almíbar se usa como un ingrediente en repostería y para preparar una bebida sabrosa, el "cocktail de algarrobina", la cual es una mezcla de una pequeña cantidad de "algarrobina" con "pisco" (aguardiente de uva) y leche (Cruz, 1999). 


\subsection{Composición de la algarroba}

Existen estudios que evalúan la composición químico nutricional de los frutos de especies de Prosopis provenientes de diferentes regiones geográficas. Los análisis proximales de vainas enteras muestran resultados similares para varias de ellas, pero éstos brindan información limitada para proponer nuevas formas de uso en nutrición humana. Trevisson (1992) reporta para $P$. alba variedad panta: proteína, 11,7\%; fibra, 12,49\%; cenizas, $4,8 \%$; y grasa, 4,32\%. Del Valle et al. (1987) reporta para especies de Norteamérica $(P$. glandulosa y $P$. velutina): proteína, 11\%; fibra, 29\%; cenizas, 4,6\%; y grasa 1,7\%. Zolfaghari et al. $(1986,1985,1982)$ analiza vainas de $P$. glandulosa verdes y maduras, con resultados comparables a estos valores. Pak et al. (1977) reporta valores similares de vainas de $P$. tamarugo de Chile. Oduol et al. (1986) analizan los contenidos de proteína y azúcares totales en vainas de las especies Prosopis alba $(9,6 \%$ y $35 \%), P$. nigra $(10,4 \%$ y $37,5 \%)$, $P$. velutina $(18,6 \%$ y $25,7 \%)$, $P$. articulata $(17 \%$ y $25,7 \%)$ y $P$. glandulosa $(13,4 \%$ y $17 \%)$. Varios autores (Saura et al., 1991; Espinoza, 1987; Sáenz et al., 1987) han estudiado las especies $P$. pallida y $P$. juliflora de Perú, los rangos son: proteína, 9-12\%; fibra, 14-23\%; cenizas, 3-5\%; grasa, menos del 1,7\%. Vainas de P. juliflora de Ecuador y Brasil muestran casi la misma composición, pero con un contenido más alto de fibra y grasa (Marangoni y Alli, 1988; Figueiredo, 1975).

\subsubsection{PULPA}

La pulpa representa aproximadamente el $56 \%$ del peso total del fruto (Cruz, 1999). En Perú se han realizado varios estudios para determinar, lo más completamente posible, la composición química de la pulpa de $P$. pallida (Bravo et al., 1994b; Grados y Cruz, 1994; Salazar, 1993; Cruz et al., 1987); los resultados se resumen en la TABLA 1.

El mayor componente de la pulpa es sacarosa $(46,1 \%)$, y representa cerca del $90 \%$ del total de azúcares solubles. Los azúcares reductores (glucosa, fructosa y xilosa); están presentes en muy pequeñas cantidades (Cruz et al., 1987). La relación sacarosa/glucosa/fructosa concuerda bien con la de pulpa de mesquite (Meyer, 1984). Para el pericarpio de $P$. juliflora, se ha reportado que el $75 \%$ de azúcares solubles corresponde a sacarosa; $12 \%$, fructosa; $5 \%$, glucosa; $5 \%$, inositol; y $1 \%$, rafinosa (Marangoni y Alli, 1988). En $P$. glandulosa y $P$. velutina se encontró que el fruto entero contiene $21,3 \%$ de sacarosa y $6,5 \%$ de azúcares reductores (Del Valle et al., 1983). Después de la autólisis del pericarpio, un pequeño incremento en glucosa y fructosa indica baja actividad de invertasa (Becker et al., 1980). En la pulpa de Prosopis alba se han encontrado 59,14\% de azúcares solubles totales y $27,6 \%$ de azúcares reductores (Prokopiuk et al., 2001). 
TABLA 1. Composición de la pulpa de Prosopis pallida

\begin{tabular}{|l|c|}
\hline \multicolumn{2}{|c|}{ Componentes principales (g/100 g b.s.) } \\
\hline & \\
Azúcares solubles totales & 48,5 \\
Sacarosa & 46,1 \\
Fructosa & 1,26 \\
Glucosa & 1,02 \\
Xilosa & 0,27 \\
& \\
Fibra dietética total & 32,2 \\
Fibra dietética insoluble & 30,6 \\
Fibra dietética soluble & 1,6 \\
Proteína ( $\mathrm{N}$ x 6,25$)$ & 8,1 \\
Suma de aminoácidos & 7,1 \\
Proteína resistente & 2,2 \\
& 0,77 \\
Grasa & 3,6 \\
Cenizas & 0,41 \\
& \\
Taninos condensados & 0,81 \\
Polifenoles solubles totales & \\
& \\
\hline
\end{tabular}

\begin{tabular}{|l|r|c|}
\hline \multicolumn{3}{|c|}{ Aminoácidos (g/100 g proteína) } \\
\hline & & $\begin{array}{c}\text { WHO/FA0 } \\
\text { patrón }\end{array}$ \\
Hidroxiprolina & 2,13 & \\
Ácido aspártico & 8,51 & \\
Treonina & 4,68 & 4 \\
Serina & 4,96 & \\
Ácido glutámico & 10,07 & \\
Prolina & 23,40 & \\
Glicina & 4,68 & \\
Alanina & 4,26 & \\
Cisteína & 0,43 & \\
Metionina & 0,57 & \\
Met + Cis & 1,00 & 3,5 \\
Valina & 7,80 & \\
Isoleucina & 3,26 & 4 \\
Leucina & 7,94 & 7 \\
Tirosina & 2,84 & \\
Fenilalanina & 2,98 & \\
Tir + Fen & 5,82 & 6 \\
Lisina & 4,26 & 5,5 \\
Histidina & 1,99 & \\
Arginina & 4,82 & \\
Triptófano & 0,89 & 1 \\
\hline
\end{tabular}

\begin{tabular}{|l|c|}
\hline \multicolumn{2}{|c|}{ Minerales (g/kg b.s.) } \\
\hline Potasio & 26,5 \\
Sodio & 1,1 \\
Calcio & 0,76 \\
Magnesio & 0,9 \\
Cobre & trazas \\
Zinc & trazas \\
Manganeso & trazas \\
Hierro & 0,33 \\
\hline
\end{tabular}

Cruz, 1999

\begin{tabular}{|l|c|}
\hline \multicolumn{2}{|c|}{ Vitaminas (mg/kg muestra) } \\
\hline Vitamina A & no detectada \\
Vitamina E & 5 \\
Vitamina B1 & 1,9 \\
Vitamina B2 & 0,6 \\
Vitamina B6 & 2,35 \\
Ácido nicotínico & 31 \\
Vitamina C & 60 \\
Ácido fólico & 0,18 \\
Pantotenato de calcio & 10,5 \\
\hline
\end{tabular}

El contenido de proteína cruda en la pulpa de Prosopis es considerablemente alto $(7,1 \%$ en Prosopis alba y $8,1 \%$ en $P$. pallida), teniendo en cuenta que las semillas no están incluidas (Prokopiuk et al., 2001; Rozycki et al., 1998). De la composición aminoacídica en $P$. pallida mostrada en la TABLA 1 puede verse que casi todos los aminoácidos esenciales están presentes en cantidades que satisfacen los requerimientos de la FAO/WHO (1973), lo cual indica una aceptable calidad nutricional de la proteína. Los aminoácidos limitantes son metionina y cisteína. 
Estos resultados son concordantes con los estudios sobre $P$. juliflora (Marangoni y Alli, 1988; Del Valle et al., 1983) y P. glandulosa (Meyer, 1984; Zolfaghari et al., 1982; Felker et al., 1977).

La digestibilidad de la proteína de la pulpa de Prosopis es alta: $62 \%$ para $P$. alba variedad panta; $73 \%$ para $P$. pallida; y $75,2 \%$ para $P$. juliflora (Bravo et al., 1994b; Trevisson, 1992; Marangoni y Alli, 1988).

La fibra dietética de $P$. pallida representa aproximadamente el $32 \%$ de la pulpa y es en su mayor parte fibra insoluble (TABLA 1); más de la mitad de la fibra está compuesta de polisacáridos neutros (Bravo et al., 1994). Se han publicado contenidos más altos de fibra dietética de pulpa de otras especies, aunque los métodos de análisis son distintos. Meyer (1984) reportó 35\% de fibra dietética en pulpa de mesquite y Zolfaghari et al. (1986) reportaron $25 \%$ de celulosa, $11 \%$ de hemicelulosa y $7 \%$ de lignina para el pericarpio de $P$. glandulosa, mientras que para Prosopis alba se informaron valores inferiores de fibra dietética total $(26,56 \%)$ con un importante contenido de solubles $(24,36 \%)$ (Prokopiuk et al., 2001).

La pulpa de $P$. pallida contiene altas cantidades de hierro y bajos niveles de calcio en comparación a los valores reportados para mesquite (Zolfaghari et al., 1982; Becker et al., 1980). También se han reportado altos niveles de hierro en Prosopis alba (Prokopiuk et al., 2001), P. juliflora (Marangoni y Alli, 1988; Figueiredo, 1975), y P. tamarugo (Pak et al., 1977), pero no se indica la biodisponibilidad. Con respecto a las vitaminas, son relevantes las cantidades de vitamina C, B6 y pantotenato de calcio en la pulpa de $P$. pallida (Grados y Cruz, 1996).

\subsubsection{ENDOCARPIO}

El endocarpio (carozo) es una cápsula dura y fibrosa en la cual está encerrada la semilla (FIGURA 3). La composición química del endocarpio de $P$. pallida se muestra en la TABLA 2.

TABLA 2. Composición de endocarpio de Prosopis pallida

\begin{tabular}{|l|c|}
\hline Componentes principales (g/100 g & b.s.) \\
\hline Fibra dietética total & 92,3 \\
Fibra dietética insoluble & 88,9 \\
Fibra dietética insoluble & 3,4 \\
Azúcares solubles & 1,6 \\
Proteína & 2,3 \\
Grasa & 1,3 \\
Cenizas & 1,3 \\
Polifenoles solubles & 0,7 \\
\hline
\end{tabular}


La fibra dietética insoluble es el componente mayoritario del endocarpio. El análisis más detallado de esta fracción muestra a polisacáridos celulósicos $(40 \%)$ y lignina $(17 \%)$ como sus principales constituyentes (Saura et al., 1991).

\subsubsection{SEMILLAS}

El cotiledón de la semilla de $P$. pallida contiene $65 \%$ de proteína, lo cual representa el $31 \%$ del peso de esta. La composición de aminoácidos de las proteínas en el cotiledón se muestra en la TABLA 3.

TABLA 3. Composición de aminoácidos en el cotiledón de semillas de Prosopis pallida

\begin{tabular}{|l|r|c|}
\hline \multicolumn{2}{|c|}{ Aminoácidos (g/100 g proteína) } \\
\hline & & $\begin{array}{c}\text { WHO/FA0 } \\
\text { patrón }\end{array}$ \\
Ácido aspártico & 8,30 & \\
Treonina & 2,42 & 4 \\
Serina & 4,87 & \\
Ácido glutámico & 21,31 & \\
Prolina & 7,49 & \\
Glicina & 4,59 & \\
Alanina & 4,34 & \\
Cisteína & 1,31 & \\
Metionina & 0,88 & \\
Met + Cis & 2,19 & 3,5 \\
Valina & 4,56 & \\
Isoleucina & 3,09 & 4 \\
Leucina & 7,51 & 7 \\
Tirosina & 1,84 & \\
Fenilalanina & 4,29 & \\
Tir + Fen & 6,13 & 6 \\
Lisina & 4,09 & 5,5 \\
Histidina & 3,10 & \\
Arginina & 14,63 & \\
Triptófano & 1,37 & 1 \\
\hline Cruz, 1999 & & \\
\hline
\end{tabular}

El contenido de aminoácidos esenciales es alto, siendo cisteína y metionina los aminoácidos limitantes. Los valores son comparables con otros reportados para $P$. juliflora y mesquite (Baiâo, 1987; Meyer, 1984; Zolfaghari et al., 1982; Figueiredo, 1975).

En cuanto a la digestibilidad aparente de proteínas crudas en semillas se reportaron: $70,9 \%$ para $P$. glandulosa; y $81,3 \%$ para $P$. juliflora (Marangoni y Alli, 1988; Zolfaghari et al., 1982). 
El contenido de grasa del cotiledón de $P$. pallida alcanza el 7\% (Jiménez et al., 1977). Los principales ácidos grasos encontrados en el aceite extraído fueron linoleico $(39 \%)$, oleico $(29 \%)$, palmítico $(13 \%)$ y esteárico $(10 \%)$. Este aceite sin refinar muestra una acidez de 1,7\%. Similares valores han sido reportados para mesquite (Ortega-Nieblas et al., 1995; Becker et al., 1980) y $P$. juliflora (Marangoni y Alli, 1988). También se han estudiado en la Argentina composiciones de ácidos grasos y esteroles de varias especies de Prosopis (Lamarque et al., 1994).

Trabajos en Brasil (Figueiredo, 1990, 1987, 1983 y 1975; Figueiredo et al., 1990; Bobbio, 1987) reportan las posibilidades de producción y uso de un polisacárido galactomanano (hidrocoloide) a partir del endospermo de las semillas de $P$. juliflora, con una relación manosa/galactosa igual a 4 . Meyer (1984) estudió la producción de un galactomanano de la semilla de mesquite ( $P$. glandulosa y $P$. velutina), y encontró una relación $\mathrm{M} / \mathrm{G} 1,6$, es decir, similar a la de goma de guar. En un trabajo anterior, con semillas de mesquite, se reportó una relación $M / G$ de aproximadamente 1 (Becker et al., 1980). Espinosa (1987) determinó para $P$. pallida una relación $M / G$ 1,35, la cual fue corroborada por otros autores (Bravo et al., 1994b; Cruz et al., 1987). También se han estudiado algunas propiedades reológicas de galactomananos de semillas de P. chilensis (Romeo et al., 1989; Vásquez et el., 1988), y de $P$. juliflora (Holmquist-Donquis et al., 1997). El estudio más actual y completo de producción y caracterización de galactomananos de Prosopis fue llevado a cabo por Cruz (1999), que trabajó con el endospermo de $P$. pallida, proveniente de Perú y la comparó con otras especies.

En harina de semillas completas se ha determinado el contenido de proteína: 33,06\% en $P$. alba variedad panta (López Hernández et al., 1985); $35,8 \%$ en $P$. ruscifolia (Freyre et al., 2000); y 32,57\% en $P$. pallida (Espinoza, 1987).

\subsubsection{FACTORES ANTINUTRICIONALES}

Investigada cada fracción de fruto de P. pallida (Bravo et al., 1994b; Salazar, 1993), se encontraron polifenoles y taninos sólo en pequeñas cantidades, significativamente menores al compararlas con vainas de algarrobo español (Ceratonia siliqua). Estos resultados son similares a los reportados en India para $P$. chilensis (Vijayakumari, et al., 1997; Rajaram et al., 1991).

Las semillas de vainas de mesquite $(P$. glandulosa) muestran una baja actividad de inhibidores de tripsina < 6 UTI/mg (Ortega-Nieblas et al., 1996; Zolfaghari et al., 1982), mientras que Freyre et al. (2001) informan para semillas de $P$. ruscifolia un valor ligeramente superior $(8,5 \mathrm{UTI} / \mathrm{mg})$, encontrando, además, otros antinutrientes como polifenoles $(975 \mathrm{mg} / 100 \mathrm{~g})$ y ácido fítico $(778 \mathrm{mg} / 100 \mathrm{~g})$, no obstante, este último está siendo apreciado por su capacidad antioxidante. Análisis químicos de vainas y semillas de $P$. glandulosa, $P$. velutina, y $P$. tamarugo, han revelado que no tienen glicósidos cianogénicos u otros compuestos tóxicos (Becker et al., 1980; Pak et al., 1977). 


\subsection{Procesamiento para obtener nuevos productos}

Investigaciones más recientes en Perú están orientadas a la producción de harinas refinadas y jugos concentrados (almíbares) de la algarroba y es muy promisoria su aplicación en alimentos humanos (Felker et al., 2003). Por su valor nutritivo y fácil disponibilidad, las algarrobas pueden ser procesadas y usadas como suplementos e ingredientes alimenticios. El procesamiento involucra la separación de las partes del fruto, siendo la fracción de mesocarpio (pulpa) la que ofrece más posibilidades de aplicación, en forma de harinas o extractos (Cruz, 1999).

Varias unidades procesadoras de tamaño semiindustrial se han adaptado o diseñado específicamente para procesar algarrobas de Prosopis $s p$. En Brasil, en varios lugares, se están construyendo instalaciones para el secado y molido de algarrobas de $P$. juliflora, las que son un buen ejemplo de proceso en pequeña escala para uso comunal y de granjeros locales. El proceso incluye el secado de las algarrobas con un secadero a leña en grandes recipientes abiertos a aproximadamente $80^{\circ} \mathrm{C}$ durante $4 \mathrm{~h}$ inmediatamente antes de la molienda. Los molinos son de martillos con cribas de varios tamaños (Pasiecznik et al., 2001). Varios tipos de micro molinos para moler cereales y alimentos de animales también se usan para algarrobas de $P$. juliflora (Kanzaria y Varshney, 1998).

En estudios detallados sobre la molienda y la separación de partes de la algarroba de P. glandulosa (Saunders et al., 1986; Meyer, 1984; Meyer et al., 1982), se obtuvieron harina de pulpa, semillas y endocarpios, y se propusieron técnicas para una mayor separación de la semilla en endospermo, cotiledón y epispermo (cáscara). También fue investigada la molienda integral de algarrobas, incluyendo las semillas, para la producción de harinas de alta-proteína y baja-fibra (Del Valle et al., 1987 y 1986).

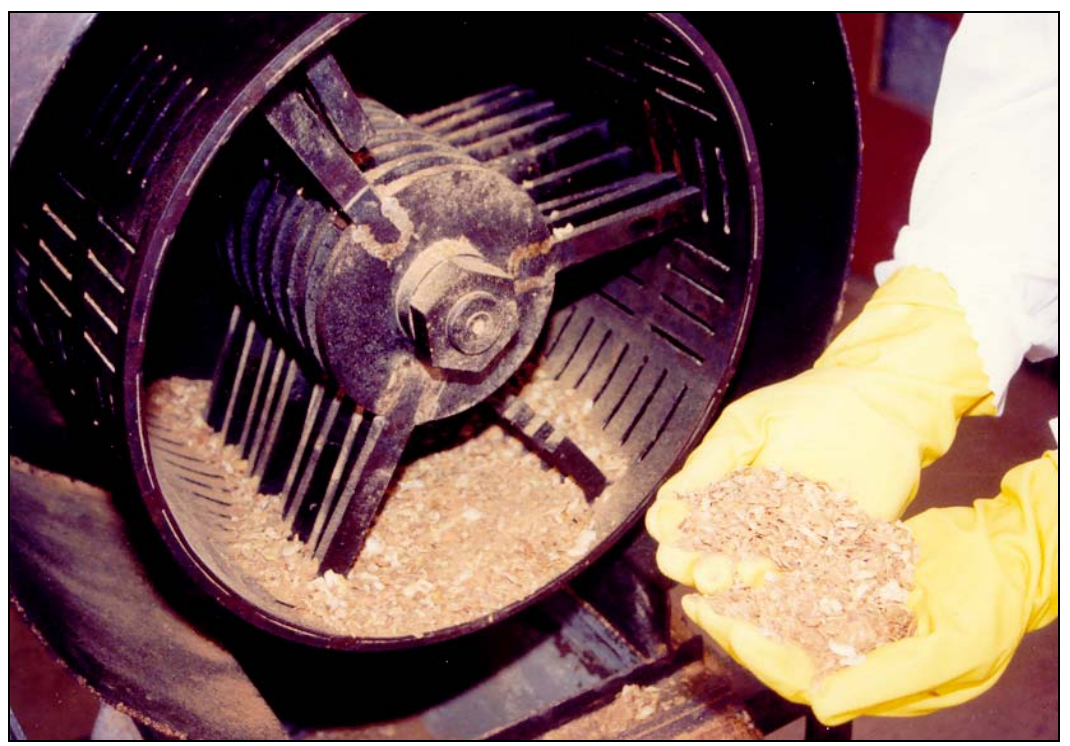

FIGURA 5. Molino trillador de martillos, Universidad de Piura, Perú 
En Perú, se construyó un prototipo de molino específicamente para procesar algarrobas de $P$. pallida perfeccionando el diseño de una trilladora de cereal; cuenta con varios martillos fijados a un eje rotativo y cortos martillos montados en una malla metálica (FIGURA 5). Con este molino de escala piloto se consigue la separación de algarroba en cuatro fracciones y la recuperación de semillas enteras (Grados y Cruz, 1996, 1994). En la FIGURA 6 se muestra el diagrama de fraccionamiento de los frutos de $P$. pallida.

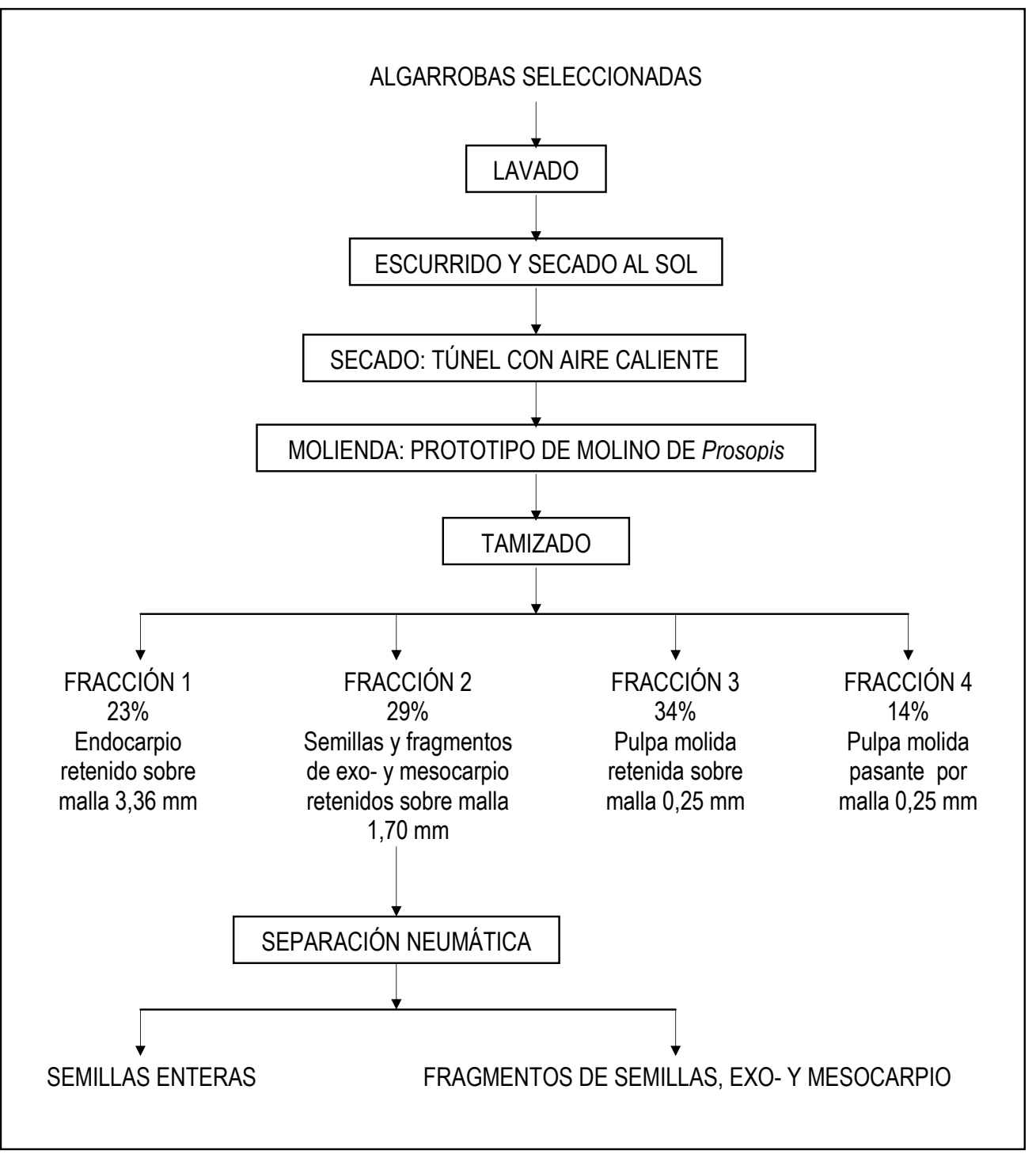

Cruz, 1999

FIGURA 6. Diagrama de fraccionamiento de frutos de Prosopis pallida

En la TABLA 4 se indican los resultados de un estudio comparativo realizado en la planta piloto de la Universidad de Piura, Perú. 
TABLA 4. Fracciones y Rendimientos (\%) de Molienda y Tamizado

\begin{tabular}{|c|c|l|c|c|}
\hline Fracción & Tamiz & \multicolumn{1}{|c|}{ Material } & Prosopis alba & Prosopis pallida \\
\hline 1 & $3,36 \mathrm{~mm}$ & Carozo & 23,00 & 29,00 \\
2 & $1,70 \mathrm{~mm}$ & Cáscara y semilla & 22,50 & 16,00 \\
3 & $0,15 \mathrm{~mm}$ & Pulpa & 45,40 & 45,34 \\
4 & & Pulpa & 9,10 & 9,66 \\
\hline
\end{tabular}

Prokopiuk et al., 2001

De la molienda y tamizado de las algarrobas secas de Prosopis alba y $P$. pallida se obtuvieron cuatro fracciones, con rendimientos en pulpa del $54,5 \%$ y $55 \%$, respectivamente. La cantidad de semillas enteras en la Fracción 2 fue del orden del $80 \%$ para ambas algarrobas. (Prokopiuk et al., 2001).

La harina de pulpa de $P$. pallida también puede usarse para obtener almíbar ("algarrobina") (FIGURA 7). Al estar finamente molida, la extracción es más rápida que en el proceso tradicional de obtención de "algarrobina" (de frutos enteros), y además no requiere tanto calor. La torta de filtro que queda de la extracción, lavada y secada, puede usarse para enriquecer productos alimenticios con fibra dietética (Cruz, 1999). Se han caracterizado estos almíbares y fibras dietéticas, procesados bajo diferentes condiciones (Bravo et al., 1998).

Se puede, de acuerdo con un ensayo realizado en la Argentina, reemplazar la harina de trigo por harina de Prosopis alba, hasta el $4 \%$ en la obtención de pan francés y pan de molde, y hasta el $12 \%$ en el caso de galletitas dulces (Rozycki et al., 1998). La harina puede ser incorporada dentro de una variedad de productos alimenticios incluyendo pan, bizcochos y tortas. La ausencia de almidón es sin embargo una limitación para los niveles de harina de Prosopis en las formulaciones del pan (Cruz, 1999). Se ha estudiado el comportamiento reológico de las harina compuestas por $P$. pallida y trigo, con porcentajes de algarroba de: 5 a $10 \%$ en pan; y hasta $25 \%$ en galletas (Cruz, 1988). En el pan se ha determinado que la harina de algarroba aumenta la elasticidad de la masa, pero le resta resistencia, con lo cual, el pan leudado es más suave pero con menor volumen. El pan que contiene $5 \%$ de harina de $P$. pallida se ha calificado como aceptable, tanto en textura como en sabor. En galletas, la sustitución de harina de trigo por harina de algarroba tiene efecto positivo, pues reemplaza parte del azúcar en la formulación, y confiere sabor y aroma muy agradables. Algunas personas han reportado un ligero gusto amargo después de consumir estos productos, pero otras, sin embargo, lo encuentran agradable (Cruz, 1999).

Se ha ensayado en Perú la obtención de harina de $P$. pallida enriquecida en proteína (del 8,11 al 15,64\%) por fermentación aeróbica con Saccharomyces sp. (Ruiz, 1999), y la producción de alcohol etílico, por el alto contenido de azúcares en la pulpa, con un rendimiento del $51 \%$ respecto al teórico (Clavijo, 1991). También en Argentina, un trabajo (López Hernández et al., 1985) reporta la obtención de 30,12\% de alcohol etílico por fermentación de la pulpa de $P$. alba variedad panta, con Saccharomyces cerevisiae. 
Se han hecho trabajos para promover el uso de los frutos de Prosopis en la industria alimenticia, enfocados principalmente en su utilización como fuente de proteína y fibra dietética (Del Valle, 1988; Del Valle et al., 1986; Meyer et al., 1986; Zolfaghari et al., 1986). También, se llevaron a cabo estudios sobre las propiedades de las gomas extraídas del endospermo de las semillas (Cruz, 1999; Fernandes y Figueiredo, 1995).

Estudios preliminares muestran que se puede obtener un polvo soluble instantáneo de las harinas finas de Prosopis alba y $P$. pallida remoliendo y tamizando a través de una malla de $0,15 \mathrm{~mm}$, que podría usarse como sucedáneo de cacao (Prokopiuk et al., 2001; La Torre, 1990). Se han llevado a cabo mejoras de las propiedades nutricionales y sensoriales de harina de pulpa de $P$. pallida mezclándola con otras harinas de cereales y con cacao (Grados y Cruz, 1996). En Perú, se están desarrollando nuevos productos alimenticios de las vainas de $P$. pallida adaptando tecnologías de proceso a situaciones rurales. Se produce un polvo llamado "algarropolvo" a partir de frutos enteros finamente molidos en un pequeño molino rural procesador de vainas (Cruz, 1999) (FIGURA 7).

\section{SUCEDÁNEOS DEL CAFÉ}

\subsection{Antecedentes}

Las propiedades farmacológicas de la cafeína del café (Coffea sp.), en algunos casos, son indeseadas, lo que provoca la demanda del café descafeinado y sucedáneos del café, obtenidos de cereales como cebada (Hordeum vulgare) y centeno (Secale cereale), de maltas de cereales, o también, de leguminosas como soja (Glicina max). La producción de sucedáneos de café logró reducir el consumo de cerca de $1 / 4$ del café genuino (Belitz y Grosch, 1997).

Entre los sucedáneos del café se tienen la achicoria, malta tostada y cebada tostada. La achicoria (Cichorium intybus) es la raíz de dicha planta, convenientemente lavada, troceada, tostada, molida y tamizada. La malta tostada es el producto obtenido por el tostado de la malta verde, procedente de la cebada en grano, con composición por cada $100 \mathrm{~g}$ de: $9 \mathrm{~g}$ de proteína; $1,4 \mathrm{~g}$ de grasa; $20 \mathrm{mg}$ de $\mathrm{Ca} ; 0,7 \mathrm{mg}$ de $\mathrm{Fe} ; 0,15 \mathrm{mg}$ de vitamina $\mathrm{B}_{1} ; 0,08 \mathrm{mg}$ de vitamina $\mathrm{B}_{2}$; y $2,5 \mathrm{mg}$ de ácido nicotínico. Cebada tostada es el producto obtenido por el tostado de la cebada, a la que se añade durante el proceso un $10 \%$ de azúcares, glucosa o el equivalente de melaza (Bender, 1994; Madrid, 1991).

En Francia, el café contiene como ingrediente adicional la raíz tostada de achicoria. A pesar de que ésta no posee cafeína aporta un sabor amargo, así como un color oscuro resultante de la caramelización producida durante el tostado. La razón de añadir achicoria al café es que es mucho más barata, pero legalmente la mezcla debe contener cuanto menos $51 \%$ de café (Fox y Cameron, 1992). 
En Polonia, se produce un sucedáneo de café instantáneo, conocido como café Inka, mediante la evaporación del extracto acuoso de remolacha dulce termolizada (Beta vulgaris subespecie cicla), endibia (Chicorium endivia), centeno y cebada. La generación térmica del aroma y compuestos colorantes de café está basada en reacciones tipo Maillard de los azúcares, y polisacáridos con las proteínas, presentes en el material vegetal. La reacción de aminoácidos con los polisacáridos del centeno y cebada genera los compuestos de aroma, y la reacción de aminoácidos con el azúcar de la remolacha y endibia genera los compuestos de aroma y color. La intensidad del color y del aroma depende de los aminoácidos implicados en la reacción (Tomasik y Zawadzki, 1998).

En Rusia, se elabora un sucedáneo del café combinando extracto de achicoria y jugo de manzana (Malus silvestres) en proporción 1:1. La bebida es marrón oscuro y de gusto dulce-amargo, con agradable sabor a manzana. Contiene azúcares fácilmente digeribles, especialmente fructosa. El valor nutricional es elevado por la adición de pectina (Nachmedov y Kuljasova, 1990).

La determinación enzimática de fructosa y glucosa después de hidrólisis ácida, se utiliza para detectar la adulteración de café con sucedáneos tales como la achicoria, malta, higos (Ficus carica), cereal, y cáscaras de café tostadas y no tostadas (Berger et al., 1991).

Sobre la base de la mezcla de cebada germinada, remolacha, achicoria e higo, todos tostados y molidos, se elabora en Córdoba (Epifanio Jiménez SA., marca bosanova, Argentina) un sucedáneo de café instantáneo, marrón oscuro y de sabor dulzón, y se señala como información nutricional: valor energético, $375 \mathrm{kcal} ; 7,5 \%$ de proteínas; $87,5 \%$ de glúcidos; $0,25 \%$ de lípidos; $0,25 \%$ de fibra alimentaria; y $0 \%$ de cafeína (Información del fabricante al consumidor).

En Brasil, la fuerza del hábito del consumo de café ha prevalecido sobre las alzas del producto. En el medio rural, el desfase del poder adquisitivo ha incitado a buscar sustitutos entre las plantas disponibles en el medio ambiente. Los productos más utilizados como sustitutos de café son mucuná (Mucuna altísima y Mucuna urens), maíz (Zea mays), manjerioba (Cassia corymbosa), arroz (Oryza sativa), sorgo (Sorghum vulgare), quiabo (Quiabeiro comun), raíces de batata de purga (Ipomea altisima e Ipomea operculata), y algarroba ( $P$. juliflora DC). Por su mayor disponibilidad en el nordeste semiárido, incluso en períodos críticos de sequía, la algarroba se encuentra entre los principales sustitutos. En esa sustitución intervienen también aspectos culturales y nutricionales muy significativos (Azevedo Rocha, 1987).

En el nordeste semiárido de Brasil, se usa la algarroba ( $P$. juliflora) como sustituto del café tradicional. El que se elabora mediante el secado al sol de las vainas maduras, posterior tostado y molido manual. La aceptabilidad de $P$. juliflora como sustituto de café deriva principalmente de sus características organolépticas (Vieira et al., 1986).

La adición al café de $50 \%$ de vainas molidas de $P$. juliflora, ligeramente tostadas, da un producto agradable y de buena aceptación (Figueiredo, 1990). 
El proceso de obtención de sustituto de café consiste en el tostado de la pulpa de algarroba triturada ( $P$. pallida). El tostado se realiza en un recipiente de fondo ligeramente cóncavo y de gran diámetro, donde se calienta la algarroba hasta que se torna marrón oscuro uniforme. Se deja enfriar y se muele para uniformar el tamaño del grano. El producto fino logrado se utiliza de la misma manera que el café, es decir, obteniendo la "esencia" de café por percolación. El producto presenta ventajas respecto al café porque al no contener cafeína no es estimulante ni dañino a la salud, y es ligeramente más barato. Además, tiene cierto valor nutritivo, pues la bebida preparada con el café de algarroba contiene los azúcares naturales de ella (Ruiz et al., 1999).

Recientemente, algunas pequeñas fábricas en Perú comenzaron a elaborar nuevos productos alimenticios de vainas de $P$. pallida. Por ejemplo, sucedáneos de café o "café de algarroba" se producen y comercializan con buen resultado en el mercado peruano, envasados en bolsas plásticas de $250 \mathrm{~g}$ a un precio conveniente bajo nombres comerciales registrados (Cruz, 1999) (FIGURA 7).

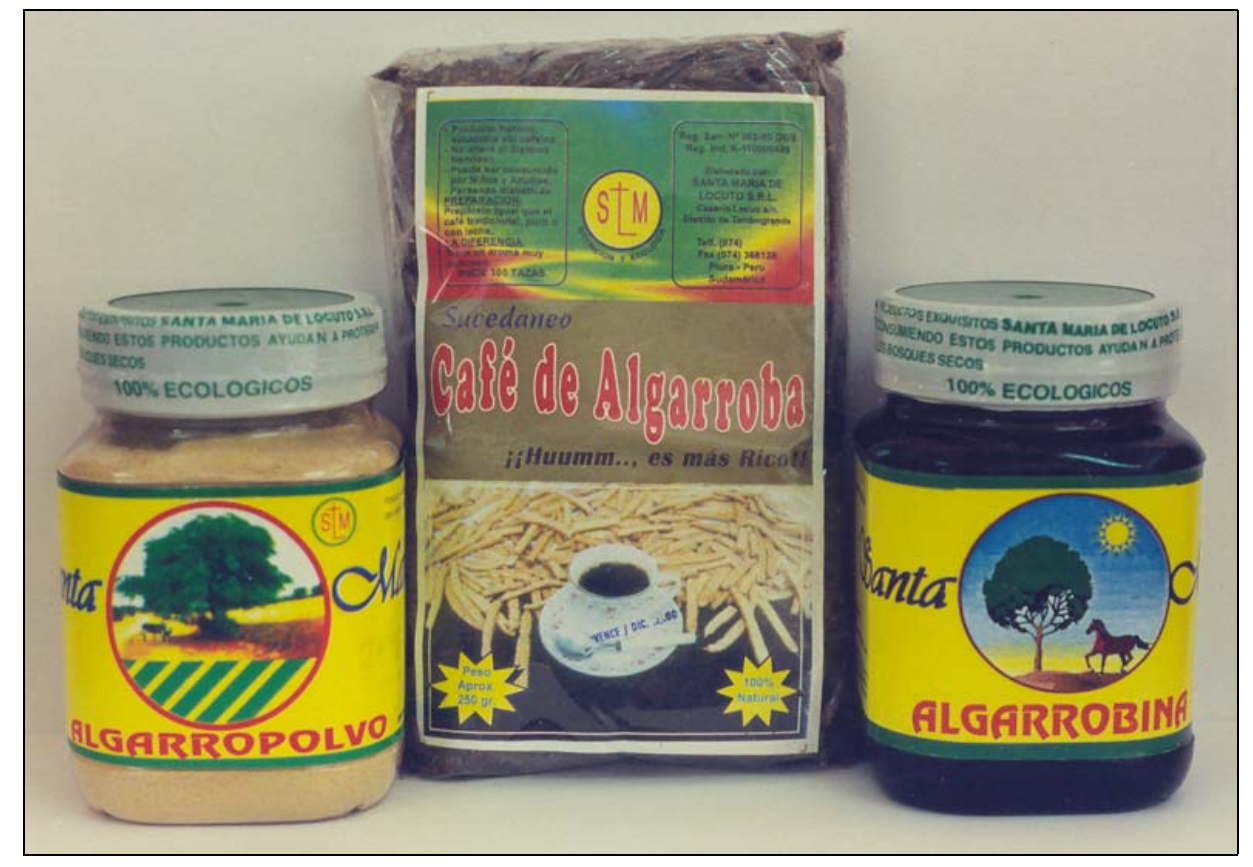

FIGURA 7. Algarropolvo, sucedáneo de café y algarrobina, Piura, Perú 


\section{CAFÉ GENUINO}

\subsection{Generalidades}

El café es una bebida preparada por extracción de materia soluble en agua caliente de los granos tostados y molidos de un arbusto tropical ( $s p$.) que se cultiva principalmente en los Trópicos de Cáncer y Capricornio a una altitud de 610 a $1830 \mathrm{~m}$ sobre el nivel del mar y a una temperatura aproximada de $21^{\circ} \mathrm{C}$ con precipitaciones anuales del orden de $1270 \mathrm{~mm}$. El género Coffea incluye 40 especies de plantas, pero solamente tres son comercialmente cultivadas para producción de café, Coffea arabica Linn, Coffea canephora Pierre ex Foechner (robusta) y Coffea iberica. El comercio internacional anual es de alrededor de 55 millones de bolsas (de $60 \mathrm{~kg}$ ) de café verde con un valor cercano a los 2,5 billones de dólares. En la actualidad, Brasil es el principal productor mundial $(25,4 \%)$, seguido por Vietnam (9,9\%), Costa Rica $(9,4 \%)$. Indonesia (9\%), Colombia $(8,9 \%)$, y México (4\%). Los Estados Unidos y Europa consumen el $85 \%$ de las exportaciones, casi por partes iguales. La bebida de café no tiene valor nutritivo y se consume por su sabor y sus efectos estimulantes, debido principalmente al contenido de cafeína. El arbusto del café arábica es nativo de Abisinia, (hoy Etiopía), donde se cultiva silvestre en los bosques y sus semillas fueron utilizadas por los nativos desde antes de que existieran registros históricos. El arbusto del café robusta es nativo de Congo. En los años 900 d.C., los árabes introdujeron el arbusto del café etíope en Yemen y durante 700 años la propagación del café estuvo limitada a esa área consumiéndose principalmente en Arabia. Los árabes hicieron de este fruto y de su bebida un motivo de atracción para los viajeros y comerciantes europeos. Los peregrinos de la Meca regresaban con granos de café a sus tierras nativas India y Sri Lanka. Uno de los primeros usos del café fue medicinal, también para mantener despiertos a los fieles en las mezquitas. EI café llenó las necesidades de un estimulante útil ya que los musulmanes no pueden consumir alcohol. Durante el siglo XVII el café se introdujo a los países europeos y se vendió en las salas de café, que se hicieron lugares de reunión muy populares para mercaderes y artistas. Los holandeses iniciaron los plantíos comerciales en Java y Sri Lanka por el año 1696, y hacia 1714 trajeron las primeras semillas de café a América, más precisamente a la Guyana holandesa (hoy Surinam). Los franceses, ingleses y españoles empezaron a estimular el cultivo en las Indias Occidentales desde 1715 hasta 1750. Los jesuitas fueron los primeros en cultivar café en Colombia, hacia 1730. México y Centroamérica comenzaron a cultivarlo en 1800, y Hawai en 1825. En África el cultivo comercial del café se inició después de la Segunda Guerra Mundial (Sivetz, 1983). 


\subsection{El fruto del café}

Los frutos de café se cosechan al llegar a su madurez, lo que se advierte por el marrón intenso que adquiere el grano, aunque también existen variedades rojo oscuro y otras amarillo cuando están maduras. En un corte longitudinal de un fruto de café pueden verse las fracciones anatómicas del fruto: el grano de café propiamente dicho o endospermo, la cáscara o endocarpio, una capa mucilaginosa, y la pulpa o mesocarpio. La semilla del café presenta una superficie plana que se encuentra con otra parte igual dentro del fruto. Cada mitad está recubierta por un delicado tejido conocido como película. Estas dos fracciones se sostienen dentro del endocarpio, membrana conocida también con el nombre de pergamino o cascarilla de café, que es duro y quebradizo cuando se seca, y el cual rodea individualmente a cada una de las dos fracciones que constituyen un grano. La cascarilla, en cambio, está cubierta por una gruesa capa de células esponjosas que forman la pulpa. Esta capa tiene un espesor aproximado de $5 \mathrm{~mm}$. Debido a la consistencia viscosa del mucílago, una leve presión sobre el fruto es suficiente para expulsar fuera de él las dos mitades que constituyen el grano. Esta característica ha sido aprovechada en el proceso que desde hace largo tiempo se utiliza para separar los granos del resto de los componentes estructurales del fruto (Bressani, 1978). Los principales tipos de granos de café, por su forma, son: redondos (Borbón-Moka), ovales cortos (Brasil, Colombia, América Central), alargados (Antillas), y puntudos (Borbón puntudo) (Código Alimentario Argentino, 1998).

\subsection{Procesamiento del fruto del café}

El procesamiento del fruto del café para obtener los granos comerciales consiste básicamente en dos operaciones. En la primera se los pone en remojo, dando como producto pulpa de café, mucílago y aguas de desecho, por una parte, y por otra, los granos de café y la cascarilla, como unidad. En la segunda operación, mediante un proceso seco, se separa la cascarilla del grano del café. Luego de la remoción del mucílago, los granos de café son lavados antes de pasar al proceso de deshidratación. Este se lleva a cabo en dos etapas: un período inicial de exposición al sol, y luego, se seca con aire caliente en un tambor de cilindro perforado. Una vez secos, mediante un rodillo helicoidal se separa la cascarilla, la cual representa un tercer subproducto (Bressani, 1978). Los granos de café de un azul verdoso se clasifican por tamaño, peso, color y densidad en lotes de aspecto y sabor uniforme, en bolsas de $125 \mathrm{~kg}$. Hasta que los granos de café verde se tuestan, el café no tiene aroma y sabor característico.

Los granos de café tienen grandes cambios durante el tostado a medida que la temperatura interna aumenta. A $60^{\circ} \mathrm{C}$ comienza el proceso endotérmico de deshidratación y finaliza aproximadamente a los $150^{\circ} \mathrm{C}$. A $100^{\circ} \mathrm{C}$ el agua libre es vaporizada y ocurre un primer aumento de volumen de granos debido al ablande de la estructura y a la presión de vapor interna. 
Al mismo tiempo comienza la caramelización del azúcar y la ruptura del contenido celular del café, los que alcanzan su máximo alrededor de los $200^{\circ} \mathrm{C}$. A esta temperatura el proceso es fuertemente exotérmico (Clarke, 1987; Lee, 1979; Barbetti y Chiappini, 1978); comienza alrededor de los 140$180^{\circ} \mathrm{C}$ y es acompañado por la dilatación del grano. Desde los $180^{\circ} \mathrm{C}$, las reacciones pirolíticas de carbohidratos y proteínas producen una gran cantidad de $\mathrm{CO}_{2}, \mathrm{CO}$ y ácidos. Como resultado de estos fenómenos ocurre una considerable disminución en la densidad del grano. Arriba de los $200^{\circ} \mathrm{C}$, las reacciones de ruptura, condensación y polimerización producen las típicas melanoidinas y compuestos aromáticos del café tostado. Todo el tiempo, la fuerte presión interna de los gases formados contribuye a un continuo incremento del volumen hasta aproximadamente los $270^{\circ} \mathrm{C}$, momento en que los granos se tornan negro mate y el aumento se detiene. El origen botánico y geográfico, el contenido de agua de los granos verdes, y las condiciones del proceso de tostado son algunos de los factores que afectan la relativa intensidad de los cambios descritos (Clarke, 1987; Dalla Rosa et al., 1980), estos factores, también afectan las propiedades físicas y químicas finales del tueste del café. El tiempo y la temperatura, pero más que nada el color del grano tostado, se utiliza, para establecer el punto final de tostado que corresponde al sabor y aroma deseado. Los granos tostados del café son quebradizos y fáciles de moler. Los cafés blandos de sabor suave, limpio y dulce tienen precios más altos que los duros o de sabores ásperos, sucios, fermentados y contaminados. Los nombres comerciales son característicos por su origen: por ejemplo, Medellín, Armenio y Manizales de Colombia; Santos, Paraná y Minas de Brasil; Coatepec, Oaxaca y Tapachula de México; Antigua de Guatemala; Copans de Honduras; Djimmas y Harrars de Etiopía; Oicru de Congo; Ambriz de Angola; y Kona de Hawai (Sivetz, 1983).

\subsection{Composición química}

La composición química de los granos de café es extremadamente compleja, se han identificado más de 300 constituyentes; a causa de esta complejidad se desconoce en gran parte la base química del sabor y el aroma del café. La TABLA 5 indica la composición química promedio del café verde y del café tostado (Fox y Cameron, 1992).

A pesar de que el tostado tiene poco efecto sobre la cafeína (trimetilxantina), el ácido clorogénico se desdobla en los ácidos cafeico y quínico y la trigonelina se convierte en gran parte en niacina. Al preparar el café-bebida, la cafeína es rápidamente extraída, especialmente si el agua está muy caliente; a $95^{\circ} \mathrm{C}$ se extrae cerca del $80 \%$ después de 2 min, y el $90 \%$, después de $10 \mathrm{~min}$. Un tiempo corto de 1 a 2 min resulta ideal ya que favorece la extracción de la cafeína pero no de las sustancias menos solubles que contribuyen al amargor. Una taza de café bastante fuerte contiene cerca de $100 \mathrm{mg}$ de cafeína, junto con $10 \mathrm{mg}$ de potasio y $1 \mathrm{mg}$ de niacina. La variedad de café robusta contiene casi el doble de cafeína que la arábica. 
TABLA 5. Composición química porcentual (\%) del café verde y tostado, en base seca

\begin{tabular}{|l|c|c|}
\hline & Granos verdes & Granos tostados \\
\hline Proteínas & 13 & 11 \\
Azúcares & 10 & 1 \\
Almidón y dextrinas & 10 & 12 \\
Polisacáridos complejos & 40 & 46 \\
Aceite & 13 & 15 \\
Minerales & 4 & 5 \\
Ácido clorogénico & 7 & 5 \\
Trigonelina & 1 & 1 \\
Fenoles & 0 & 2 \\
Cafeína (en Coffea arabica) & 1 & 1,3 \\
\hline " principalmente K & \multicolumn{2}{|}{}
\end{tabular}

Se ha estudiado ampliamente la influencia de la cafeína en los humanos. Hay bastantes indicios que sugieren que beber café en exceso (más de 5 tazas al día) origina niveles elevados de colesterol e incrementa el riesgo de contraer insuficiencia coronaria en personas principalmente no fumadoras (Fox y Cameron, 1992). Aunque la cafeína sea generalmente considerada como estimulante a dosis bajas, el consumo de una taza de café, que supone la ingestión de cafeína de $1-2 \mathrm{mg} / \mathrm{kg}$ de peso corporal, da una concentración plasmática máxima de $50 \mu \mathrm{M}$. Un consumo excesivo (concentración plasmática $>50 \mu \mathrm{M}$ ) produce síntomas de cafeinismo (ansiedad, agitación, dificultades para conciliar el sueño, diarrea, tensión muscular, y palpitaciones cardíacas) (Anónimo, 1983).

\subsection{Composición lipídica}

Los lípidos en los granos de café verde se encuentran localizados en el aceite de café, presente en el endospermo y en pequeñas cantidades en la llamada cera del café, localizada en otras partes del grano (Folstar, 1985). Una composición característica de lípidos en granos de café verde indica: triglicéridos, 75,2\%; ésteres de alcoholes diterpénicos y ácidos grasos, $18,5 \%$; alcoholes diterpénicos, $0,4 \%$; ésteres de esteroles y ácidos grasos, $3,2 \%$; esteroles, $2,2 \%$; tocoferoles, $0,06 \%$; fosfátidos, $0,5 \%$; y derivados de la triptamina, $1 \%$ (Maier, 1985). Durante el tostado, el aceite sale a la superficie de los granos, lo que da el aspecto característico del tostado oscuro, e impide la salida de parte de los componentes volátiles del aroma (Clarke, 1987).

El contenido en ácidos grasos representa las tres cuartas partes del total de lípidos del café, y forma parte de triglicéridos, alcoholes diterpénicos, esteroles, o ácidos grasos libres. Como ácidos grasos se identificaron: palmítico, $30 \%$; linoleico, $35 \%$; esteárico, $7 \%$; oleico, $8 \%$; linolénico, $1 \%$; y araquídico, 1\% (Carisano y Garibaldi, 1964). 
Durante el tostado del café, se observó una disminución del contenido total en ácidos grasos libres del $20 \%$, no existiendo diferencias significativas debidas a las distintas temperaturas de tueste (Speer et al., 1993).

\subsection{Componentes aromáticos}

La mayoría de los componentes volátiles del café derivan de componentes no volátiles presentes en el grano verde, los cuales reaccionan durante el tostado formando mezclas muy complejas. El sabor y aroma característicos del café tostado es el resultado de un conjunto de reacciones, por un lado, entre la que se destaca la pirolisis, y por otro lado, de una serie de interacciones entre componentes muy diversos del grano: azúcares, aminoácidos, ácidos orgánicos y componentes fenólicos. La composición final de volátiles en un determinado café depende de numerosos factores, tales como la especie y variedad del grano, las características del suelo y factores climáticos durante su cultivo, las condiciones de almacenamiento de los granos verdes, el método utilizado para su tueste, así como el tiempo y la temperatura de tostado. Todos estos factores influyen en el aroma final del producto por afectar directamente sobre la cantidad y calidad de precursores no volátiles presentes en el grano verde y su posterior evolución durante el tostado.

Se identificaron varios volátiles en café verde, tales como piridinas, quinoleínas, pirazinas, pirroles y poliaminas. Otros componentes (furanos, alcoholes, carbonilos, ésteres, fenoles y tioles), se encontraron en determinadas variedades de café. También se detectó la presencia de metoxipirazinas, compuesto que parece ser el responsable del característico aroma del café verde (Poisson, 1977).

Más de 800 volátiles se han aislado en el aroma del café tostado, los principales tipos de componentes identificados son: aldehídos, azufres, cetonas, fenoles, furanos, pirazinas, piridinas, pirroles y oxazoles.

En los cafés tostados se han caracterizado varios furanos tiosustituidos. Posiblemente, el compuesto 2-furilmetanotiol tenga carácter impacto del café tostado. Su umbral en agua es de 0,01 ppb y a concentraciones de 0,1-5 ppb tiene el aroma del café tostado (Tressl y Silwar, 1981). Los ésteres, aldehídos y cetonas de los grupos tiofenos aportan aromas dulces, a caramelo y nuez (Maga, 1975).

Los aldehídos probablemente sean los componentes volátiles más abundantes en el café. El metanal y etanal tienen aromas picantes, pero a medida que el número de átomos de carbono de la cadena aumenta, los aromas tienden a ser frutados y florales. Las cetonas cíclicas derivadas de la caramelización de azúcares, confieren al café aromas dulces, frutados y de azúcar quemado (Hodge, 1967).

Los fenoles son característicos de cafés muy tostados, poseen aromas típicos de ahumado, quemado, picante y amargo, aportando una cierta astringencia a la bebida (Tressl et al., 1978). 
Otro compuesto es la trigonelina que está presente en los granos crudos de café a niveles de 1\%. Contrariamente a la cafeína, que es termoestable, la trigonelina se descompone fácilmente a las temperaturas de tostado para dar una serie de piridinas y pirroles (Block, 1985).

Las pirazinas son abundantes en el aroma del café tostado (Shimoda et al., 1990); poseen aromas entre amargo y dulce, pero en sus alquilderivados se aprecian aromas a nueces, tostado y picante (Maga, 1982). Los pirroles aportan sensaciones de dulce, amargo y aromas tostados (Maga, 1981).

\subsection{Componentes ácidos}

Análisis efectuados sobre café verde arábica indican la presencia de ácidos no volátiles: cítrico, málico, oxálico y tartárico (Mabrouk y Deatherage, 1956). El aroma ácido del café se debe a muchos ácidos orgánicos. Los ácidos fenólicos alcanzan una media del 7,5\% del peso seco de los granos crudos de café. Entre éstos se tienen los ácidos ferúlico, cafeico, y clorogénico, que es el principal componente (Wong, 1995).

Durante el tostado se da una continua producción de ácidos, al mismo tiempo que se produce una degradación y volatilización de los mismos. La concentración de ácidos, analizada a través del valor del $\mathrm{pH}$ y de la acidez valorable, es una función del origen de los granos verdes, del método de procesado de esos granos, del tipo de tostado, del color del café tostado, y del método de extracción de la bebida. Normalmente, la acidez de la bebida es mayor en café arábica que en robusta, el procesado en húmedo de los granos verdes origina infusiones de café más ácidas que el procesado en seco. A su vez, del tostado medio resulta una bebida más ácida que de los tuestes más oscuros (Sivetz, 1972).

Aproximadamente la mitad de ácido clorogénico que se pierde durante el tostado se transforma en una serie de pigmentos, en fenoles de bajo peso molecular o ácido quínico libre, componente importante este en el desarrollo del café tostado. Además, algunos productos de la fragmentación del ácido clorogénico pueden volatilizarse junto con los gases del tostado (Tressl et al., 1976). 


\section{OBJETIVOS}




\section{OBJETIVOS}

\subsection{Objetivo general}

- El objetivo general de la tesis consiste en desarrollar un sucedáneo de café a partir de la algarroba de Prosopis alba Griseb.

\subsection{Objetivos específicos}

Los objetivos específicos, conducentes a alcanzar el objetivo general, han sido planteados en diferentes etapas y son los siguientes:

- Obtención de algarroba tostada a distintas temperaturas y tiempos, y molienda de las muestras para la obtención de harina.

- Caracterización de la harina de algarroba cruda-seca y tostada en algunas propiedades físicas relevantes como distribución del tamaño de partículas, isotermas de sorción de agua y color.

- Caracterización química-nutricional y sensorial de la algarroba tostada.

- Caracterización sensorial de infusiones de harina de algarroba tostada.

- Estudio de la influencia del tostado sobre las características del producto final. 
III. MATERIALES Y MÉTODOS 


\section{PREPARACIÓN DE LAS MUESTRAS}

\subsection{Recolección}

La recolección de frutos maduros de algarrobo (Prosopis alba Griseb), se hizo a mano tomando los caídos en el suelo de árboles seleccionados de rodales puros en Presidencia Roque Sáenz Peña (Chaco, Argentina).

\subsection{Selección}

La selección de las algarrobas maduras se efectuó a mano.

\subsection{Limpieza}

La limpieza de las algarrobas se realizó en forma mecánica utilizando una amoladora de banco (Creusen, DS $7200 \mathrm{~T}, 575 \mathrm{~W}$, Holanda) provista de cepillo circular de cerda natural $(200 \times 25 \times 15 \mathrm{~mm})$.

\subsection{Secado}

El secado de la algarroba cruda se ejecutó en estufa de convección de aire (Dalvo, $4 \mathrm{R} / \mathrm{l}$, Argentina) a $60^{\circ} \mathrm{C}$ por $60 \mathrm{~h}$.

\subsection{Tostado}

El tostado de las algarrobas secas se hizo en un horno de panadería a gas (Zunino, Argentina), con circulación forzada de aire, provisto de una zorra rotativa con nueve bandejas de acero inoxidable $(400 \times 600 \mathrm{~mm})$, y termostato analógico $\left(50 \mathrm{a} 350^{\circ} \mathrm{C}\right)$. Se trabajó a seis temperaturas $(100,115$, $130,145,160$ y $\left.175^{\circ} \mathrm{C}\right)$ y a tres tiempos cada una de ellas (30, 45 y $\left.60 \mathrm{~min}\right)$.

\subsection{Molienda}

La molienda de las muestras de algarroba cruda y las muestras tostadas (a los distintos grados de tostado), se efectuó con un molino a martillos (Retsch Mühle, SK 1, Alemania) ( $\varnothing$ carcasa $22 \mathrm{~cm}, 1,5 \mathrm{HP}, 3000 \mathrm{rpm}$ ), tamiz de fondo con malla de acero inoxidable de $10 \mathrm{~mm}$ (FIGURA 8). 


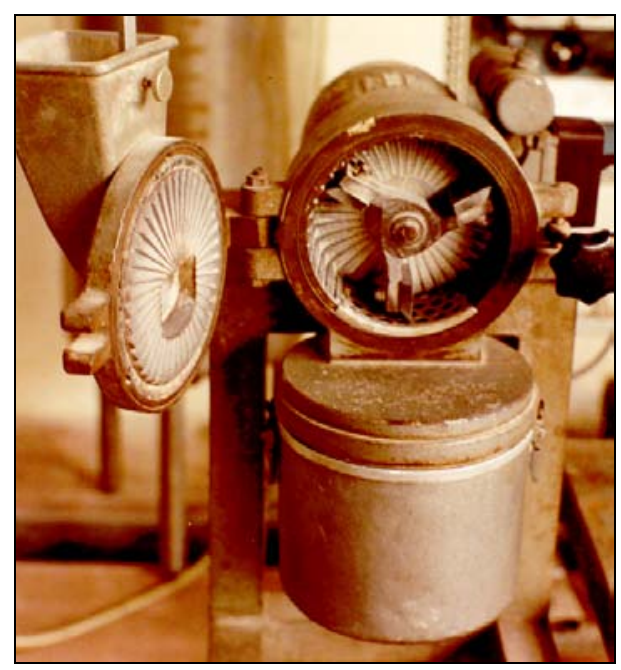

FIGURA 8. Molino a martillos Retsch Mühle SK 1

\subsection{Tamizado}

El tamizado de las muestras de algarroba seca molida y de las muestras tostadas molidas (a los distintos grados de tostado), se realizó en una tamizadora electromagnética de laboratorio (Fritsch, Analysette 3, Alemania), con tamices con aros de bronce (200 mm de diámetro y $50 \mathrm{~mm}$ de alto) y mallas de acero inoxidable de 0,85, 0,25 y 0,15 mm (ASTM 20, 60 y 100). El tamizado se realizó a 3000 vibraciones por minuto durante 20 min, tiempo en el que se alcanzó la situación de equilibrio.

Para alcanzar la situación de equilibrio se realizó un tamizado inicial de $10 \mathrm{~min}$, se pesó el material retenido en el tamiz de $0,25 \mathrm{~mm}$, se continuó tamizando cada 5 min hasta diferencia en peso del material no mayor del $0,2 \%$ (Phillips et al., 1988). Cada fracción obtenida fue colectada separadamente para el sucesivo envasado.

\subsection{Envasado}

Las muestras de algarroba cruda molida y las muestras tostadas molidas (a los distintos grados de tostado) retenidas en el tamiz de 0,25 mm, se envasaron para realizar los diferentes controles analíticos y la evaluación sensorial, a razón de $125 \mathrm{~g}$ cada una, en bolsas de material coextruido de poliamida con polietileno y otros monómeros, transparentes, de 100 micrones de espesor, de $150 \times 300 \mathrm{~mm}$, y con permeabilidad al oxígeno de 20 (g $\left.\cdot 100 \mu \mathrm{m} / \mathrm{m}^{2} \cdot 24 \mathrm{~h} \cdot 1 \mathrm{~atm}\right)$. Las bolsas fueron provistas por el fabricante (Envaril Plastic Packaging SRL., Buenos Aires, Argentina) y son las que se utilizan para envasar al vacío café en granos.

El resto de las fracciones se envasaron para futuros estudios ocupando toda la capacidad de las bolsas.

Las bolsas se termosellaron en una envasadora (RAPI-VAC, S-750, Argentina) aplicando vacío (30 cm Hg). 


\section{CARACTERIZACIÓN FÍSICA Y QUÍMICA DE LA ALGARROBA CRUDA Y TOSTADA}

Las determinaciones analíticas se realizaron sobre las fracciones de algarrobas molidas, crudas y tostadas, retenidas sobre el tamiz de 0,25 mm.

\subsection{Caracterización del grado de tueste}

El grado de tueste se evaluó a través de las medidas de color. El color de la harina obtenida de las algarrobas secas y tostadas se midió por triplicado, usando un colorímetro Minolta (Japón), modelo CR-300, con procesador de datos DP-301, cápsula para material granular CR-A50, área de lectura de 8 $\mathrm{mm}$ de diámetro, iluminación difusa y ángulo $0^{\circ}$. Para asentar las muestras y quitar las burbujas de aire, se golpearon suavemente los laterales de la cápsula, antes de cada medición. Las coordenadas de color CIE L*a*b* (CIE, 1976) fueron determinadas teniendo en cuenta fuente lumínica $D_{65}$ y observador $10^{\circ}$.

El índice de color de cada muestra se calculó con la ecuación:

$$
I_{c}=\frac{1000 \cdot a^{*}}{L^{*} \cdot b^{*}}
$$

Donde:

$\mathrm{L}^{*}$ : luminosidad de la algarroba.

$a^{*}$ y $b^{*}$ : coordenadas de cromaticidad en el espacio de color $L^{*} a^{*} b^{*}$.

Las diferencias de color $\Delta \mathrm{E}^{*}$ ab entre las algarrobas tostadas y cruda, las cuales indican el grado de diferencia de color pero no la dirección, fueron determinadas mediante la ecuación:

$$
\Delta \mathrm{E}^{*}{ }_{\mathrm{ab}}=\sqrt{\left(\Delta \mathrm{L}^{*}\right)^{2}+\left(\Delta \mathrm{a}^{*}\right)^{2}+\left(\Delta \mathrm{b}^{*}\right)^{2}}
$$

Donde:

$\Delta L^{*}$ : diferencia entre la luminosidad de la algarroba tostada y cruda.

$\Delta \mathrm{a}^{*}$ : diferencia entre la coordenada de cromaticidad $\mathrm{a}^{*}$ de la algarroba tostada y cruda.

$\Delta b^{*}$ : diferencia entre la coordenada de cromaticidad $b^{*}$ de la algarroba tostada y cruda.

La función intensidad de color métrica $\left(\mathrm{C}^{*}\right.$ ab $)$ se calculó a través de la ecuación:

$$
C^{*}{ }_{a b}=\sqrt{\left(a^{*}\right)^{2}+\left(b^{*}\right)^{2}}
$$


Donde:

$a^{*}$ y $b^{*}$ : coordenadas de cromaticidad de la muestra.

\subsection{Distribución del tamaño de partículas}

Se determinó por triplicado en las muestras de algarroba cruda, algarroba tostada a $160^{\circ} \mathrm{C}$ durante 60 min elegida por percepción visual (Lozano, 1978), café tostado molido comercial (Argentina, variedad Coffea arabica Linn) y malta tostada molida comercial (Argentina) utilizando una tamizadora electromagnética de laboratorio (Fritsch, Analysette 3, Alemania), con tamices con aros de bronce (200 $\mathrm{mm}$ de diámetro y $50 \mathrm{~mm}$ de alto) y mallas de acero inoxidable de 1,40, 0,85, 0,60, 0,25, 0,15 y 0,075 mm (ASTM 14, $20,30,60,100$ y 200$)$.

El tamizado se realizó a $100 \mathrm{~g}$ de cada muestra, a 3000 vibraciones por minuto durante $20 \mathrm{~min}$, tiempo en el que se alcanzó la situación de equilibrio.

Cuando se completó el tamizado se pesó en balanza analítica el material retenido en cada tamiz.

\subsubsection{NIVEL Y GRADO DE FINEZA}

El módulo de fineza se calculó con el método recomendado por Hall (1972) mediante la ecuación:

$$
\text { Módulo de fineza }=\frac{\sum(A \cdot B)}{100}
$$

Donde:

A: fracción porcentual de muestra retenida en cada tamiz.

B: número de orden asignado a cada tamiz.

El módulo de uniformidad se calculó por el método recomendado por Hall (1972), mediante la ecuación:

$$
\text { Módulo de uniformidad por grupo de partículas }=\frac{\sum\left(A_{n}\right)}{C}
$$

Donde:

$A_{n}$ : fracción porcentual de muestra retenida en cada tamiz, agrupada por tamaños de partículas: gruesas $(1,40$ y $0,85 \mathrm{~mm})$, medianas $(0,60$ y 0,25 $\mathrm{mm})$, y finas $(0,15$ y $0,075 \mathrm{~mm})$.

C: cantidad de muestras. 


\subsection{Determinación de las isotermas de sorción de agua}

Los datos de equilibrio para realizar las isotermas de sorción de la algarroba cruda y tostada $\left(160^{\circ} \mathrm{C}, 60 \mathrm{~min}\right)$ se determinaron por el método gravimétrico estático estandarizado por la European Cooperation in Scientific and Technological Research Project COST-90 (Wolf et al., 1985; Spiess y Wolf, 1983), basado en la determinación del contenido de humedad de la muestra después que ésta ha alcanzado el equilibrio con aire de humedad relativa conocida.

Muestras por duplicado de aproximadamente $1 \mathrm{~g}$ de algarroba se distribuyeron uniformemente en pequeños pesa-muestras de aluminio (diámetro $38 \mathrm{~mm}$, alto $10 \mathrm{~mm}$ ). Estos se colocaron sobre trípodes de polipropileno (diámetro $42 \mathrm{~mm}$, alto $41 \mathrm{~mm}$ ) dentro de recipientes con tapa hermética de igual material (diámetro inferior $48 \mathrm{~mm}$, diámetro superior 61 $\mathrm{mm}$, alto $74 \mathrm{~mm}$ ) (Kanade y Pai, 1988), a los que previamente se le cargaron disoluciones salinas saturadas de referencia (con actividades de agua $a_{w}$ conocidas), con volúmenes que iban desde $40 \mathrm{ml}$ para las soluciones salinas de baja $a_{w}$, hasta $20 \mathrm{ml}$ para las soluciones salinas de alta $a_{w}$ (Norma AOAC $978.18,1995)$, para mantener constante y a niveles conocidos la humedad relativa interna de cada uno de los recipientes.

Los niveles de $a_{w}$ a $25^{\circ} \mathrm{C}$ y a $45^{\circ} \mathrm{C}$ de las soluciones saturadas de las sales utilizadas se indican en la TABLA 6 (Greenspan, 1977).

TABLA 6. Actividad de agua de soluciones salinas saturadas a $25^{\circ} \mathrm{C}$ y $45^{\circ} \mathrm{C}$

\begin{tabular}{|l|l|l|}
\hline \multicolumn{1}{|c|}{ Soluciones salinas } & $\mathrm{a}_{\mathrm{w}\left(25^{\circ} \mathrm{C}\right)}$ & $\mathrm{a}_{\mathrm{w}\left(45^{\circ} \mathrm{C}\right)}$ \\
\hline $\mathrm{LiCl}$ (Cloruro de litio) & 0,1130 & 0,1115 \\
$\mathrm{CH}_{3} \mathrm{COOK}$ (Acetato de potasio) & 0,2251 & 0,2150 \\
$\mathrm{MgCl}_{2}$ (Cloruro de magnesio) & 0,3278 & 0,3105 \\
$\mathrm{~K}_{2} \mathrm{CO}_{3}$ (Carbonato de potasio) & 0,4316 & 0,4320 \\
$\mathrm{NaBr}$ (Bromuro de sodio) & 0,5757 & 0,5600 \\
$\mathrm{NaCl}$ (Cloruro de sodio) & 0,7529 & 0,7455 \\
$\mathrm{KCl}$ (Cloruro de potasio) & 0,8434 & 0,8175 \\
$\mathrm{BaCl}_{2}$ (Cloruro de bario) & 0,9026 & 0,8700 \\
\hline
\end{tabular}

Las soluciones saturadas de las sales a $25^{\circ} \mathrm{C}$ se prepararon adicionándole agua destilada a razón de $2 \mathrm{ml}$ por vez removiendo bien con espátula después de cada adición, hasta que la sal no absorbía más agua como se probaba por la presencia de líquido libre (Norma AOAC 978.18, 1995), utilizando las cantidades de sales y agua recomendadas por Spiess y Wolf (1987) consignadas en TABLA 7. 
TABLA 7. Preparación de soluciones salinas saturadas a $25^{\circ} \mathrm{C}$

\begin{tabular}{|l|c|c|c|}
\hline Soluciones salinas & $a_{\mathrm{w}}$ & Sal $(\mathrm{g})$ & Agua (ml) \\
\hline $\mathrm{LiCl}$ & 0,1130 & 15 & 8,5 \\
$\mathrm{CH}_{3} \mathrm{COOK}$ & 0,2251 & 20 & 6,5 \\
$\mathrm{MgCl}_{2}$ & 0,3278 & 20 & 2,5 \\
$\mathrm{~K}_{2} \mathrm{CO}_{3}$ & 0,4316 & 20 & 9,0 \\
$\mathrm{NaBr}_{\mathrm{NaCl}}$ & 0,5757 & 20 & 8,0 \\
$\mathrm{KCl}$ & 0,7529 & 20 & 6,0 \\
$\mathrm{BaCl}_{2}$ & 0,8434 & 20 & 8,0 \\
\hline
\end{tabular}

Las muestras de algarroba cruda y tostada se mantuvieron en una cámara a temperaturas constantes (Sabadini, Argentina) de $25^{\circ} \mathrm{C} \pm 0,02$ y de $45^{\circ} \mathrm{C} \pm 0,02$ hasta que alcanzaron peso constante, equilibrando su contenido en humedad y la humedad relativa en el interior de los frascos herméticos. Esto se consideró cuando las variaciones de peso entre dos pesadas consecutivas fueron inferiores a $\pm 0,0001 \mathrm{~g}$ (Labuza et al., 1985).

El procedimiento empleado requirió un tiempo de estabilización de 10 días, y se previno la posibilidad de crecimiento de microorganismos (que podía ocurrir en las muestras equilibradas con sales saturadas de $\left.a_{w}>0,65\right)$ con el agregado de pequeñas cantidades $(1 \mathrm{mg} / \mathrm{g}$ ) de sorbato de potasio, el que inhibió el desarrollo de microorganismos sin afectar el proceso de sorción (Pilosof, 2000).

Alcanzado el equilibrio, se determinó el contenido en humedad de las muestras de algarrobas cruda y tostada por cálculo, conociendo la humedad inicial (determinada mediante el método descrito en 2.5) así como los pesos inicial y final. La ecuación de cálculo utilizada fue:

$$
w_{e \text { (b.s. })}=\frac{P_{o} \cdot w_{o}+\left(P_{f}-P_{o}\right)}{P_{o} \cdot\left(1-w_{\circ}\right)}
$$

Donde:

$\mathrm{W}_{\mathrm{e}}$ : humedad de equilibrio en base seca, en $\mathrm{g}$ de agua / $\mathrm{g}$ de materia seca de algarroba.

$\mathrm{W}_{\mathrm{P}}$ : humedad inicial en base húmeda, en $\mathrm{g}$ de agua / $\mathrm{g}$ de algarroba.

$P_{0}$ : peso inicial de la algarroba en $\mathrm{g}$.

$P_{f}$ : peso final de la algarroba en $g$. 


\subsubsection{AJUSTE DEL MODELO DE BET}

Los valores experimentales se ajustaron al modelo de BET (Brunauer, Emmett y Teller, 1938) para $a_{w}<0,5$, pues fuera de esta zona el modelo tiene sentido físico dudoso (Iglesias et al., 1976; Van der Berg, 1985), esto se debe fundamentalmente, a que a partir de esos niveles de $a_{w}$, los fenómenos que describen mayoritariamente las interacciones del agua en el alimento no son de sorción, sino más bien del tipo soluto-disolvente y el agua empieza a estar presente en el sistema movilizando los solutos en forma de fase líquida (Martínez et al., 1998). Sus parámetros $\mathrm{w}_{1}$ (humedad del producto correspondiente a una capa molecular de agua adsorbida) y $\mathrm{C}$ (constante característica del material relacionada con el calor desprendido en el proceso de sorción), se estimaron mediante regresión lineal y posteriormente fueron optimizados mediante regresión no lineal.

La ecuación de BET en forma linealizada se expresa como:

$$
\frac{a_{w}}{\left(1-a_{w}\right) \cdot w_{e}}=\frac{1}{w_{1} \cdot C}+\frac{C-1}{w_{1} \cdot C} \cdot a_{w}
$$

Siendo:

$$
\begin{aligned}
& \frac{1}{W_{1} \cdot C}=\text { ordenada al origen. } \\
& \frac{C-1}{W_{1} \cdot C}=\text { pendiente. }
\end{aligned}
$$

A partir de los valores de $\mathrm{w}_{1}$ se obtuvieron las superficies específicas del sustrato adsorbente (algarroba) o área disponible para los fenómenos de adsorción de agua, muy importante en el establecimiento de velocidades de reacción superficiales (Labuza, 1980b).

$$
S_{\left(m^{2} / g \text { de algarroba }\right)}=3,5 \cdot 10^{3} \cdot w_{1}
$$

\subsubsection{AJUSTE DEL MODELO DE GAB}

Los datos experimentales se ajustaron, igualmente, al modelo de GAB (Guggenheim-Anderson-de Boer) (Van der Berg y Bruin, 1981), recomendado como el mejor modelo con fines predictivos para alimentos por el proyecto COST-90 en un amplio intervalo de $a_{w}(0,1$ a 0,9$)$ (Schär y Rüegg, 1985; Wolf et al., 1985). Sus parámetros $w_{1}$ (humedad del producto correspondiente a la situación en que los puntos de adsorción primarios están saturados por moléculas de agua), C (constante de Guggenheim, característica del producto y relacionada con el calor de adsorción de la monocapa), $\mathrm{K}$ (factor de corrección relacionado con el calor de sorción de la monocapa), se ajustaron por regresión no lineal en todo el intervalo de $a_{w}$ estudiado. 
La ecuación de GAB en forma linealizada (polinomio de segundo grado) se expresa como:

$$
\frac{a_{w}}{W_{e}}=\frac{1}{w_{1} \cdot C \cdot K}+\frac{C-2}{w_{1} \cdot C} a_{w}+\frac{K(1-C)}{w_{1} \cdot C} a_{w}^{2}
$$

Siendo:

$\frac{1}{\mathrm{~W}_{1} \cdot \mathrm{C} \cdot \mathrm{K}}=$ coeficiente independiente.

$\frac{C-2}{W_{1} \cdot C}=$ coeficiente lineal.

$\frac{K(1-C)}{W_{1} \cdot C}=$ coeficiente cuadrático.

\subsubsection{EFECTO DE LA TEMPERATURA. CALOR ISOSTÉRICO DE SORCIÓN}

El conocimiento de los datos de sorción de agua a diferentes temperaturas, hace posible un análisis termodinámico del sistema alimentovapor de agua.

La aplicación de la ecuación de Clapeyron-Clausius (10) para el equilibrio líquido-vapor permitió calcular, para diferentes niveles de humedad, el cambio de entalpía asociado al proceso de sorción. La variación de entalpía $(\Delta \mathrm{H})$ mide los cambios de energía que ocurren durante los procesos de sorción y se pueden asociar a las fuerzas de atracción y repulsión en el sistema $(\Delta \mathrm{H}<0$ significa que existen fuerzas de atracción que se desarrollan en el mecanismo de sorción) (Apostolopoulos y Gilbert, 1990).

$$
\ln \mathrm{p}=\frac{\Delta \mathrm{H}}{\mathrm{R}} \cdot \frac{1}{\mathrm{~T}}+\text { constante }
$$

Donde:

p: presión parcial del vapor de agua en equilibrio con el material a una temperatura dada (atm).

$\Delta \mathrm{H}$ : calor diferencial de adsorción $(\mathrm{kJ} / \mathrm{mol})$.

R: constante universal de los gases $\left(0,00831\right.$ Joules $\left./{ }^{\circ} \mathrm{K} \cdot \mathrm{mol}\right)$.

$\mathrm{T}$ : temperatura de adsorción ( $\left.{ }^{\circ} \mathrm{K}\right)$.

Siendo:

$$
p=p_{w}{ }^{0} \cdot a_{w}
$$


Donde:

$\mathrm{p}_{\mathrm{w}}{ }^{\circ}$ : presión de vapor del agua pura a cada temperatura (de tablas, a $25^{\circ} \mathrm{C}=$ $0,0313 \mathrm{~atm}$ y a $\left.45^{\circ} \mathrm{C}=0,0946 \mathrm{~atm}\right)$.

$a_{w}$ : actividad de agua (predecida del modelo de GAB ajustado a los datos experimentales, para diferentes niveles de humedad).

El signo de la variación de energía libre de Gibbs $(\Delta G)$ da idea de la espontaneidad del proceso $(\Delta G<0$, espontáneo) (Apostolopoulos y Gilbert, 1990), y se calculó aplicando la ecuación:

$$
\Delta G=R \cdot T \cdot \ln a_{w}(k J / m o l)
$$

La variación de entropía de adsorción $(\Delta S)$ se puede asociar con la disposición espacial que ocurre en la interfase agua-sorbente $(\Delta S<0$ describe un sistema más estructurado) (Apostolopoulos y Gilbert, 1990), y se calculó aplicando la ecuación:

$$
\Delta S=\frac{\Delta \mathrm{H}-\Delta \mathrm{G}}{\mathrm{T}}\left(\mathrm{J} /{ }^{\circ} \mathrm{K} \cdot \mathrm{mol}\right)
$$

El calor isostérico de sorción (cambio entálpico asociado al proceso de sorción, $\mathrm{Q}_{\mathrm{s}}$ ) se calculó aplicando la ecuación:

$$
\mathrm{Q}_{\mathrm{s}}=\Delta \mathrm{H}-\Delta \mathrm{H}_{\mathrm{v}}(\mathrm{kJ} / \mathrm{mol})
$$

Donde:

$\Delta \mathrm{H}$ : calor diferencial de adsorción.

$\Delta \mathrm{H}_{\mathrm{v}}$ : calor de evaporación del agua pura $\left(\mathrm{a} 25^{\circ} \mathrm{C}=-43,46 \mathrm{~kJ} / \mathrm{mol}\right)$.

\subsection{Cuantificación de sólidos solubles}

El contenido de sólidos solubles se determinó colocando las muestras de algarroba cruda y tostada $\left(160^{\circ} \mathrm{C}, 60 \mathrm{~min}\right)$ en un erlenmeyer con agua hirviendo durante exactamente $5 \mathrm{~min}$. Se filtró con filtro de papel tarado, y el filtrado se secó en estufa de convección de aire (Dalvo, 4R/l, Argentina) a $105^{\circ} \mathrm{C}$ hasta peso constante. El resultado se expresó como $\mathrm{g}$ de sólidos solubles en $100 \mathrm{~g}$ de algarroba seca. Norma AOAC 973.21 (1995).

\subsection{Humedad}

El contenido de humedad en las muestras de algarroba cruda y tostada $\left(160^{\circ} \mathrm{C}, 60 \mathrm{~min}\right)$ se determinó en estufa de convección de aire (Dalvo, 4R/l, Argentina) a $70^{\circ} \mathrm{C}$, hasta peso constante. Por diferencia de peso se obtuvo la humedad $\mathrm{w}_{\mathrm{o}}$ (base húmeda). Norma AOAC 925.10 modificada (1995). 


\subsection{Proteínas totales}

El nitrógeno total en las muestras de algarroba tostada $\left(160^{\circ} \mathrm{C}, 60 \mathrm{~min}\right)$ se determinó siguiendo el método Kjeldahl y el contenido en proteína se calculó aplicando el factor general N x 6,25. Norma AOAC 960.52 (1995).

\subsection{Lípidos totales}

Los lípidos totales en las muestras de algarroba tostada $\left(160^{\circ} \mathrm{C}, 60 \mathrm{~min}\right)$ se determinaron por extracción con éter de petróleo, en un equipo de tipo Soxhlet, y posterior evaporación del disolvente. Comprenden la totalidad de los lipoides solubles en el éter (glicéridos, carotenoides, aceites esenciales, etc.). Método AOCS Aa 4-38 (1989).

\subsection{Cenizas}

Las cenizas se cuantificaron gravimétricamente en las muestras de algarroba tostada $\left(160^{\circ} \mathrm{C}, 60 \mathrm{~min}\right)$ tras calcinación en mufla (Indef, 331, Argentina) $6 \mathrm{~h}$ a $550^{\circ} \mathrm{C}$. Norma AOAC 923.03 (1995).

\subsection{Minerales}

Los contenidos de calcio, magnesio, hierro, zinc, cobre y manganeso se determinaron en las cenizas por espectrofotometría de absorción atómica (Perkin Elmer, 3110, EE.UU.), tras mineralización por vía húmeda con ácido nítrico. El contenido total de fósforo se determinó espectrofotométricamente a absorbancia $410 \mathrm{~nm}$ (UV-Visible, Milton Roy, Genesis 5, EE.UU.), tras incubación con una solución de molibdovanadato, previa digestión de las cenizas con ácidos nítrico y sulfúrico. El contenido de potasio y sodio se determinó en las cenizas por fotometría de llama (Corning, 405, Inglaterra). Normas AOAC 929.07, 931.09, 931.10, 944.02, 965.30, 966.16, 969.32, 970.39 (1995).

\subsection{Fibra cruda}

La fibra cruda se determinó atacando las muestras de algarroba tostada $\left(160^{\circ} \mathrm{C}, 60 \mathrm{~min}\right)$, sucesivamente con ácido sulfúrico e hidróxido de sodio, en caliente, hasta dejar sólo la fracción no digerible, que es principalmente celulosa y parte de lignina como lignocelulosa. Como en el residuo hay también algo de minerales, para mayor exactitud se incineró y se descontaron las cenizas. Método AOCS Ba 6-61 (1989).

\subsection{Carbohidratos totales}

Los carbohidratos totales de la muestra de algarroba tostada $\left(160^{\circ} \mathrm{C}, 60\right.$ min) se calcularon restando a 100, la suma de los porcentajes de humedad, lípidos, proteína y cenizas. Código Alimentario Argentino (1998). 


\subsection{Valor energético}

El valor energético de la muestra de algarroba tostada $\left(160^{\circ} \mathrm{C}, 60 \mathrm{~min}\right)$ se calculó utilizando los coeficientes de Atwater o sistema 4-9-4 (Adrián et al., 2000), multiplicando los gramos de proteína, grasa, carbohidratos totales menos los gramos de fibra cruda o carbohidratos no disponibles, por sus factores (4 kcal/g de proteína, $9 \mathrm{kcal} / \mathrm{g}$ de grasa, $4 \mathrm{kcal} / \mathrm{g}$ de carbohidratos) y suma de los productos. Código Alimentario Argentino (1998).

\subsection{Taninos condensados}

Los taninos condensados se cuantificaron en las muestras de algarroba tostada $\left(160^{\circ} \mathrm{C}, 60 \mathrm{~min}\right)$ por el método volumétrico de Lowenthal, basado en la determinación del material presente en una infusión acuosa de la muestra, que es oxidado por el permanganato de potasio y precipitado con gelatina. Hart y Fisher (1984).

\subsection{Polifenoles solubles totales}

El contenido de polifenoles solubles totales en las muestras de algarroba tostada $\left(160^{\circ} \mathrm{C}, 60 \mathrm{~min}\right)$, se determinó en las soluciones obtenidas tras extraer sucesivamente $1 \mathrm{~g}$ de muestra con metanol-agua $(5: 5 \mathrm{v} / \mathrm{v})$ y acetonaagua $(7: 3 \mathrm{v} / \mathrm{v})$ con agitación constante durante $60 \mathrm{~min}$ a temperatura ambiente en ambos casos (Bravo et al., 1994a). La cuantificación se realizó espectrofotométricamente utilizando el reactivo de Folin-Ciocalteau (ácido fosfomolíbdico-ácido fosfotúngstico) y ácido tánico $\left(\mathrm{C}_{75} \mathrm{H}_{52} \mathrm{O}_{46}\right.$, peso molecular 1701) como estándar (Singleton y Rossi, 1965). Para ello se tomaron $2 \mathrm{ml}$ de la solución obtenida, a la cual se agregó una solución acuosa (1/10) del reactivo de Folin-Ciocalteau, agitando, después de $0,5 \mathrm{~min}$ y antes de $8 \mathrm{~min}$ se adicionaron $8 \mathrm{ml}$ de una solución acuosa de carbonato de sodio anhidro (75 g/l). Se dejó reposar $120 \mathrm{~min}$ a $25^{\circ} \mathrm{C}$. Luego se leyó a absorbancia 765 nm (UV-Unicam, UV2 2000E, Gran Bretaña), previa puesta a 0 con un blanco de reactivos. Se utilizó ácido tánico como solución estándar (100 $\mathrm{mg} / \mathrm{l})$, y a partir de esta se prepararon disoluciones entre 50 y $200 \mathrm{mg} / \mathrm{l}$ y se efectuó la curva de calibración absorbancia-concentración correspondiente. El contenido de polifenoles solubles totales se expresó en equivalentes de ácido tánico por comparación con la curva estándar.

\subsection{Cafeína}

La cafeína en las muestras de algarroba tostada $\left(160^{\circ} \mathrm{C}, 60 \mathrm{~min}\right)$ se determinó empleando el método de Bailey-Andrew modificado. Se hirvieron las muestras con óxido de magnesio pesado, se extrajo la cafeína con cloroformo y se tituló el residuo con ácido sulfúrico. Norma AOAC 925.17 (1995). 


\subsection{Fibra dietética}

La fibra dietética en la muestra de algarroba tostada $\left(160^{\circ} \mathrm{C}, 60 \mathrm{~min}\right) \mathrm{se}$ determinó por método combinado enzimático y gravimétrico.

Se pesaron las muestras de algarroba $(1 \mathrm{~g})$, se gelatinizaron con $\alpha$ amilasa termoestable $\left(95^{\circ} \mathrm{C}, \mathrm{pH} 6,15 \mathrm{~min}\right)$, se digirieron con proteasa $\left(60^{\circ} \mathrm{C}\right.$, $\mathrm{pH} 7,5,30 \mathrm{~min}$ ) y amiloglucosidasa $\left(60^{\circ} \mathrm{C}, \mathrm{pH} 4,5,30 \mathrm{~min}\right.$ ) (kit enzimático Sigma TDF-100, EE.UU.) para remoción de la proteína y almidones presentes. Con la adición de etanol se precipitó la fibra dietética soluble.

Se filtró (módulo de filtración Fibretec E, Tecator, Suecia) y lavó el residuo con etanol y acetona. Se secó y pesó. Con una mitad se determinó proteína (Kjeltec autodestilador 2200 y digestor 2006, Tecator) y con la otra cenizas (crisoles de $30 \mathrm{ml}$ porosidad $2 \mathrm{P}$, mufla $5 \mathrm{~h}$ a $525^{\circ} \mathrm{C}$ ). La fibra dietética total se obtuvo restando al peso del residuo el de proteína y cenizas. Normas AOAC 920.86, 985.29 (1995).

\subsection{Lisina}

La lisina liberada en las muestras de algarroba tostada $\left(160^{\circ} \mathrm{C}, 60 \mathrm{~min}\right)$ se determinó por el método de Carpenter, que consiste en hacer reaccionar el grupo $\varepsilon$-amino libre de la lisina con 2,4-dinitrofluorobenceno. Las muestras se pusieron en contacto con 2,4-dinitrofluorobenceno, en medio alcohólico, por $2 \mathrm{~h}$, dando dinitrofenil-lisina, a la que se le efectuó una hidrólisis clásica con ácido clorhídrico $6 \mathrm{M}$ durante $16 \mathrm{~h}$. Los dinitrofenil-aminoácidos distintos de la dinitrofenil-lisina se eliminaron por extracción con éter. La dinitrofenillisina se cuantificó espectrofotométricamente a absorbancia $435 \mathrm{~nm}$ (UVVisible, Milton Roy, Genesis 5, EE.UU.). Norma AOAC 975.44 (1995).

\subsection{Azúcares}

\subsubsection{AZÚCARES TOTALES}

Los azúcares totales se extrajeron de las muestras de algarroba cruda y tostada (a los distintos grados de tostado) con etanol-agua $(8: 2 \mathrm{v} / \mathrm{v})$, y cuantificaron por el método volumétrico de Fehling-Causse-Bonans, previa inversión en medio ácido en caliente $\left(\mathrm{HCl}, 6 \mathrm{~N}, 60^{\circ} \mathrm{C}, 10 \mathrm{~min}\right)$, utilizando azul de metileno como indicador. Norma AOAC 920.184 (1995); Montes, 1981.

\subsubsection{AZÚCARES REDUCTORES}

Los azúcares reductores se extrajeron de las muestras de algarroba tostada (a los distintos grados de tostado) con etanol-agua $(8: 2 \mathrm{v} / \mathrm{v})$, y cuantificaron por el método volumétrico de Fehling-Causse-Bonans, utilizando azul de metileno como indicador. Norma AOAC 920.183 (1995), Montes, 1981. 


\subsubsection{TIPOS DE AZÚCARES POR HPLC}

La identificación y cuantificación de cada uno de los azúcares (xilosa, fructosa, glucosa y sacarosa) presentes en las muestras de algarroba cruda y tostada $\left(160^{\circ} \mathrm{C}, 60 \mathrm{~min}\right)$, se realizó mediante cromatografía líquida de alta resolución (HPLC).

Se utilizó un cromatógrafo Konic (modelo KNK 500A, España), columna Konic con relleno Spheridorb $\mathrm{NH}_{2}(25 \times 0,4 \mathrm{~cm})$ tamaño de partícula $5 \mu \mathrm{m}$, detector de índice de refracción Konic, fase móvil acetonitrilo-agua (8:2 v/v), flujo 1,5 $\mathrm{ml} / \mathrm{min}$, presión máxima 450 psi, presión mínima 0 , volumen de muestra $5 \mu \mathrm{l}$.

A $2 \mathrm{~g}$ de muestra se le agregaron $10 \mathrm{ml}$ de mezcla acetonitrilo-agua (8:2 $\mathrm{v} / \mathrm{v}$ ), agitando durante $2 \mathrm{~h}$. Luego se filtró con filtro de papel con ayuda de vacío, y antes de inyectar se filtro nuevamente con el sistema de filtración de HPLC. Se inyectaron primero los patrones xilosa, fructosa, glucosa y sacarosa (Sigma, EE.UU.), para conocer sus tiempos de retención y después diluciones de los mismos para confeccionar las curvas de calibración correspondientes. Por último se inyectaron las muestras de algarroba cruda y tostada. Las determinaciones se realizaron por duplicado.

La cuantificación se realizó por comparación de áreas, por el método de patrón externo, utilizando como referencia disoluciones patrón de los azúcares en las proporciones adecuadas.

\section{EVALUACIÓN SENSORIAL}

\subsection{Preparación de la infusión}

Se trabajó con todas las muestras de algarroba tostada molida retenidas sobre el tamiz de 0,25 mm (ASTM 60). Se realizaron infusiones al 1,5\% (g producto/100 ml agua) con agua potable a punto de hervor y luego de $5 \mathrm{~min}$ de reposo el extracto se coló con colador común (malla de acero de 0,15 $\mathrm{mm}$ ). Por percepción visual (Lozano, 1978) se seleccionaron tres muestras de entre todos los tipos de tostado ensayados:

T1: algarroba tostada a $160^{\circ} \mathrm{C}$ durante $60 \mathrm{~min}$.

T2: algarroba tostada a $175^{\circ} \mathrm{C}$ durante $30 \mathrm{~min}$.

T3: algarroba tostada a $175^{\circ} \mathrm{C}$ durante $45 \mathrm{~min}$.

A los efectos de mantener la temperatura constante las muestras se presentaron en vasos de poliestireno expandido blanco a la temperatura de consumo de $50^{\circ} \mathrm{C}$ (Leino et al, 1991), identificadas con números aleatorios.

\subsection{Selección del panel de catadores}

El panel fue conformado por 9 evaluadores entrenados en evaluación sensorial de productos alimenticios y en la metodología de ensayo (Zamora y Calviño, 1996; ASTM, 1981a). 


\subsection{Organización de las sesiones de cata}

\subsubsection{ANÁLISIS DESCRIPTIVOS}

Para caracterizar organolépticamente el producto se aplicaron análisis descriptivos cuantitativos utilizando escalas no estructuradas de $10 \mathrm{~cm}$, ancladas en los extremos (ASTM, 1992; Meilgaard et al., 1991; ASTM, 1981b; Stone et al., 1974). En tales escalas se ubicaron las muestras de café, malta y cascarilla de cacao, a modo de referencias internas. Se evaluaron los atributos aroma, color, aspecto, sabor y textura, tanto del material molido como de las infusiones. En cada caso, los descriptores utilizados fueron seleccionados por consenso de los integrantes del panel de catadores en sesiones preliminares.

Las pruebas de análisis descriptivos se realizaron en una sala de catas, en sesiones de mañana de 9 a 11 (Anzaldúa-Morales, 1994), en días alternos y en cuatro etapas.

$1^{\circ}$ ) Familiarización del panel con los atributos sensoriales de café, malta y cascarilla de cacao, tanto en la muestra molida tal cual, como en una infusión al 1,5\%. Se realizaron cuatro sesiones de trabajo conjunto en las que las muestras se presentaron a la temperatura de consumo junto con la muestra molida tal cual.

$2^{\circ}$ ) Familiarización, propuesta y selección de los atributos sensoriales de infusión de algarroba. Se realizaron cuatro sesiones de trabajo conjunto, utilizando al mismo tiempo las muestras de café, malta y cascarilla de cacao.

A fin de no confundir los términos y para memorizarlos mejor, se confeccionaron dos tablas con las características organolépticas (descriptores) utilizadas por el panel para definir cada uno de los productos, tanto del material molido como de la infusión correspondiente.

$3^{\circ}$ ) Evaluación individual y cuantificación de las características organolépticas de las muestras de café, malta y cascarilla de cacao. Se realizaron tres sesiones en las que se presentaron las tres muestras combinadas de dos en dos y en forma sucesiva; es decir, en cada sesión se evaluaba una muestra y a continuación se presentaba la siguiente.

$4^{\circ}$ ) Evaluación individual y cuantificación de las características organolépticas de la infusión de algarroba. Se realizaron seis sesiones, dos con cada infusión preparada al 3\%, 4,5\% y $6 \%$. Las muestras se presentaron identificadas con números aleatorios, una por vez, en sesiones separadas con el propósito de evitar la saturación de los evaluadores.

\subsubsection{ACEPTABILIDAD SENSORIAL}

Participaron 113 consumidores (60 mujeres y 53 varones) (ASTM, 1981a; Amerine et al., 1965), distribuidos en los siguientes rangos de edades:

42 consumidores entre 17 y 27 años

37 consumidores entre 28 y 39 años

32 consumidores entre 40 y 58 años. 
Se evaluaron infusiones al 4,5\% (g producto/100 $\mathrm{ml}$ leche) preparadas con las tres muestras de algarroba tostada mezcladas con leche entera en la proporción 1:1, indicando el grado de gusto según una escala hedónica de nueve puntos (Costell y Durán, 1981). Las pruebas de aceptabilidad sensorial se realizaron en una sala de catas, en sesiones por la mañana de 9 a 11 hs y por la tarde de 16 a 18 hs (Anzaldúa-Morales, 1994), en días seguidos.

\subsubsection{ANÁLISIS ESTADÍSTICO DE LOS RESULTADOS}

Los resultados obtenidos en las distintas etapas fueron procesados estadísticamente aplicando un Soporte Statgraphic Plus 3.0. 
IV. RESULTADOS Y DISCUSIÓN 


\section{CARACTERIZACIÓN FÍSICA Y QUÍMICA DE LA ALGARROBA CRUDA Y TOSTADA}

\subsection{Selección}

De los $21 \mathrm{~kg}$ de algarrobas maduras recolectadas se eligieron manualmente $19 \mathrm{~kg}$, desechando las rotas, las manchadas y las picadas por insectos; $18 \mathrm{~kg}$ se destinaron a tostado y $1 \mathrm{~kg}$ se mantuvo crudo.

\subsection{Secado}

El secado en estufa de $1 \mathrm{~kg}$ de algarroba cruda se realizó bajando la humedad del 12 al $6 \%$, para que se tornen quebradizas y fáciles de moler.

\subsection{Caracterización del grado de tueste}

El color es un importante atributo de los productos alimenticios. Los consumidores frecuentemente miran un producto y toman una decisión basada ampliamente en el aspecto total, incluyendo el color. El color puede estar influenciado y relacionado a muchas otras propiedades. A menudo el color y el sabor están directamente relacionados. También lo están la variación de color y el contenido de humedad (Good, 2002). Existe una clara tendencia de controlar el color de los productos alimenticios, sobre todo en aquellos cuya apariencia externa tiene como componente importante al color, como lo son los que se someten a tostado. El tostado de la algarroba promueve el desarrollo de coloraciones pardas en función del grado de tueste o tiempo y temperatura de tostado.

En la FIGURA 9 se muestran las algarrobas a tres niveles de tostado comparadas con algarrobas crudas, pudiendo observarse la gran diferencia de color entre ellas. 


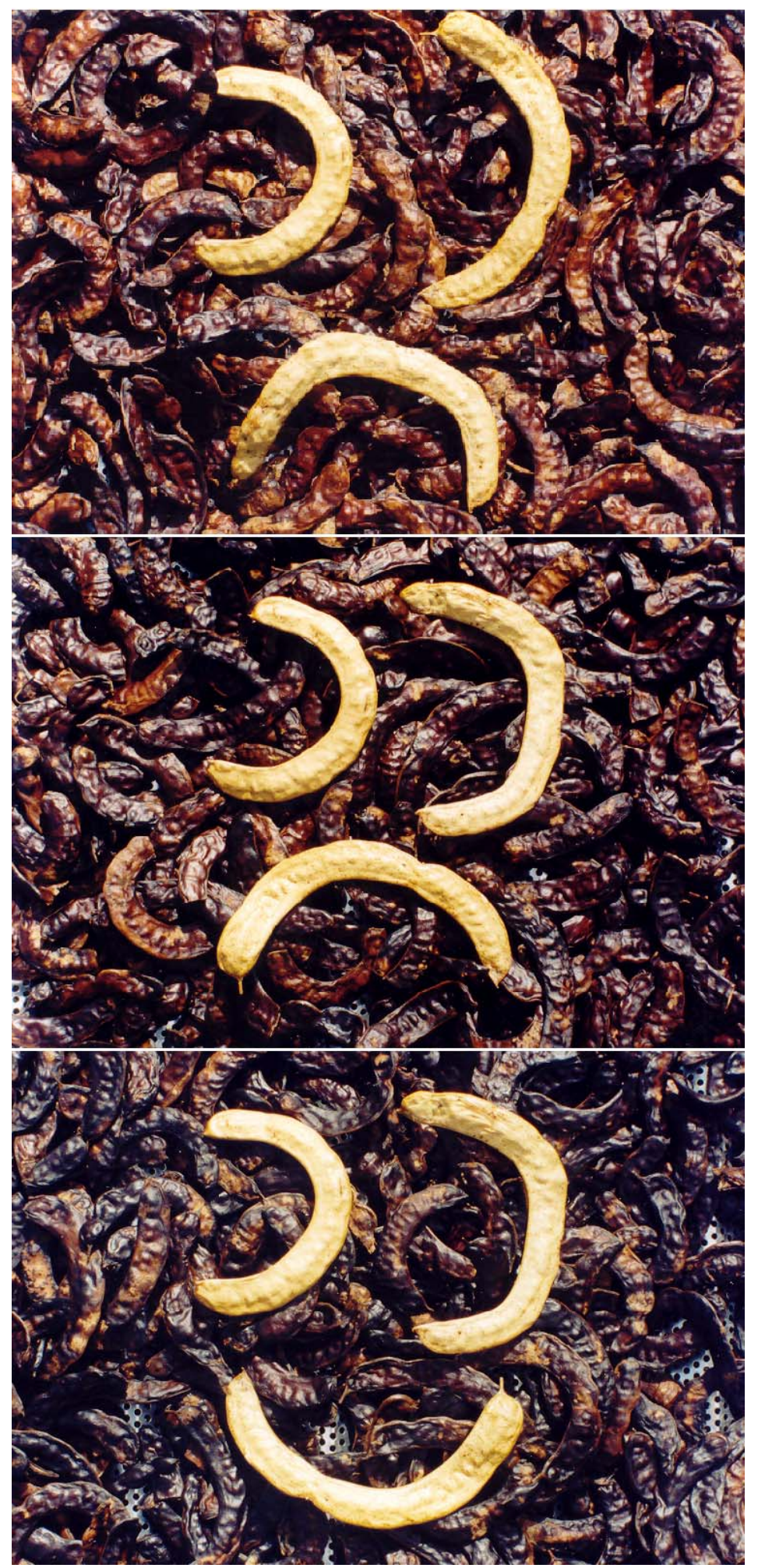

FIGURA 9. Algarroba tostada $\left(160^{\circ} \mathrm{C}, 60 \mathrm{~min} ; 175^{\circ} \mathrm{C}, 30 \mathrm{~min} ; 175^{\circ} \mathrm{C}, 45 \mathrm{~min}\right)$ comparada con algarroba cruda 
En la TABLA 8 se muestran las coordenadas de color luminosidad $\left(\mathrm{L}^{*}\right)$ y cromaticidad $\left(a^{*}\right.$ y $\left.b^{*}\right)$ de la harina de algarroba cruda y tostadas en todos los niveles, y el café tostado molido comercial (Argentina, variedad Coffea arabica Linn). También se indican los valores de los índices de color $\mathrm{I}_{\mathrm{c}}$ para cada muestra [calculados con la ec. (1)] y los de las diferencias de color $\Delta \mathrm{E}^{*}{ }_{\mathrm{ab}}$ entre la algarroba tostada y la cruda [calculados con la ec. (2)].

TABLA 8. Coordenadas de color, índices de color y diferencias de color para algarroba cruda, algarroba tostada y café tostado

\begin{tabular}{|c|c|c|c|c|c|}
\hline Muestra & $L^{*}$ & $a^{*}$ & $b^{*}$ & $I_{c}$ & $\Delta \mathrm{E}_{\mathrm{ab}}^{*}$ \\
\hline Algarroba cruda & $64,37 \pm 1,03$ & $4,92 \pm 0,05$ & $25,57 \pm 0,39$ & $2,99 \pm 0,11$ & 0 \\
\hline & & & & & \\
\hline 10 & $64,36 \pm 0,03$ & $6,51 \pm 0,03$ & $25,65 \pm 0,06$ & $3,94 \pm 0,02$ & $1,59 \pm$ \\
\hline $100^{\circ} \mathrm{C} 45 \mathrm{~min}$ & $60,29 \pm 0,18$ & $7,14 \pm 0,16$ & $24.26 \pm 0,29$ & $4,88 \pm 0,05$ & $4,83 \pm 0,17$ \\
\hline $100^{\circ} \mathrm{C} 60 \mathrm{~min}$ & $61,14 \pm 0,84$ & $7,97 \pm 0,08$ & $23,69 \pm 0,36$ & $5,48 \pm 0,20$ & $4,82 \pm 0,74$ \\
\hline $30 \mathrm{~min}$ & $56,32 \pm 0,01$ & $10,06 \pm 0,07$ & $22,96 \pm 0,03$ & $7,78 \pm 0,06$ & $9,90 \pm 0,04$ \\
\hline $45 \mathrm{~min}$ & $54,39 \pm 0,01$ & $9,99 \pm 0,03$ & 21,99 & $8,35 \pm 0,01$ & $11,75 \pm 0,00$ \\
\hline $\min$ & $40 \pm 0,04$ & $9,78 \pm 0,04$ & $22,81 \pm 0,04$ & $7,89 \pm 0,05$ & $3 \pm 0,05$ \\
\hline $130^{\circ} \mathrm{C} 30 \mathrm{~min}$ & $47,05 \pm 0,05$ & $11,07 \pm 0,09$ & $19,76 \pm 0,05$ & $11,91 \pm 0,14$ & $19,27 \pm 0,08$ \\
\hline $130^{\circ} \mathrm{C} 45 \mathrm{~min}$ & $44,67 \pm 0,02$ & $9,41 \pm 0,02$ & $18,28 \pm 0,01$ & $11,52 \pm 0,03$ & $21,48 \pm 0,02$ \\
\hline 13 & $44,04 \pm 0,58$ & $8,74 \pm 0,19$ & 17,61 & $11,27 \pm 0,14$ & $22,16 \pm 0,63$ \\
\hline 14 & $47,03 \pm 0,03$ & $10,66 \pm 0,07$ & 17,45 & $12,99 \pm 0,04$ & $19,99 \pm 0,03$ \\
\hline $145^{\circ} \mathrm{C} 45 \mathrm{~min}$ & $43,38 \pm 0,05$ & $9,36 \pm 0,03$ & 15,63 & $13,80 \pm 0,06$ & $23,65 \pm 0,07$ \\
\hline $145^{\circ} \mathrm{C} 60 \mathrm{~min}$ & $40,70 \pm 0,01$ & $8,14 \pm 0,06$ & $13,75 \pm$ & $14,55 \pm 0,11$ & $26,65 \pm 0,02$ \\
\hline $160^{\circ} \mathrm{C} 30 \mathrm{n}$ & $37,32=$ & 7,49 & 10,70 & $18,76 \pm 0,06$ & 30,98 \\
\hline 16 & $34,13 \pm 0$ & $5,60 \pm$ & 7,67 & $21,38 \pm 0,26$ & $35,15 \pm 0,03$ \\
\hline $160^{\circ} \mathrm{C} 60 \mathrm{~min}$ & $33,09 \pm 0,01$ & $5,13 \pm 0,00$ & $7,09 \pm 0,01$ & $21,85 \pm 0,02$ & $36,33 \pm 0,00$ \\
\hline $175^{\circ} \mathrm{C} 30 \mathrm{~min}$ & $31,79 \pm 0,03$ & $4,58 \pm 0,07$ & $5,97 \pm 0,02$ & $24,12 \pm 0,48$ & $38,02 \pm 0,03$ \\
\hline & $32,07=$ & $4,19 \pm$ & 6,16 & $21,23 \pm 0,10$ & $37,69 \pm 0,01$ \\
\hline & & $4,24 \pm 0,02$ & $6,20 \pm$ & $21,57 \pm 0,12$ & $38,00 \pm 0,01$ \\
\hline Café tostado & $30,67 \pm 0,03$ & $5,31 \pm 0,20$ & $6,53 \pm 0,04$ & $26,49 \pm 1,08$ & $38,71 \pm 0,04$ \\
\hline
\end{tabular}

Se observa que a medida que aumentan la temperatura y el tiempo de tostado disminuyen los valores de luminosidad $L^{*}$, lo que significa que la algarroba se va oscureciendo. Mientras que el índice de color $\mathrm{I}_{\mathrm{c}} \mathrm{y}$ las diferencias de color $\Delta \mathrm{E}^{*}$ ab respecto a la algarroba cruda aumentan. También puede verse la buena aproximación de esos valores a los del café. 
Las FIGURAS 10 y 11 muestran, respectivamente, la representación en los planos de color $b^{*} a^{*}$ y $L^{*} a^{*}$ de los puntos correspondientes a la harina de algarroba cruda y tostada en diferentes condiciones. Puede observarse la trayectoria de color del producto a lo largo del tueste desde el punto correspondiente a la algarroba cruda, tanto en el plano cromático $\mathrm{b}^{*} \mathrm{a}^{*}$ como el plano de luminosidad $L^{*} a^{*}$. Con los tiempos utilizados en el diseño experimental, únicamente se alcanzan colores similares a los del café tostado en cuanto a tono, croma y luminosidad con las temperaturas de 160 y $175^{\circ} \mathrm{C}$ que serían las recomendables para el proceso. A temperaturas inferiores las características de color difieren notablemente y para conseguir una mejor igualación serían necesarios tiempos de tostado superiores a los utilizados en el presente estudio.

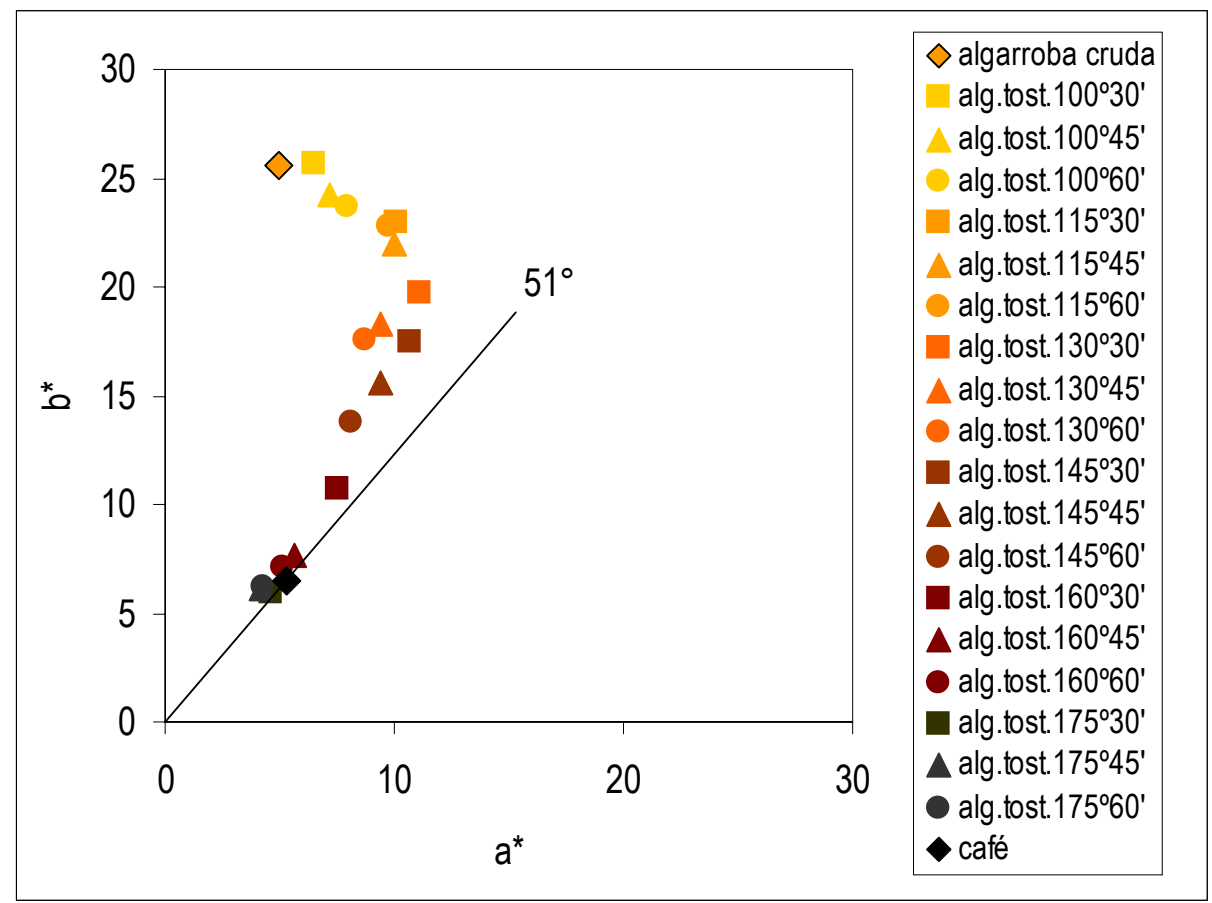

FIGURA 10. Representación en el plano $b^{*} a^{*}$ de los puntos de color alcanzados en las diferentes condiciones de tostado. Se incluye la línea isotono correspondiente al café tostado 


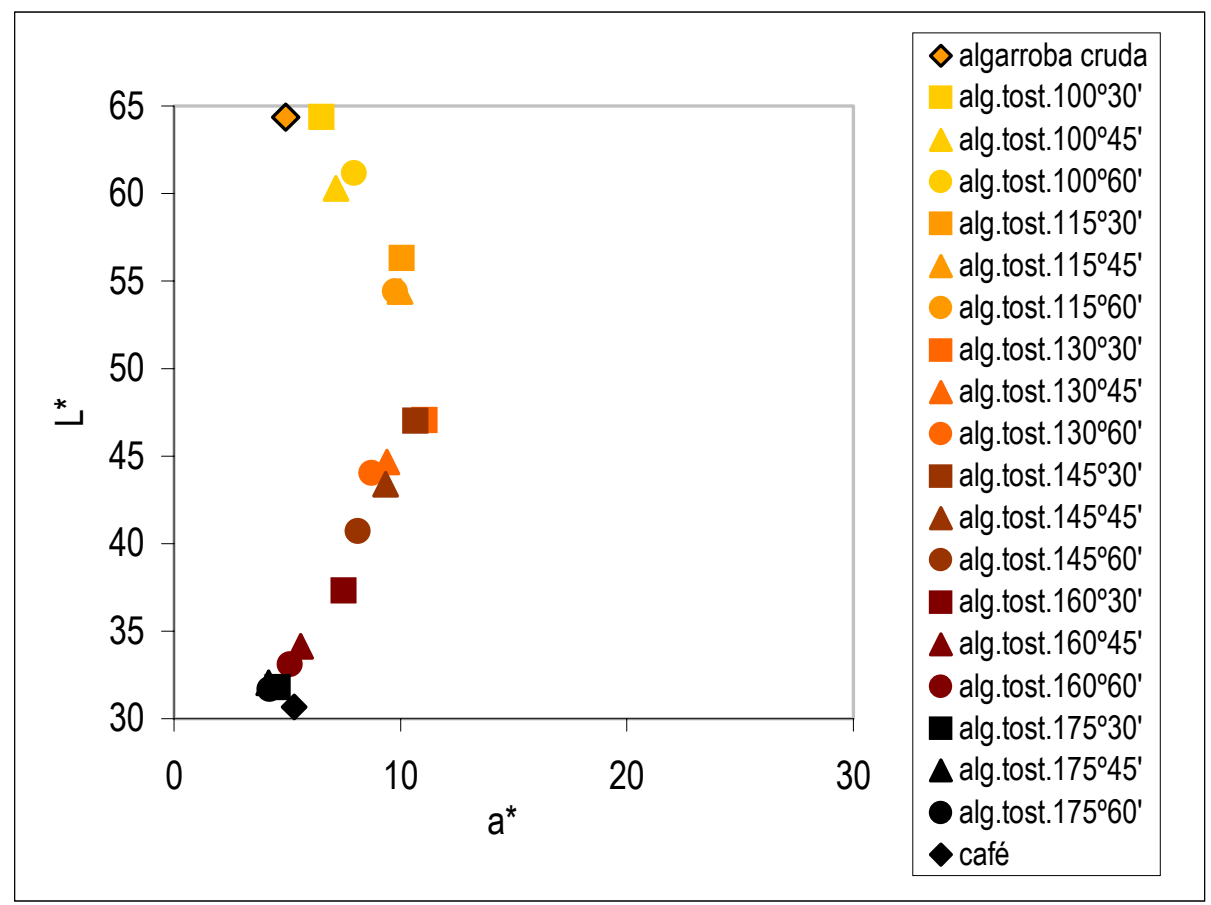

FIGURA 11. Representación en el plano L*a* de los puntos de color alcanzados en las diferentes condiciones de tostado

En las TABLAS 9 y 10 se muestran las diferencias de valores de las funciones de color luminosidad $\left(\mathrm{L}^{*}\right)$ e intensidad de color métrico $\left[\mathrm{C}^{*}{ }_{\mathrm{ab}}\right.$, ec. (3)] para la algarroba en sus diferentes niveles de tostado, respecto de los de la algarroba cruda.

TABLA 9. Función luminosidad $\left(\mathrm{L}^{*} \mathrm{o}^{-} \mathrm{L}^{*}\right)$, tiempo y temperatura

\begin{tabular}{|c|c|c|c|c|c|c|}
\hline \multicolumn{7}{|c|}{$\left(L^{*}{ }^{*}-L^{*}\right)$} \\
\hline \multirow{2}{*}{ Tiempo (min) } & \multicolumn{7}{|c|}{ Temperatura $\left.{ }^{\circ} \mathrm{C}\right)$} \\
\cline { 2 - 7 } & 100 & 115 & 130 & 145 & 160 & 175 \\
\hline 30 & 0,01 & 8,05 & 17,32 & 17,34 & 27,05 & 32,58 \\
45 & 4,08 & 9,98 & 19,70 & 20,99 & 30,24 & 32,30 \\
60 & 3,23 & 9,97 & 20,33 & 23,67 & 31,28 & 32,68 \\
\hline
\end{tabular}


TABLA 10. Función intensidad de color métrica $\left(\mathrm{C}^{*}{ }_{0}-\mathrm{C}^{*}\right)$ ab, tiempo y temperatura

\begin{tabular}{|c|r|r|r|r|r|c|}
\hline \multicolumn{7}{|c|}{$\left(\mathrm{C}^{*}{ }_{0}-\mathrm{C}^{*}\right)_{\mathrm{ab}}$} \\
\hline \multirow{2}{*}{ Tiempo (min) } & 100 & 115 & 130 & 145 & 160 & 175 \\
\cline { 2 - 7 } & $-0,42$ & 0,97 & 3,39 & 5,59 & 12,98 & 18,51 \\
\hline 30 & 0,75 & 1,89 & 5,48 & 7,82 & 16,54 & 18,59 \\
45 & 1,04 & 1,22 & 6,38 & 10,06 & 17,29 & 18,53 \\
60 & &
\end{tabular}

Las FIGURAS 12 y 13 muestran las funciones de luminosidad y cromaticidad respectivamente en función del tiempo de calentamiento para las temperaturas de proceso más bajas, ya que se observó que en los intervalos de las variables tiempo-temperatura seleccionados no es posible ajustar una ecuación cinética en todos los casos. A partir de $130^{\circ} \mathrm{C}$, la función luminosidad apenas cambia con el tiempo y tampoco son muy apreciables los cambios de croma. A temperaturas inferiores se advierte una cinética de orden cero [ec. (15)], tal como han observado algunos autores para el tostado de algarroba (Ceratonia siliqua) (Chiralt et al., 1987).

$$
\left(\frac{d B}{d t}\right)=k_{B}=\text { velocidad de pardeamiento }
$$

Donde $\mathrm{B}$ puede ser expresada en términos de cualquiera de las funciones del color $L^{*}$ o $C^{*}$ ab.

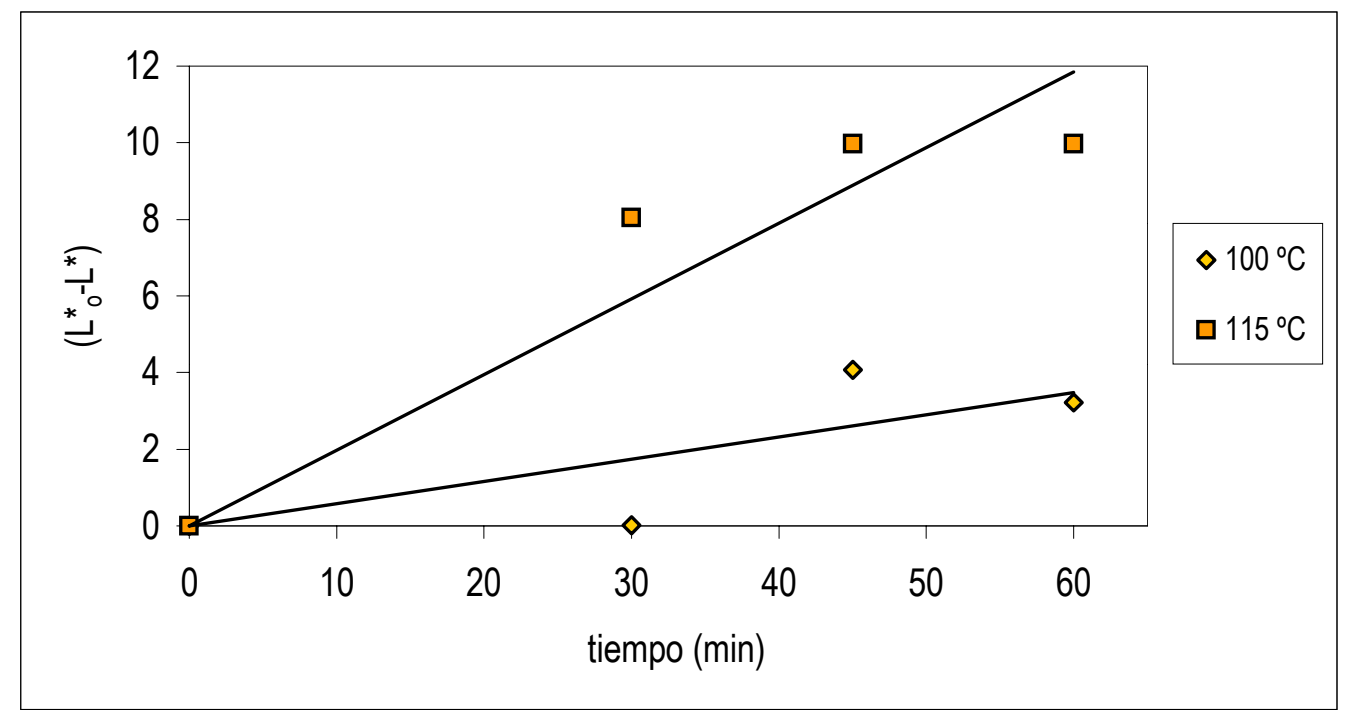

FIGURA 12. Luminosidad en función del tiempo 


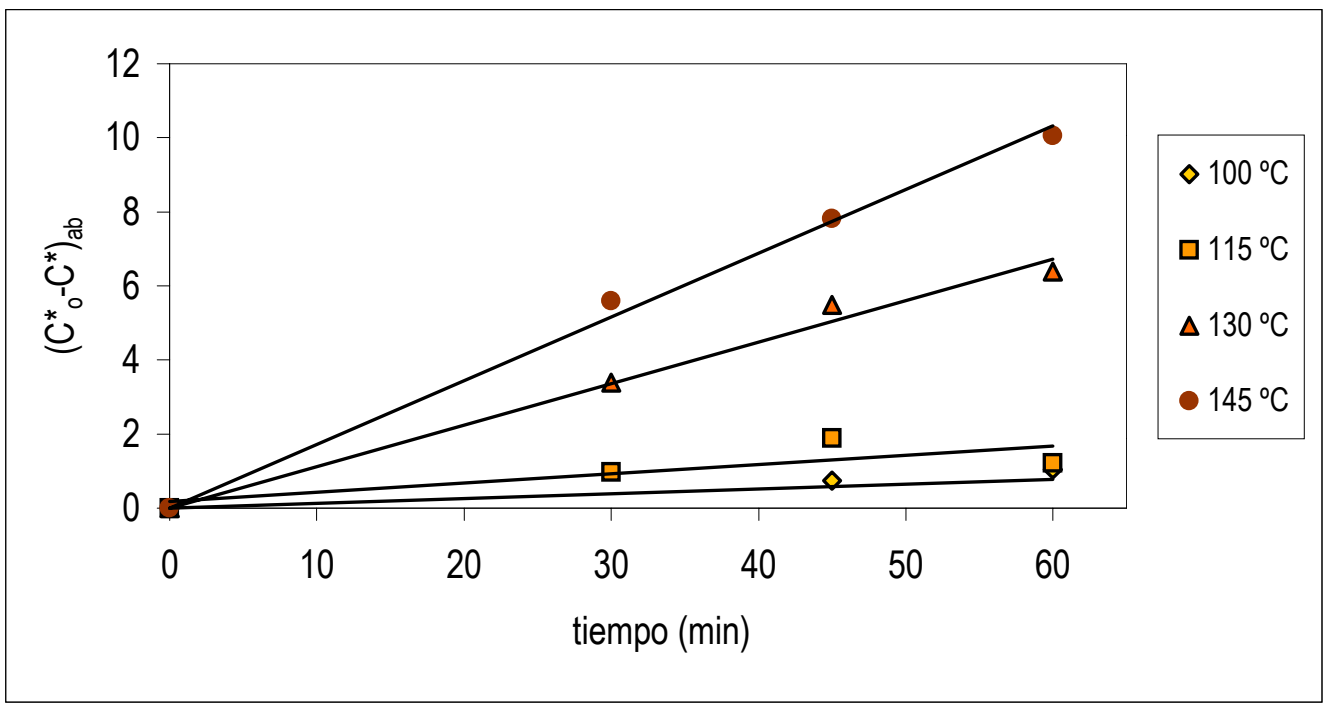

FIGURA 13. Intensidad de color métrica en función del tiempo

Los valores de las constantes $k_{\left(L^{*} \circ-L^{*}\right)}$ y $k\left(C^{*} \circ-C^{*}\right)$ ab para el desarrollo de color de la algarroba y los $R^{2}$ se listan en la TABLA 11, ellos se obtuvieron por análisis de regresión lineal de las FIGURAS 12 y 13. Se puede ver que el efecto relativo de las variables de proceso fue similar para ambas funciones de color.

TABLA 11. Constantes de desarrollo de color y $R^{2}$

\begin{tabular}{|l|c|c|c|c|}
\hline Temperatura $\left({ }^{\circ} \mathrm{C}\right)$ & 100 & 115 & 130 & 145 \\
\hline $\mathrm{K}_{\left(\mathrm{L}^{*} \mathrm{O}-\mathrm{L}^{*}\right)}$ & 0,0579 & 0,1975 & & \\
$\mathrm{R}^{2}$ & 0,6188 & 0,8637 & & \\
\hline $\mathrm{K}_{\left(\mathrm{C}^{*} \mathrm{o}-\mathrm{C}^{*}\right) \mathrm{ab}}$ & 0,0128 & 0,0287 & 0,1120 & 0,1729 \\
$\mathrm{R}^{2}$ & 0,4445 & 0,6619 & 0,9871 & 0,9954 \\
\hline
\end{tabular}

La ecuación de Arrhenius relaciona la temperatura y la constante de velocidad de reacción, y puede ser aplicada a las reacciones químicas de los alimentos (Labuza, 1980a).

$$
k=A \cdot e^{-\frac{E_{a}}{R \cdot T}}
$$

Donde:

$\mathrm{k}$ : constante de velocidad

A: factor de frecuencia.

$E_{a}$ : energía de activación en cal $/ \mathrm{mol}$. 
R: constante molar de los gases $=1,987 \mathrm{cal} /{ }^{\circ} \mathrm{K} . \mathrm{mol}$.

$\mathrm{T}$ : temperatura absoluta en ${ }^{\circ} \mathrm{K}$.

Aplicando logaritmos a la ecuación de Arrhenius se tiene:

$$
\ln \mathrm{k}=\ln \mathrm{A}-\frac{\mathrm{E}_{\mathrm{a}}}{\mathrm{R} \cdot \mathrm{T}}
$$

La energía de activación $\left(E_{a}\right)$ se obtiene de la linealización [ec. (17)] y ajuste de los datos experimentales.

Los valores de $E_{a}$ encontrados para ambas funciones de color fueron:

$$
\begin{gathered}
E_{a\left(L^{*} O-L^{*}\right)}=23,44(\mathrm{kcal} / \mathrm{mol}) \\
E_{a\left(C^{*} O-C^{*}\right) a b}=18,93(\mathrm{kcal} / \mathrm{mol})
\end{gathered}
$$

Los valores de $E_{a}$ son muy similares para ambas funciones de color lo cual indica que son indicadores equivalentes de la evolución del pardeamiento durante el proceso de tostado (Chiralt et al., 1987). Estos valores son similares a los recopilados por Labuza y Baisier (1992) para el pardeamiento de una serie de productos con diferentes $a_{w}$ y condiciones de temperatura, los cuales oscilan entre 16 y $30 \mathrm{kcal} / \mathrm{mol} ;$ y resultan algo superiores a los encontrados por Ibarz y Navés (1995), 8,91 y 15,68 kcal/mol trabajando con altas $a_{w}$, o lo que es lo mismo, con bajos contenidos de sólidos solubles en el pardeamiento no enzimático de zumos clarificados de manzana variedad Jonagold.

En general los valores de $E_{a}$ para las reacciones químicas están comprendidos entre 0 y $100 \mathrm{kcal} / \mathrm{mol}$ (Sanz Pedrero, 1992).

Desde el punto de vista químico, el color de la algarroba se produce por diferentes tipos de reacciones que ocurren durante el tostado, debido a las condiciones de $\mathrm{pH}$ y temperatura en que éste se desarrolla. En sentido general se trata de reacciones de pardeamiento tipo Maillard (Hough et al., 1991; Buera et al, 1990) y muy probablemente también a reacciones de caramelización y oxidación, teniendo en cuenta las características propias para este tipo de reacciones aportadas por numerosos investigadores (Buera et al., 1987; Theander, 1981; Kuster y Temmink; 1977; Feather y Harris, 1972).

Este pardeamiento se produce por la reacción de Maillard entre los azúcares reductores y grupos amino libre, y se ve favorecido por las altas temperaturas de tostado (Cornwell y Wrolstad, 1981; Hodge, 1953). Es por ello, que resulta interesante realizar el estudio de la variación de color a diferentes temperaturas. Esto permite obtener las constantes cinéticas de pardeamiento, a partir de la cual se puede prever el aumento de color, de desarrollo paralelo con los cambios de sabor y aroma de la algarroba (Toribio y Lozano, 1986; Karel, 1984; Labuza, 1972). Las reacciones entre azúcares reductores y aminas libres son las que mayoritariamente producen el pardeamiento no enzimático (Toribio y Lozano, 1987). 
Los sustratos mayoritarios son los compuestos carbonílicos, y en primer lugar los azúcares reductores (glucosa, fructosa), pero también pueden serlo polifenoles y aromas naturales, entre otros (Babsky et al., 1986; Cornwell y Wrolstad, 1981).

Estas reacciones son complejas, lo que hace difícil postular un mecanismo de reacción, y por tanto, deducir una expresión cinética rigurosa de este proceso. La obtención de una expresión cinética se realiza estudiando alguna de las componentes que varían a lo largo del proceso. En el caso de la algarroba, el color. Este es un método sencillo y efectivo para estudiar este fenómeno, ya que el color es una medida indirecta de la concentración de los compuestos poliméricos coloreados que se forman (Ibarz y Navés, 1995).

Integrando la ec. (15), y reemplazando los valores obtenidos en las gráficas anteriores de los factores de frecuencia $(A)$ y las energías de activación $\left(E_{a}\right)$, nos permite correlacionar las funciones de color, con las variables de proceso tiempo (en min) y temperatura (en ${ }^{\circ} \mathrm{K}$ ), para temperaturas de tostado entre 100 y $130^{\circ} \mathrm{C}$.

Las ecuaciones alcanzadas son:

$$
\begin{array}{r}
\left(L^{*}{ }_{o}-L^{*}\right)=3,12 \cdot 10^{12} \cdot e^{\left(-\frac{11,8}{T}\right)} \cdot t \\
\left(C^{*}{ }_{0}-C^{*}\right)_{a b}=1,54 \cdot 10^{9} \cdot e^{\left(-\frac{9,53}{T}\right)} \cdot t
\end{array}
$$

En ambos casos las funciones del color aumentan con la temperatura o el tiempo del proceso de tostado. No obstante a temperaturas superiores a $145^{\circ} \mathrm{C}$, el proceso se acelera notablemente, mostrando una cinética más rápida que no se pudo analizar en las condiciones del estudio, ya que a los tiempos considerados las variables de color habían alcanzado un valor prácticamente asintótico. A pesar de todo, de la ubicación en los planos de color de los puntos correspondientes a las muestras tostadas a 160 y $175^{\circ} \mathrm{C}$, se deduce que con los tiempos ensayados es posible obtener valores del tono, croma y luminosidad del producto en el intervalo de los encontrados para café tostado. Estas temperaturas permiten, pues, obtener productos adecuados en tiempos de tostado relativamente cortos de entre 30 y 60 min.

\subsection{Distribución del tamaño de partículas}

En la TABLA 12 se muestra la distribución del tamaño de partículas y los parámetros de diferenciación obtenidos de los porcentajes en pesos medios de tamizado, para la algarroba cruda, la algarroba tostada $\left(160^{\circ} \mathrm{C}, 60 \mathrm{~min}\right)$, el café tostado molido comercial (Coffea arabica Linn) y la malta tostada molida comercial. 
TABLA 12. Distribución de tamaños de partículas y parámetros de diferenciación

\begin{tabular}{|c|c|c|c|c|c|}
\hline $\begin{array}{c}\text { Tamiz } \\
(\mathrm{mm})\end{array}$ & $\begin{array}{l}\text { Número } \\
\text { asignado }\end{array}$ & $\begin{array}{l}\text { Algarroba } \\
\text { cruda (\%) }\end{array}$ & $\begin{array}{l}\text { Algarroba } \\
\text { tostada (\%) }\end{array}$ & $\begin{array}{l}\text { Café molido } \\
(\%)\end{array}$ & $\begin{array}{c}\text { Malta molida } \\
(\%)\end{array}$ \\
\hline 1,40 & 5 & 0 & 0 & $2,16 \pm 0,22$ & $30,88 \pm 0,19$ \\
\hline 0,85 & 4 & $4,40 \pm 0,14$ & $3,14 \pm 0,19$ & $50,30 \pm 0,26$ & $26,86 \pm 0,09$ \\
\hline 0,60 & 3 & $35,66 \pm 0,09$ & $38,51 \pm 0,10$ & $26,89 \pm 0,08$ & $12,30 \pm 0,14$ \\
\hline 0,25 & 2 & $46,44 \pm 0,08$ & $54,22 \pm 0,05$ & $16,70 \pm 0,09$ & $12,16 \pm 0,04$ \\
\hline 0,15 & 1 & $8,93 \pm 0,10$ & $3,61 \pm 0,09$ & $3,95 \pm 0,06$ & $5,59 \pm 0,08$ \\
\hline 0,075 & 0 & $4,57 \pm 0,08$ & $0,52 \pm 0,04$ & 0 & $12,21 \pm 0,05$ \\
\hline \multicolumn{2}{|c|}{ Módulo de fineza * } & 2,27 & 2,40 & 3,19 & 3,29 \\
\hline \multicolumn{2}{|c|}{ Módulo de uniformidad ** } & $0,73: 13,68: 2,25$ & $0,52: 15,45: 0,70$ & $8,75: 7,27: 0,65$ & $9,62: 4,08: 2,97$ \\
\hline
\end{tabular}

Puesto que es posible tener dos muestras distintas con aproximadamente el mismo módulo de fineza pero con constituyentes bastante diferentes, el módulo de uniformidad es un fuerte indicador de las cantidad de partículas gruesas, medianas y finas en las muestras (Abd El-Rashid, 1996). Los módulos de fineza de la algarroba cruda y tostada son aproximadamente iguales, y los módulos de uniformidad son los que indican en este caso en particular la aglomeración de partículas finas como consecuencia del tostado. Por otra parte se observa que el módulo de fineza de la algarroba tostada es mucho más bajo que los del café y la malta, y que el módulo de uniformidad de la algarroba tostada está indicando una gran concentración de partículas medianas, muy superior a las del café y la malta (TABLA 12).

\subsection{Isoterma de sorción de agua de la algarroba cruda}

Labuza (1984) sugirió el uso de las "isotermas de trabajo" basado en el ciclo real de secado y humidificación que sufre el alimento. Por lo que establece que deberá usarse la isoterma de sorción si el alimento va a ser humectado. Tal es el caso del alimento desarrollado a partir de la algarroba.

El contenido de humedad es uno de los factores más relevantes el cual determina la calidad del alimento. El contenido de humedad de un producto, en relación a la temperatura, puede ejercer una influencia sobre su estabilidad química, microbiológica y enzimática (Labuza, 1980b). En este sentido, el conocimiento de las características de la sorción del agua es necesario para predecir su comportamiento y para determinar la actividad crítica del agua y el contenido crítico del agua que define los rangos de aceptabilidad de los productos. Las isotermas de sorción nos permiten modelar cambios en el contenido de agua de un producto durante su manipulación y almacenaje. Por otra parte, los datos de sorción a diferentes temperaturas hacen un análisis termodinámico del posible sistema, y proveen información acerca de las interacciones agua-alimento en todos los valores de calor de sorción (Martínez y Chiralt, 1996). 
Las isotermas de sorción tienen utilidad con fines teóricos pero también con fines prácticos. Los aspectos teóricos engloban cuestiones tanto termodinámicas (determinación de la humedad de la monocapa y cálculo de las entalpías de adsorción-desorción), como investigaciones estructurales (estudios de: superficie específica, relación volumen de poros/distribución de tamaños, y cristalinidad). Existen cuatro campos concretos de aplicación práctica de las isotermas de sorción relacionadas con el procesado de alimentos, como son: secado, mezclado, envasado, y almacenamiento (Gal, 1983).

Existe poca información bibliográfica sobre isotermas de sorción en Prosopis, solo se encontró la de harinas de semillas de vinal ( $P$. ruscifolia) (Freyre et al., 2001).

Los valores de humedad de equilibrio obtenidos para cada muestra de algarroba cruda, a las distintas actividades de agua $a_{w}$ se muestran en la TABLA 13, y fueron realizados calculando la ganancia de peso utilizando la ec. (6), tomando el valor de la humedad inicial de la algarroba cruda determinado según lo expuesto en $2.5, w_{0}=6,86 \pm 0,05$ ( $\mathrm{g}$ de agua/100 $\mathrm{g}$ de algarroba cruda).

TABLA 13. Datos de equilibrio de la algarroba cruda a $25^{\circ} \mathrm{C}$ y a $45^{\circ} \mathrm{C}$

\begin{tabular}{l|l|l|l|l|}
\hline Soluciones salinas & $a_{\mathrm{w}\left(25^{\circ} \mathrm{C}\right)}$ & $\mathrm{w}_{\mathrm{e}\left(25^{\circ} \mathrm{C}\right)}$ & $\mathrm{a}_{\mathrm{w}\left(45^{\circ} \mathrm{C}\right)}$ & $\mathrm{w}_{\mathrm{e}\left(45^{\circ} \mathrm{C}\right)}$ \\
\hline $\mathrm{LiCl}$ & 0,1130 & 0,0220 & 0,1115 & 0,0180 \\
$\mathrm{CH}_{3} \mathrm{COOK}$ & 0,2251 & 0,0418 & 0,2150 & 0,0335 \\
$\mathrm{MgCl}_{2}$ & 0,3278 & 0,0501 & 0,3105 & 0,0391 \\
$\mathrm{~K}_{2} \mathrm{CO}_{3}$ & 0,4316 & 0,0689 & 0,4320 & 0,0532 \\
$\mathrm{NaBr}$ & 0,5757 & 0,1120 & 0,5600 & 0,0910 \\
$\mathrm{NaCl}$ & 0,7529 & 0,2270 & 0,7455 & 0,1849 \\
$\mathrm{KCl}$ & 0,8434 & 0,3405 & 0,8175 & 0,2785 \\
$\mathrm{BaCl}$ & 0,9026 & 0,5160 & 0,8700 & 0,4099 \\
\hline
\end{tabular}
aw: actividad de agua.
We: humedad de equilibrio en base seca, en g de agua / g de m.s.
de algarroba cruda.

En la FIGURA 14 se muestran las isotermas de sorción de agua obtenidas para la algarroba cruda, que presentan forma sigmoidal, típica de la mayor parte de los alimentos. Estas curvas corresponden a isotermas tipo II según la clasificación de Brunauer (Leung, 1986). Se observa la disminución esperada en la capacidad de adsorción de agua al aumentar la temperatura de acuerdo con el carácter exotérmico del proceso. 


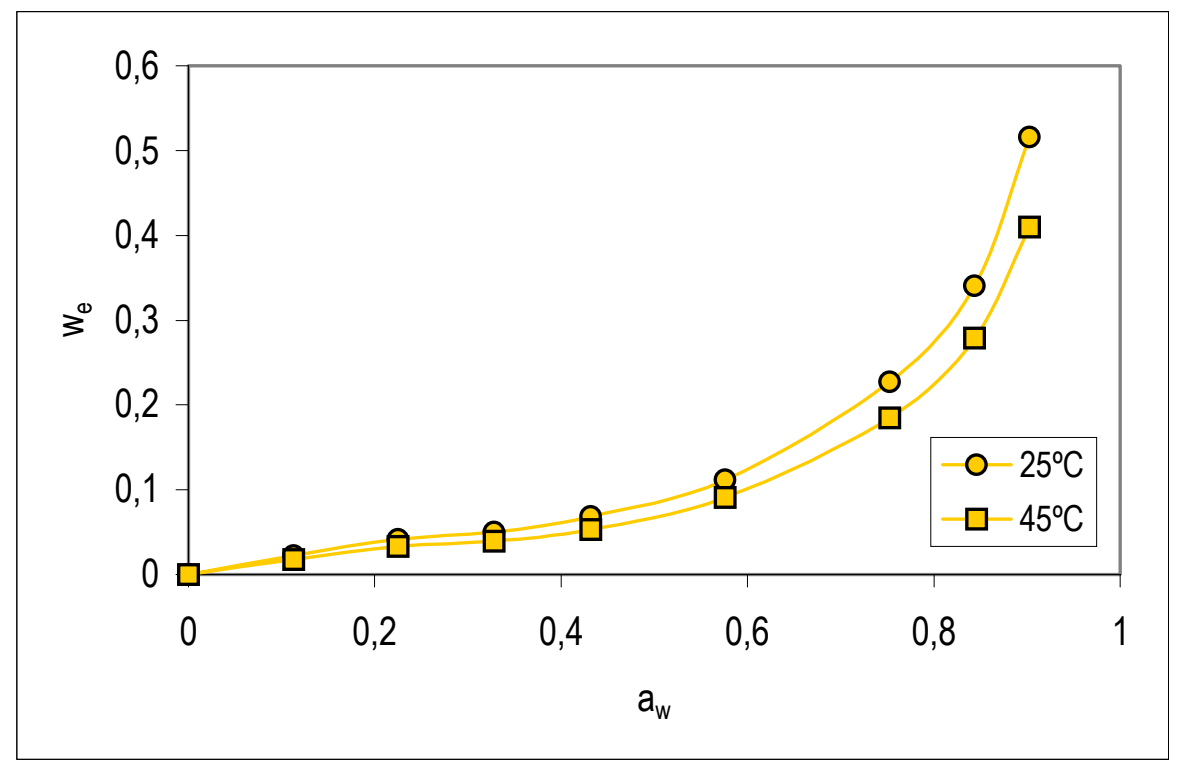

FIGURA 14. Isotermas de sorción de la algarroba cruda a $25^{\circ} \mathrm{C}$ y a $45^{\circ} \mathrm{C}$

\subsubsection{AJUSTE DEL MODELO DE BET}

En la FIGURA 15 se muestra la representación linealizada de los puntos experimentales, según la ecuación de BET (7) y las rectas ajustadas.

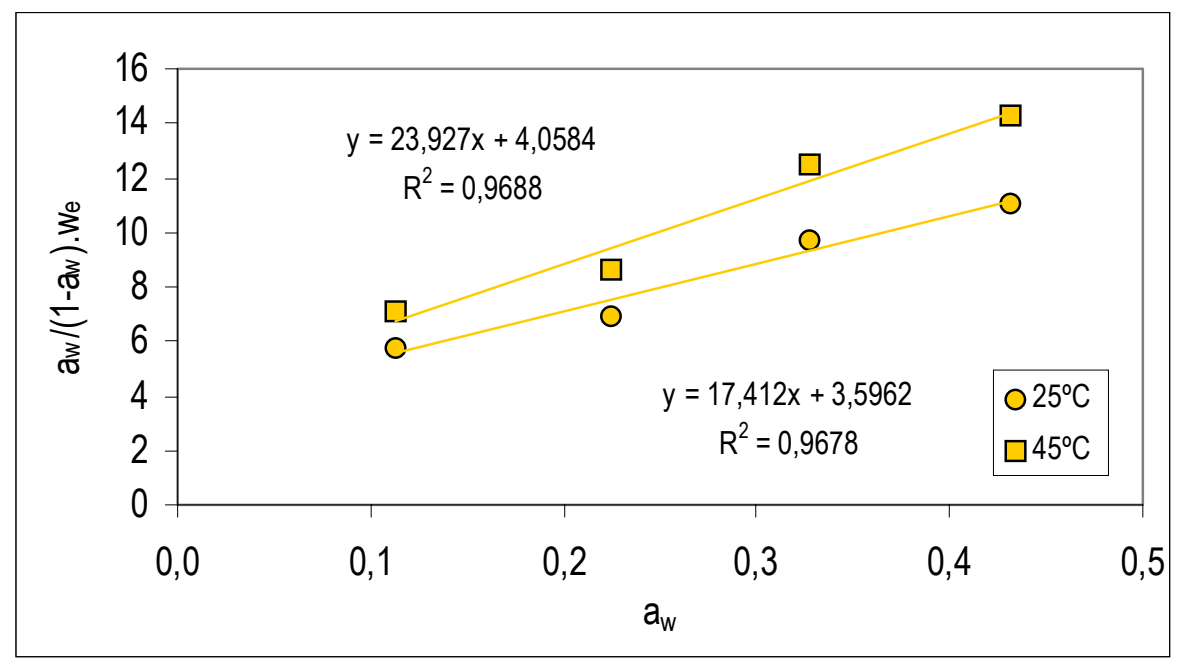

FIGURA 15. Ajuste de la ecuación de BET linealizada para algarroba cruda a $25^{\circ} \mathrm{C}$ y $45^{\circ} \mathrm{C}$ 
En la TABLA 14 se indican los valores obtenidos para cada uno de los parámetros del modelo, así como la superficie específica para la sorción, estimada a partir del parámetro $\mathrm{w}_{1}$.

TABLA 14. Parámetros obtenidos del ajuste del modelo de BET para algarroba cruda

\begin{tabular}{|c|c|c|c|}
\hline Temperatura $\left({ }^{\circ} \mathrm{C}\right)$ & $\mathrm{W}_{1}$ & $\mathrm{C}$ & $\mathrm{S}^{*}$ \\
\hline 25 & 0,0476 & 5,8418 & 166,60 \\
\hline 45 & 0,0357 & 6,8957 & 124,95 \\
\hline \multicolumn{4}{|l}{$\mathrm{m}^{2} / \mathrm{g}$ de algarroba cruda, ec. (8) }
\end{tabular}

Para la adsorción de vapor de agua, el valor de la monocapa se ha definido como el contenido de humedad para el cual muchos alimentos presentan su mayor estabilidad en relación con las reacciones químicas (Martínez et al., 1998). Para este producto oscila alrededor del $4 \%$, lo que indica que a valores muy bajos de humedad el producto presentará inestabilidad frente a muchos procesos deteriorativos. En este caso el apelmazado del producto molido y la cristalización de azúcares pueden ser una causa importante de pérdida de calidad y estabilidad.

La forma de la isoterma está relacionada con los valores del parámetro $\mathrm{C}$. La ec. (7) corresponde a una diferencia de dos hipérbolas (cada cociente representa a una); esta diferencia depende del valor de $C$ puesto que solo aparece en el segundo cociente. Se puede demostrar que solo a partir de determinado valor de $\mathrm{C}$ se da un punto de inflexión en la curva, siendo entonces la isoterma del tipo II. El punto de inflexión solo aparece para valores de C>2 (Martínez et al., 1998). Los valores de C están relacionados con el calor de sorción, y valores bajos del parámetro, como los encontrados para este producto, indican una energía de sorción baja.

\subsubsection{AJUSTE DEL MODELO DE GAB}

En la FIGURA 16 se representa la ecuación polinómica de segundo grado del modelo de GAB (9). 


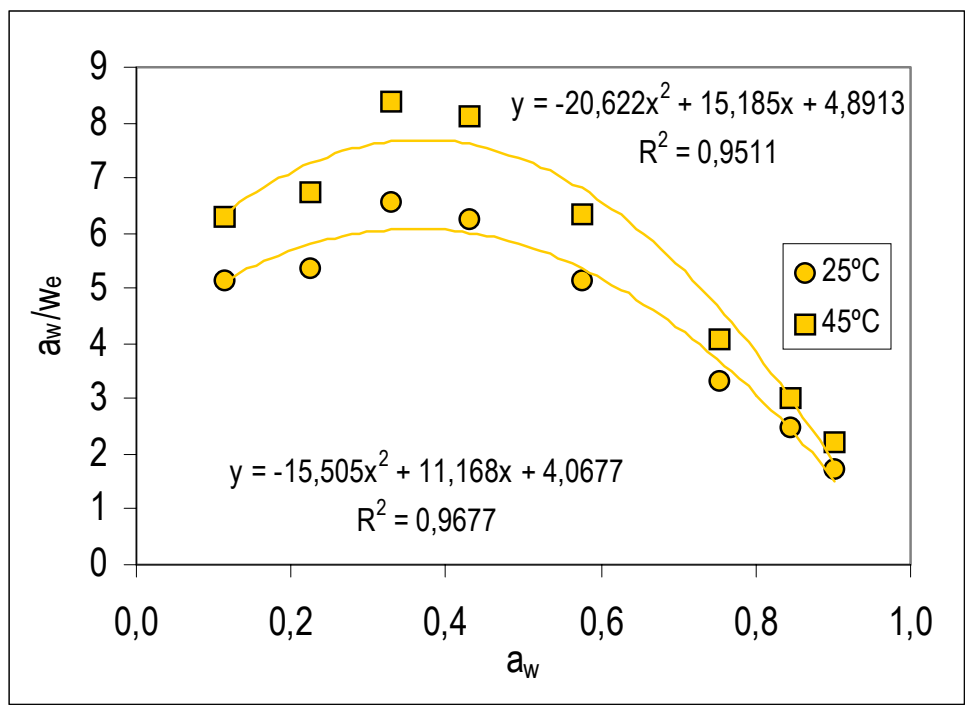

FIGURA 16. Ajuste de la ecuación de GAB para algarroba cruda a $25^{\circ} \mathrm{C}$ y $45^{\circ} \mathrm{C}$

Los valores obtenidos para cada uno de los parámetros de este modelo se muestran en la TABLA 15. La humedad de la monocapa es muy similar a la obtenida con el modelo de BET, aunque dada la mayor correlación matemática de los parámetros de GAB, los valores de BET ofrecerían mayor confianza. No obstante con este modelo, es posible predecir la relación humedad- $\mathrm{a}_{\mathrm{w}}$ en un intervalo más amplio de $\mathrm{a}_{\mathrm{w}}$.

TABLA 15. Parámetros obtenidos del ajuste del modelo de GAB para algarroba cruda

\begin{tabular}{|c|c|c|c|}
\hline Temperatura $\left({ }^{\circ} \mathrm{C}\right)$ & $\mathrm{W}_{1}$ & $\mathrm{C}$ & $\mathrm{K}$ \\
\hline 25 & 0,0515 & 4,7079 & 1,0139 \\
\hline 45 & 0,0397 & 5,0384 & 1,0218 \\
\hline
\end{tabular}

\subsubsection{EFECTO DE LA TEMPERATURA. CALOR ISOSTÉRICO DE SORCIÓN}

A partir de los datos de sorción a las dos temperaturas, se ha estimado la entalpía $(\Delta H)$, energía libre $(\Delta G)$, y entropía $(\Delta S)$ de sorción para los diferentes niveles de humedad, tal como se describe en 2.3.3. Los valores calculados se muestran en la TABLA 16. 
TABLA 16. Variables termodinámicas para algarroba cruda

\begin{tabular}{|c|c|c|c|}
\hline $\mathrm{W}_{\mathrm{e}(\% \text { b.s. })}$ & $\Delta \mathrm{H}(\mathrm{kJ} / \mathrm{mol})$ & $\Delta \mathrm{G}(\mathrm{kJ} / \mathrm{mol})$ & $\Delta \mathrm{S}\left(\mathrm{J} /{ }^{\circ} \mathrm{K} . \mathrm{mol}\right)$ \\
\hline 0,05 & $-53,42$ & $-2,97$ & $-169,20$ \\
0,10 & $-48,99$ & $-1,48$ & $-159,34$ \\
0,15 & $-47,01$ & $-0,96$ & $-154,45$ \\
0,20 & $-46,10$ & $-0,72$ & $-152,20$ \\
0,25 & $-45,51$ & $-0,57$ & $-150,72$ \\
0,30 & $-45,15$ & $-0,48$ & $-149,82$ \\
0,35 & $-44,87$ & $-0,41$ & $-149,11$ \\
0,40 & $-44,76$ & $-0,36$ & $-148,91$ \\
0,45 & $-44,56$ & $-0,33$ & $-148,34$ \\
\hline
\end{tabular}

En la FIGURA 17 se muestra la forma típica en que varían $\Delta H, \Delta G$ y $\Delta S$ en función de los diferentes niveles de humedad $\left(w_{e}\right)$. El nivel de humedad para el cual $\Delta \mathrm{H}$ y $\Delta \mathrm{S}$ son máximos coincide aproximadamente con el valor de la monocapa de BET, que representa la cantidad de agua que recubre los puntos polares primarios con una capa. Cuando la mayoría de los puntos accesibles están saturados, el vapor de agua se adsorberá en los puntos primarios de zonas menos accesibles con mayor densidad de segmentos poliméricos y por tanto de interacciones, por lo que el calor de sorción asociado será mayor justo antes de completarse la monocapa.

Los valores negativos de $\Delta G$ describen la espontaneidad del proceso de sorción para la algarroba. El descenso en $-\Delta G$ cuando el contenido de humedad aumenta, aproximándose a cero a altos niveles de humedad, pone de manifiesto la disminución de la fuerza impulsora del proceso de adsorción a medida que el producto se humecta.

El calor isostérico de sorción $\left[Q_{s}\right.$, ec. (14)] para humedades del orden de la monocapa es de 9,96 kJ/ mol, considerando el calor de vaporización del agua pura a $25^{\circ} \mathrm{C}$ de $-43,46 \mathrm{~kJ} / \mathrm{mol}$. 


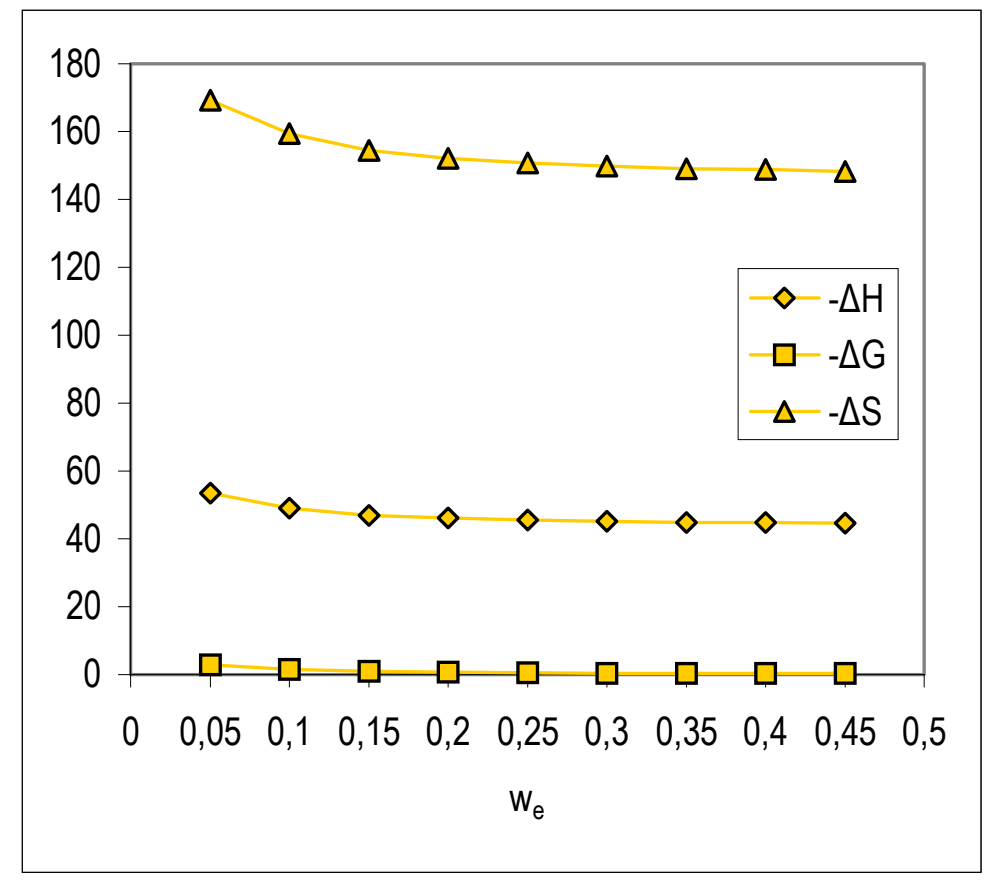

FIGURA 17. Variación de $\Delta \mathrm{H}, \Delta \mathrm{G}$ y $\Delta \mathrm{S}$ con el contenido de humedad para algarroba cruda

\subsection{Isoterma de sorción de agua de la algarroba tostada}

Los valores de humedad de equilibrio obtenidos para cada muestra de algarroba tostada $\left(160^{\circ} \mathrm{C}, 60 \mathrm{~min}\right)$, a las distintas actividades de agua $\mathrm{a}_{w}$ se indican en la TABLA 17, y fueron realizados calculando la ganancia de peso utilizando la ec. (6), tomando el valor de la humedad inicial de la algarroba tostada determinado según lo expuesto en $2.5, \mathrm{w}_{0}=7,17 \pm 0,03$ ( $\mathrm{g}$ de agua/100 $\mathrm{g}$ de algarroba tostada).

TABLA 17. Datos de equilibrio a $25^{\circ} \mathrm{C}$ y $45^{\circ} \mathrm{C}$ de la algarroba tostada

\begin{tabular}{|l|l|l|l|l|}
\hline Soluciones salinas & $a_{\mathrm{w}\left(25^{\circ} \mathrm{C}\right)}$ & $\mathrm{w}_{\mathrm{e}\left(25^{\circ} \mathrm{C}\right)}$ & $\mathrm{a}_{\mathrm{w}\left(45^{\circ} \mathrm{C}\right)}$ & $\mathrm{w}_{\mathrm{e}\left(45^{\circ} \mathrm{C}\right)}$ \\
\hline $\mathrm{LiCl}$ & 0,1130 & 0,0182 & 0,1115 & 0,0143 \\
$\mathrm{CH}_{3} \mathrm{COOK}$ & 0,2251 & 0,0345 & 0,2150 & 0,0265 \\
$\mathrm{MgCl}_{2}$ & 0,3278 & 0,0414 & 0,3105 & 0,0308 \\
$\mathrm{~K}_{2} \mathrm{CO}_{3}$ & 0,4316 & 0,0569 & 0,4320 & 0,0423 \\
$\mathrm{NaBr}$ & 0,5757 & 0,0925 & 0,5600 & 0,0731 \\
$\mathrm{NaCl}$ & 0,7529 & 0,1876 & 0,7455 & 0,1483 \\
$\mathrm{KCl}$ & 0,8434 & 0,2814 & 0,8175 & 0,2169 \\
$\mathrm{BaCl}_{2}$ & 0,9026 & 0,4264 & 0,8700 & 0,3298 \\
\hline
\end{tabular}

aw: actividad de agua.

We: humedad de equilibrio en base seca, en g de agua / g de m.s. de algarroba tostada. 
En la FIGURA 18 se muestran las isotermas de sorción de agua obtenidas para la algarroba tostada, las que presentan forma sigmoidal (tipo II según la clasificación de Brunauer) al igual que la algarroba cruda.

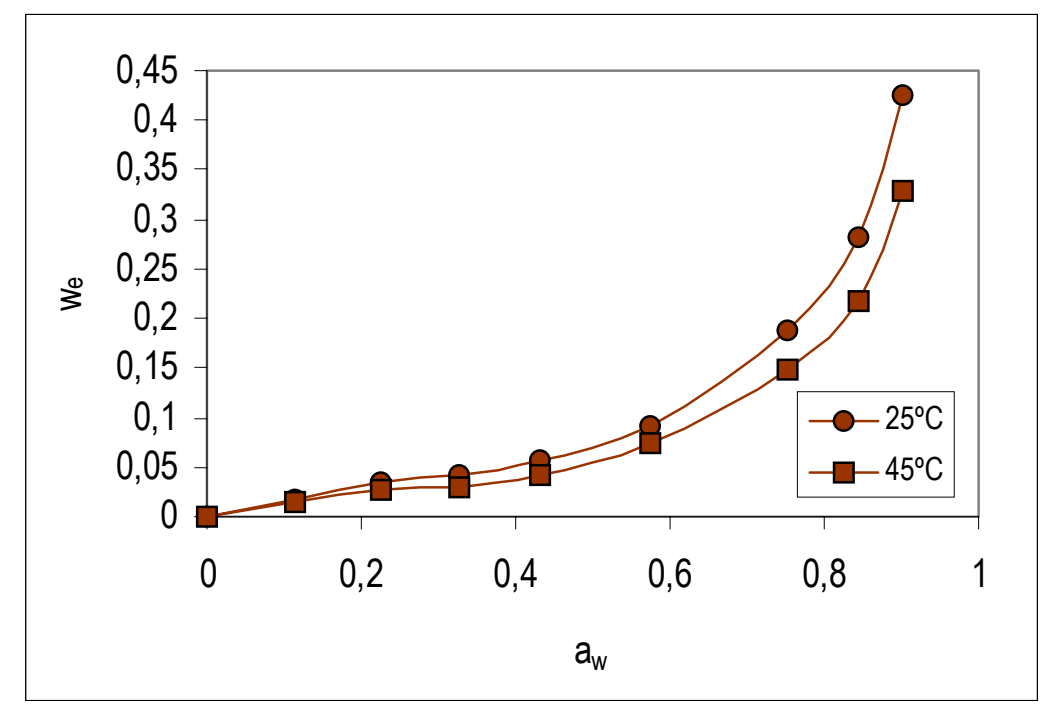

FIGURA 18. Isotermas de sorción a $25^{\circ} \mathrm{C}$ y $45^{\circ} \mathrm{C}$ para algarroba tostada

\subsubsection{AJUSTE DEL MODELO DE BET}

En la FIGURA 19 se muestra el ajuste de la ecuación de BET y en la TABLA 18 se indican los valores obtenidos para cada uno de los parámetros del modelo, así como la superficie específica para la sorción. Puede observarse el descenso en los valores de los parámetros por efecto del tostado. Tanto la capacidad de la monocapa como el parámetro C, relacionado con el calor de sorción disminuyen, indicando un descenso de la afinidad del producto por el agua. Esto puede relacionarse con la degradación-oxidación de muchos compuestos hidrofílicos durante el tostado del producto. 


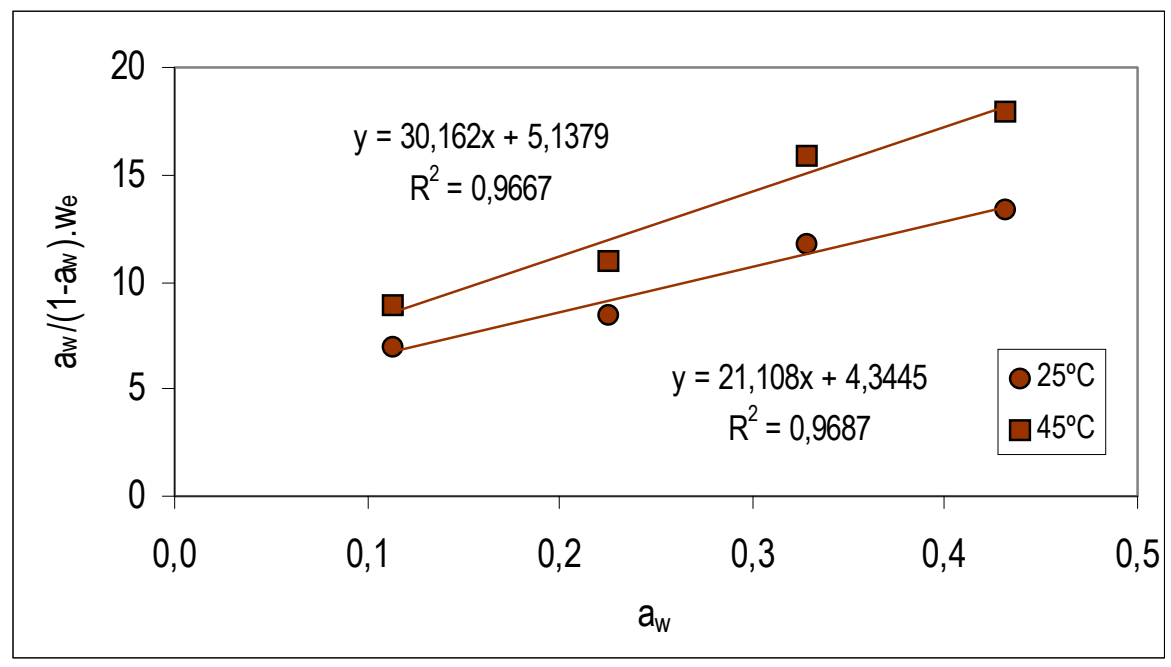

FIGURA 19. Ecuación de BET a $25^{\circ} \mathrm{C}$ y $45^{\circ} \mathrm{C}$ para algarroba tostada

TABLA 18. Parámetros obtenidos del ajuste del modelo de BET para algarroba tostada

\begin{tabular}{|c|c|c|c|}
\hline Temperatura $\left({ }^{\circ} \mathrm{C}\right)$ & $\mathrm{W}_{1}$ & $\mathrm{C}$ & $\mathrm{S}^{*}$ \\
\hline 25 & 0,0393 & 5,8586 & 137,55 \\
\hline 45 & 0,0283 & 6,8705 & 99,05 \\
\hline${ }^{*} \mathrm{~m}^{2} / \mathrm{g}$ de algarroba tostada, ec. (10)
\end{tabular}

\subsubsection{AJUSTE DEL MODELO DE GAB}

En la FIGURA 20 se muestra el ajuste de la ecuación polinómica de segundo grado del modelo de GAB. Los valores obtenidos para cada uno de los parámetros de este modelo se muestran en la TABLA 19. Estos reflejan de forma menos evidente el efecto del tostado, lo cual es atribuible a su mayor correlación matemática y por tanto su menor capacidad para reflejar un sentido físico. 


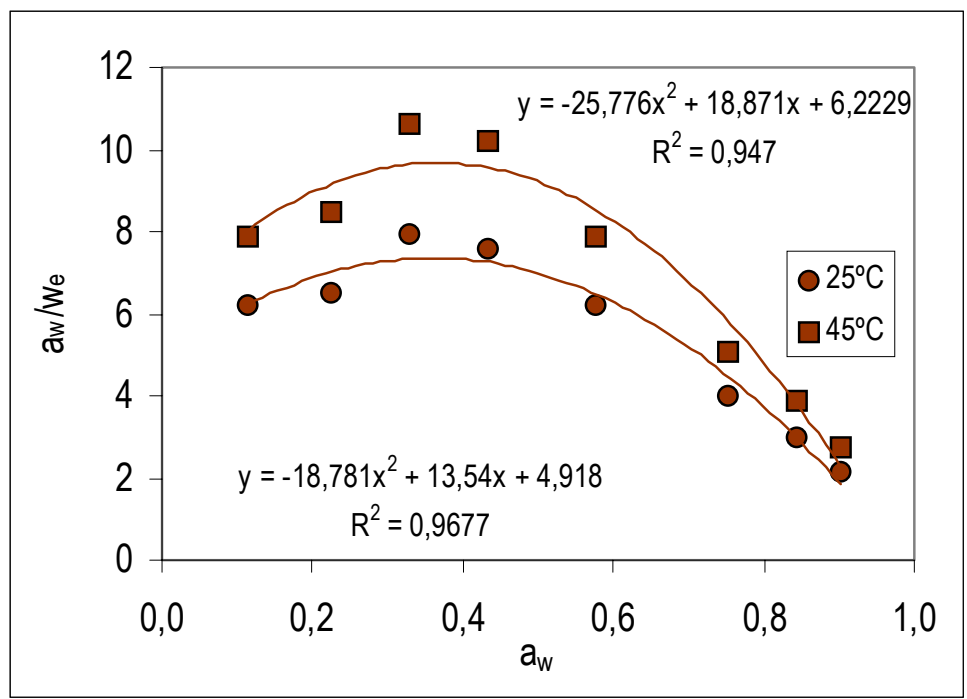

FIGURA 20. Ecuación de $\mathrm{GAB}$ a $25^{\circ} \mathrm{C}$ y $45^{\circ} \mathrm{C}$ para algarroba tostada

TABLA 19. Parámetros obtenidos del ajuste del modelo de GAB para algarroba tostada

\begin{tabular}{|c|c|c|c|}
\hline Temperatura $\left({ }^{\circ} \mathrm{C}\right)$ & $\mathrm{W}_{1}$ & $\mathrm{C}$ & $\mathrm{K}$ \\
\hline 25 & 0,0425 & 4,7158 & 1,0138 \\
\hline 45 & 0,0317 & 4,9681 & 1,0217 \\
\hline
\end{tabular}

\subsubsection{EFECTO DE LA TEMPERATURA. CALOR ISOSTÉRICO DE SORCIÓN}

El análisis de Clapeyron-Clausius (Van den Berg y Bruin, 1981) de los datos de sorción a las diferentes temperaturas ha permitido obtener los valores de entalpía, energía libre, y entropía en función del contenido en humedad para la sorción de la algarroba tostada. Los valores estimados $\Delta \mathrm{H}$, $\Delta G$ y $\Delta S$ se muestran en la TABLA 20. 
TABLA 20. Variables termodinámicas para algarroba tostada

\begin{tabular}{|c|c|c|c|}
\hline $\mathrm{W}_{\mathrm{e}(\%}$ b.s. $)$ & $\Delta \mathrm{H}_{(\mathrm{kJ} / \mathrm{mol})}$ & $\Delta \mathrm{G}_{(\mathrm{kJ} / \mathrm{mol})}$ & $\Delta \mathrm{S}_{(\mathrm{J} / \mathrm{K} \text {. mol) }}$ \\
\hline 0,05 & $-53,46$ & $-2,48$ & $-170,98$ \\
0,10 & $-48,55$ & $-1,21$ & $-158,77$ \\
0,15 & $-46,73$ & $-0,79$ & $-154,08$ \\
0,20 & $-45,82$ & $-0,59$ & $-151,70$ \\
0,25 & $-45,35$ & $-0,48$ & $-150,49$ \\
0,30 & $-44,99$ & $-0,40$ & $-149,55$ \\
0,35 & $-44,76$ & $-0,35$ & $-148,95$ \\
0,40 & $-44,60$ & $-0,31$ & $-148,54$ \\
0,45 & $-44,48$ & $-0,28$ & $-148,24$ \\
\hline
\end{tabular}

En la FIGURA 21 se muestra la forma típica en que varían $\Delta \mathrm{H}, \Delta \mathrm{G}$ y $\Delta \mathrm{S}$ en función de los diferentes niveles de humedad $\left(w_{e}\right)$. El nivel de humedad para el cual $\Delta \mathrm{H}$ y $\Delta \mathrm{S}$ son máximos coincide aproximadamente con el valor de la monocapa de BET, al igual que para la algarroba cruda.

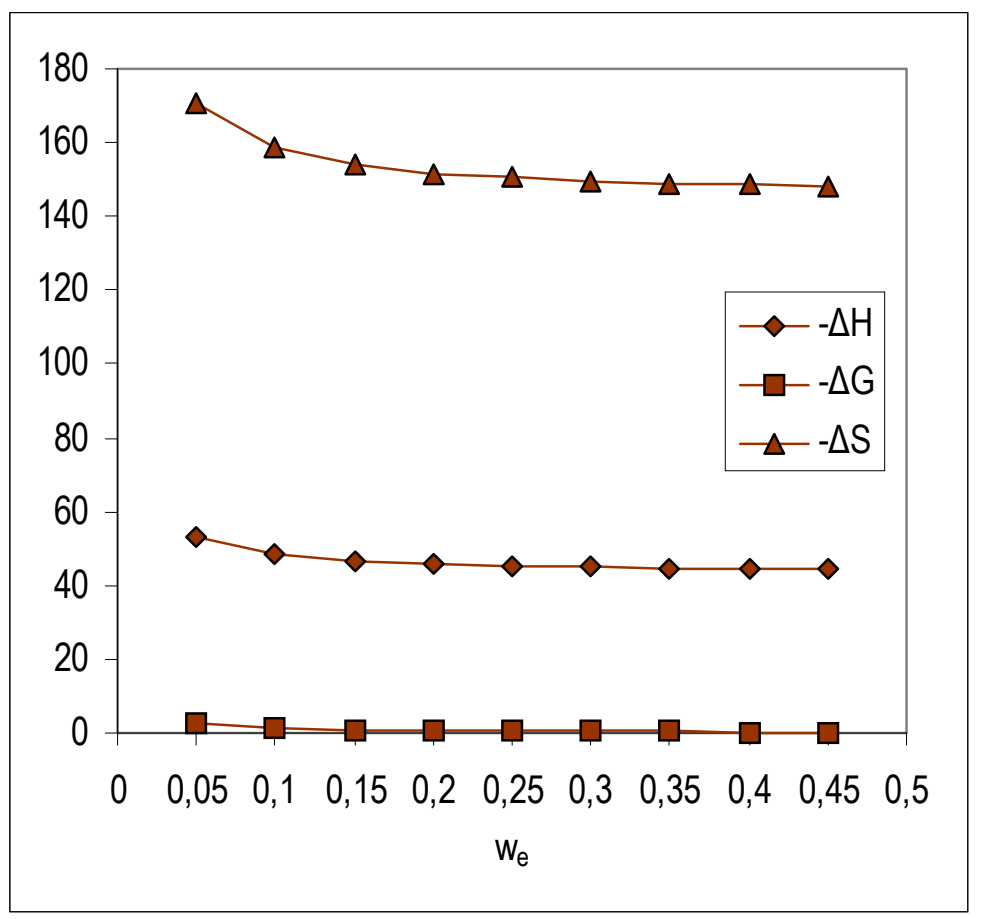

FIGURA 21. Variación de $\Delta \mathrm{H}, \Delta \mathrm{G}$ y $\Delta \mathrm{S}$ con el contenido de humedad para algarroba tostada

El calor isostérico de sorción $\left(Q_{s}\right)$ para el contenido en humedad de la monocapa fue de $10,00 \mathrm{~kJ} / \mathrm{mol}$. Del mismo orden que para la algarroba cruda. 


\subsubsection{EFECTO DEL TOSTADO}

El tostado dio lugar a diferencias entre las isotermas de la algarroba cruda y tostada, mostrando la segunda una menor capacidad para la adsorción de agua (FIGURA 22). Esto puede explicarse por las modificaciones químicas de las proteínas asociadas con el fenómeno de desnaturalización y el aumento de interacciones con otros componentes tales como carbohidratos y lípidos causados por el proceso de tostado (Pérez, 1995). Un aumento en hidrofobicidad de las proteínas, debido a las altas temperaturas de tostado podría implicar una disminución en los sitios disponibles en el sustrato para la adsorción de agua.

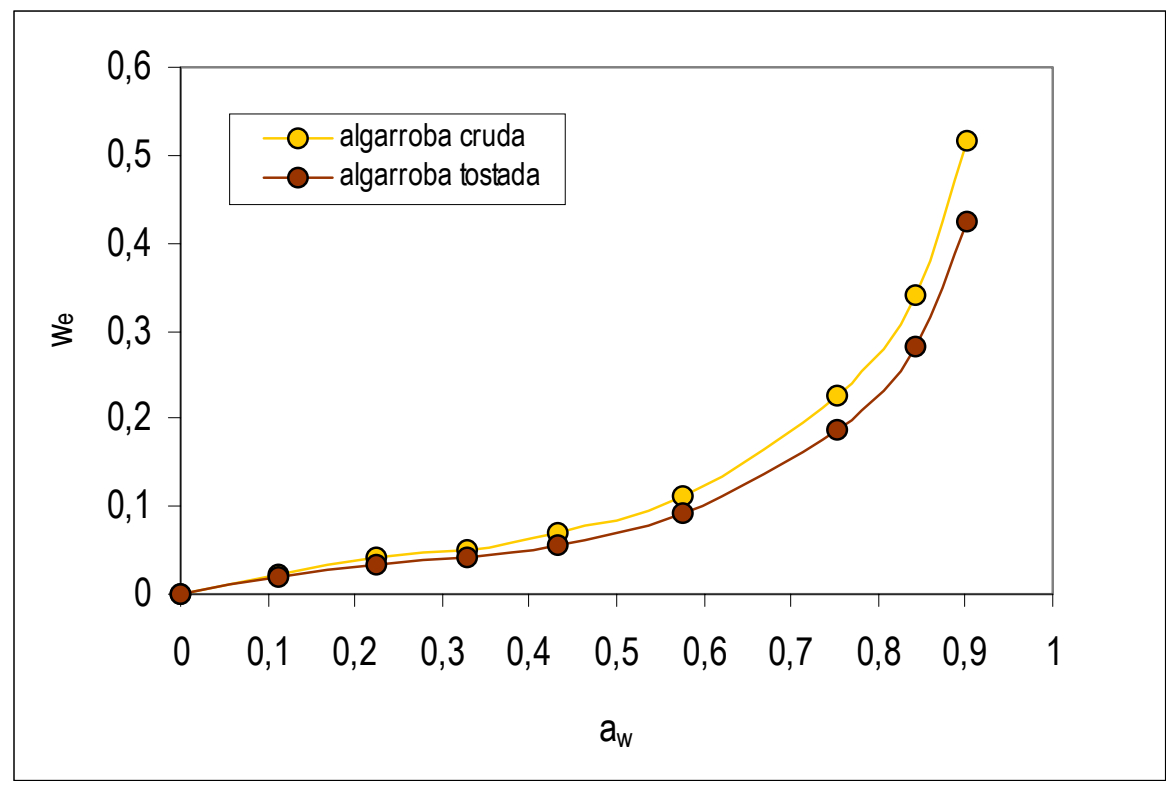

FIGURA 22. Isotermas de sorción a $25^{\circ} \mathrm{C}$ de las algarrobas cruda y tostada

En las FIGURAS 23, 24 y 25 se muestra el efecto del tostado sobre las variables termodinámicas $\Delta \mathrm{H}, \Delta \mathrm{G}$ y $\Delta \mathrm{S}$. 


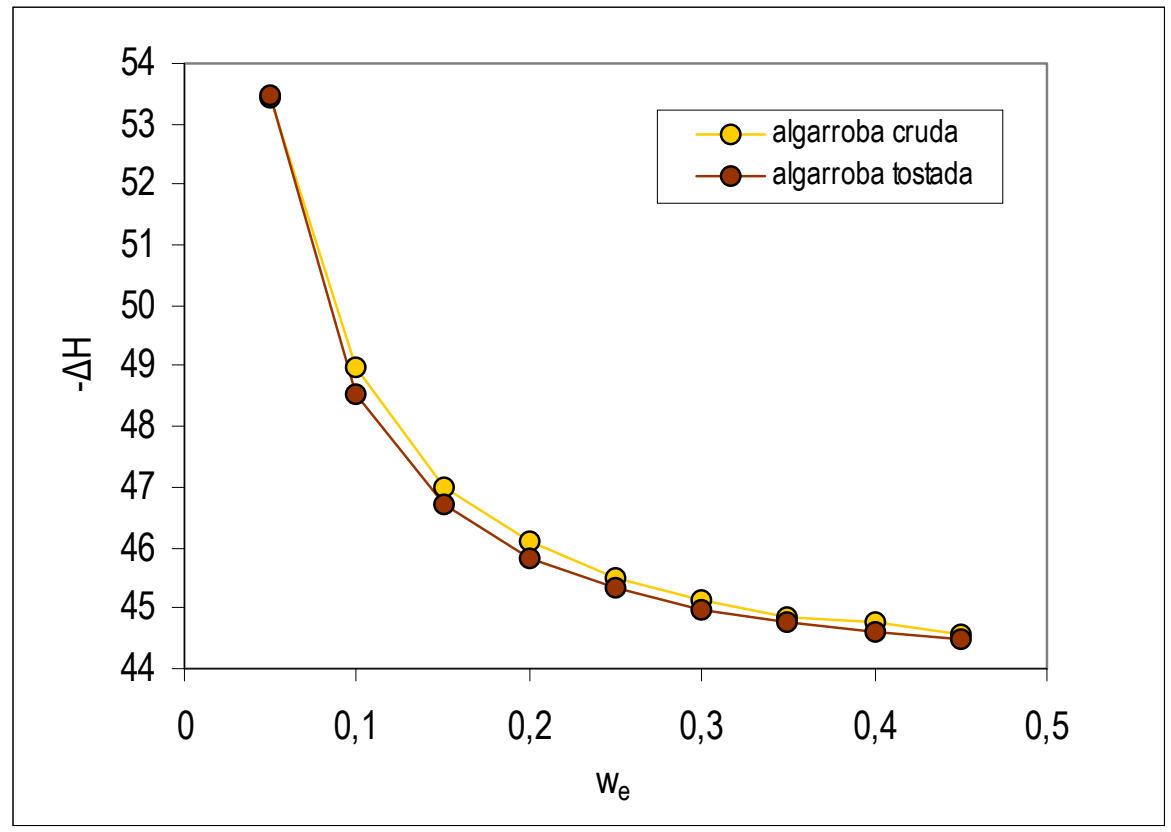

FIGURA 23. Entalpía de sorción en función de la humedad a $25^{\circ} \mathrm{C}$ para la algarroba cruda y tostada

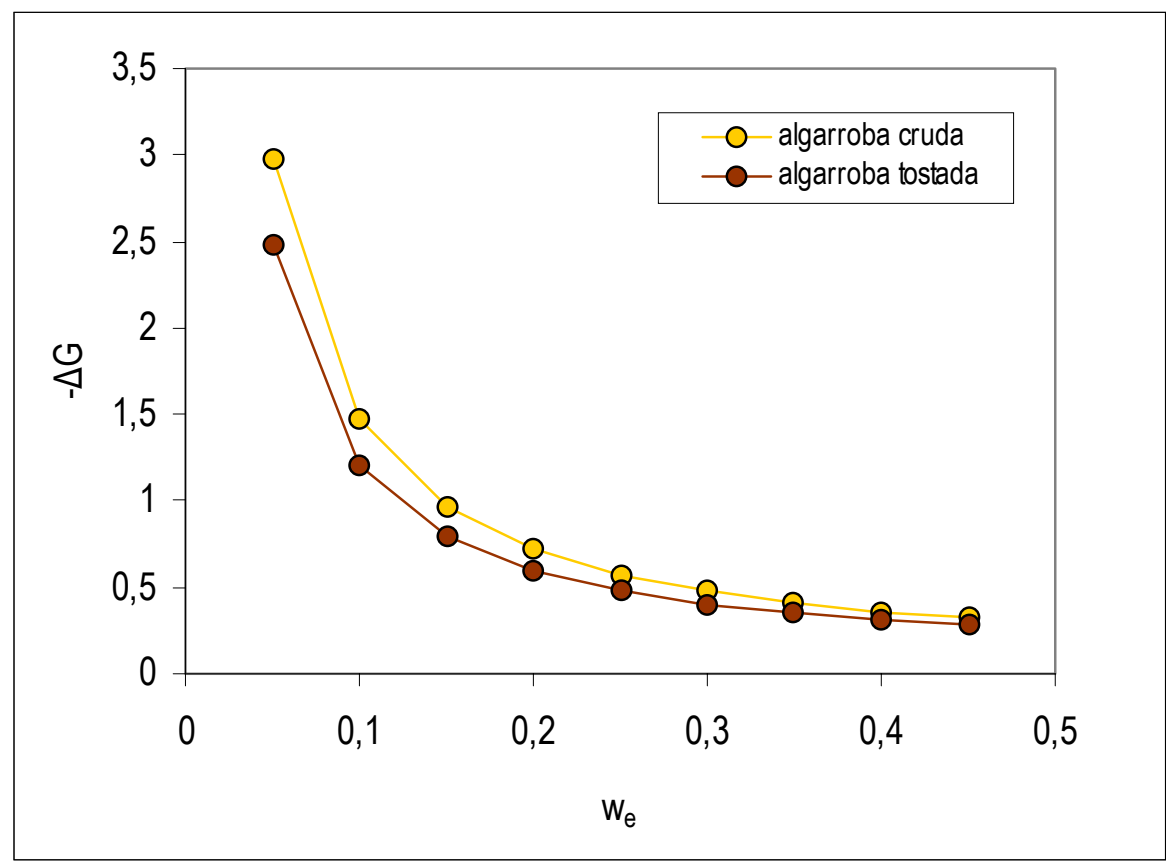

FIGURA 24. Energía libre de Gibbs de sorción en función de la humedad a $25^{\circ} \mathrm{C}$ para la algarroba cruda y tostada 


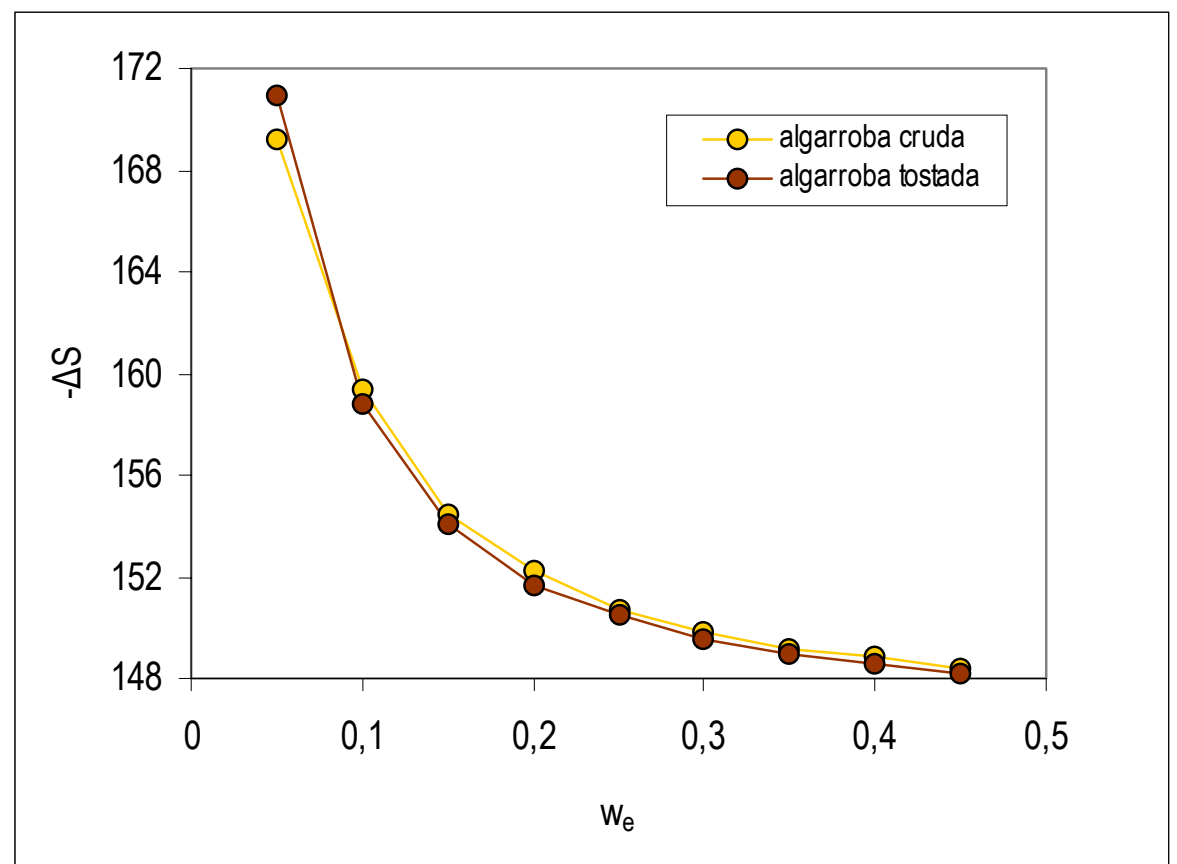

FIGURA 25. Entropía de sorción en función de la humedad a $25^{\circ} \mathrm{C}$ para la algarroba cruda y tostada

Los valores de $\triangle \mathrm{H}$ fueron ligeramente mayores para la algarroba cruda que tostada (FIGURA 23), lo que indica la existencia de mayores fuerzas ligantes involucradas en el mecanismo de sorción. También son mayores los valores de la energía libre del proceso en el caso de la algarroba cruda (FIGURA 24), lo que refleja la mayor tendencia del producto crudo a la humectación. Los valores de $\Delta S$ fueron muy similares para la algarroba cruda y tostada (FIGURA 25), lo que indica que el grado de estructuración molecular de las moléculas de agua en ambos productos fue muy similar.

En síntesis, el tostado modifica el comportamiento de la adsorción del agua en la algarroba, disminuyendo la tendencia a la humectación y la capacidad de retención de agua.

\subsection{Sólidos solubles}

En la TABLA 21 se muestra la importante disminución del contenido de sólidos solubles en la algarroba como consecuencia del tostado a $160^{\circ} \mathrm{C}$ durante $60 \mathrm{~min}$.

TABLA 21. Sólidos solubles en algarroba cruda y tostada, en base seca

\begin{tabular}{l|c|c|}
\hline & Algarroba cruda & Algarroba tostada \\
\hline Sólidos solubles ( $\mathrm{g} / 100 \mathrm{~g}$ algarroba) & $65,00 \pm 1,21$ & $33,25 \pm 0,91$ \\
\hline valor medio \pm desviación estándar $(\mathrm{n}=3)$
\end{tabular}


Cuando se prepara una infusión a partir de los granos de café tostados y molidos, cerca del 35\% de los constituyentes pasan al agua (Fox y Cameron, 1992).

\subsection{Composición química}

En la TABLA 22 se muestra la composición química de la algarroba molida tostada $\left(160^{\circ} \mathrm{C}, 60 \mathrm{~min}\right)$, exceptuando la de los azúcares que se encuentran en 1.9 .

TABLA 22. Composición química de la algarroba tostada de Prosopis alba

\begin{tabular}{|l|c|}
\hline \multicolumn{2}{|c|}{ Componentes principales (g / kg b.s.) } \\
\hline Humedad & $71,7 \pm 0,03$ \\
Proteína & $70,3 \pm 0,23$ \\
Grasa & $7,1 \pm 1,05$ \\
Cenizas & $25,8 \pm 0,21$ \\
Fibra cruda & $20,7 \pm 0,39$ \\
Carbohidratos totales & 825 \\
Valor energético * & 3563 \\
\hline Taninos condensados & $5,83 \pm 0,47$ \\
Polifenoles solubles totales & $0,14 \pm 0,92$ \\
Cafeína & $n / \mathrm{d} \#$ \\
\hline Fibra dietética insoluble & $246,8 \pm 1,09$ \\
Fibra dietética soluble & $79,2 \pm 0,95$ \\
Fibra dietética total & 325 \\
\hline Lisina ** & $2,39 \pm 0,88$ \\
\hline \multicolumn{2}{|c|}{ valor medio \pm desviación estándar $(\mathrm{n}=3)$} \\
* kcal / kg \\
** / 100g de proteína \\
* no detectable
\end{tabular}

\begin{tabular}{|l|r|}
\hline \multicolumn{2}{|c|}{ Minerales (mg / kg b.s.) } \\
\hline \multicolumn{2}{|c|}{} \\
Calcio & $2000 \pm 0,75$ \\
Fósforo & $1400 \pm 0,73$ \\
Potasio & $3600 \pm 0,56$ \\
Sodio & $1360 \pm 0,21$ \\
Magnesio & $810 \pm 0,51$ \\
Hierro & $100 \pm 0,73$ \\
Zinc & $210 \pm 0,91$ \\
Cobre & $13 \pm 0,94$ \\
Manganeso & $10 \pm 0,22$ \\
& \\
& \\
\hline
\end{tabular}

Los valores encontrados de proteínas, grasa y fibra cruda en la algarroba tostada de Prosopis alba son similares a los valores reportados para otras especies tales como $P$. juliflora (Vieira et al., 1995) y $P$. sp. (Del Valle et al., 1986).

Las proteínas, que son necesarias para la renovación y formación de los tejidos del cuerpo humano se encuentran en altas cantidades en la algarroba tostada, en el orden de alimentos de origen vegetal como arroz y garbanzos, y superior a las bananas, manzanas y mandioca (Fox y Cameron, 1992).

El contenido de grasa en la algarroba tostada es bajo aunque superior al de la mayoría de las hortalizas crudas (Fox y Cameron, 1992). Se ha reportado que el $70,5 \%$ son ácidos grasos insaturados, principalmente linoleico (42\%) para algarroba cruda de P. juliflora (Marangoni y Alli, 1988).

Los componentes principales de la fracción grasa de los alimentos cubren destinos metabólicos diferentes: los triglicéridos constituyen una reserva calórica y se queman para satisfacer la demanda de energía; los fosfolípidos constituyen la mayor parte de la membrana celular. 
Aunque, para el fin energético de los triglicéridos, no importa cuales sean sus ácidos grasos, un parte de éstos tienen otras funciones metabólicas, como los ácidos grasos esenciales, estos son poliinsaturados, principalmente el linoleico, necesario para la membrana celular, sobre todo en el tejido nervioso (Primo Yúfera, 1998).

La fibra cruda representa la parte fibrosa e indigestible de los alimentos. Como no guardan relación no se debe confundir la fibra cruda con la fibra dietética, ya que de esta forman parte pentosanos, pectinas, hemicelulosas, celulosa y lignina, que no se digieren en el intestino humano y sin embargo se hacen solubles en el proceso de análisis de fibra cruda.

El conocimiento del aporte calórico de los alimentos es importante, no solo desde el punto de vista científico, sino también comercial. Por esto actualmente las etiquetas de muchos alimentos envasados indican el valor energético de sus ingredientes. Para el caso particular de la algarroba tostada el valor calculado es alto, en relación al del pan blanco (3048 $\mathrm{kcal} / \mathrm{kg}$ ) y al del pan integral (1168 kcal $/ \mathrm{kg}$ ) (Adrian et al., 2000).

Los carbohidratos constituyen una de las tres principales clases de nutrientes. Se hallan en los alimentos como azúcares y almidones, representando una de las principales fuentes de energía de la dieta, y como celulosa, la cual es uno de los principales componentes de la fibra dietética. El valor calculado como carbohidratos totales es alto en la algarroba tostada $(82,5 \%)$, ubicándose entre los del arroz (86\%) y de la miel $(76 \%)$ (Fox y Cameron, 1992).

Desde el punto de vista de nutrición es útil la división de los polifenoles en dos grupos: polifenoles extraíbles o solubles y no extraíbles o insolubles en los disolventes usuales para estos compuestos. Los polifenoles solubles (moléculas de peso molecular menor de 5000 con unidades estructurales básicas de flavan-3-ol y ácido gálico) se caracterizan porque se absorben, en su mayor parte, en el intestino produciendo diversos efectos fisiológicos (Singleton, 1981), mientras que los polifenoles insolubles (formados por taninos condensados de alto peso molecular y complejos taninos-proteínapolisacáridos) no son absorbidos eliminándose en heces (Bravo et al., 1992). Como efectos antinutritivos de los polifenoles insolubles se han referido disminución de digestibilidad de proteínas, depresión de crecimiento e inhibición de enzimas digestivas (Horigome et al., 1988; Aw y Swanson, 1985). Como era de esperar los efectos adversos de los antinutrientes polifenoles solubles y taninos condensados son insignificantes para la algarroba tostada, por contener estas muy pequeñas cantidades, y no son aspectos limitantes para que sean usadas en productos alimenticios.

La cafeína (1,3,7 trimetil-xantina) presente en extractos de café, bebidas refrescantes (colas), fármacos y algunos tipos de té en cantidades que varían del 1 al $5 \%$, se encuentra en más de 60 especies de plantas (Belitz y Grosch, 1997). Los efectos de la cafeína sobre el ser humano ya han sido analizados en 3.4. No se ha detectado la presencia de cafeína en este estudio, no obstante, cabe mencionar que Viera et al. (1995) informan un contenido de $0,25 \%$ para el sucedáneo de café obtenido a partir de $P$. juliflora. 
La definición sobre fibra dietética consensuada por The American Association of Cereal Chemists expresa que: fibra dietética es la parte comestible de plantas o carbohidratos análogos que son resistentes a la digestión y absorción en el intestino delgado humano con completa o parcial fermentación en el intestino grueso. La fibra dietética incluye polisacáridos, oligosacáridos, lignina, y sustancias asociadas de las plantas. La fibra dietética promueve efectos fisiológicos benéficos incluyendo laxación, y/o atenuación del colesterol en la sangre, y/o atenuación de glucosa en la sangre (Jones, 2000).

La fibra consta de dos fracciones: soluble e insoluble en agua. La fibra soluble está formada por polisacáridos solubles, principalmente pectinas, hemicelulosas, gomas y mucílagos. Por su parte, la fibra insoluble consta de polisacáridos de las paredes celulares insolubles (celulosa y algunas hemicelulosas) y lignina. Las propiedades fisiológicas de la fibra varían en función de la proporción de fracción soluble e insoluble de la misma. Así, la fibra soluble es fermentada y sus principales efectos fisiológicos se relacionan con la disminución de los niveles sanguíneos de glucosa y colesterol, así como con el desarrollo de la flora intestinal. Por su parte, la fibra insoluble es poco fermentable, siendo sus principales propiedades la regulación de los hábitos intestinales y su marcado efecto laxante (Bravo, 1999).

Los cereales y derivados tienen un bajo contenido en fibra dietética, 0,6$2,7 \%$, siendo un poco mayor en verduras y hortalizas, $1,0-3,5 \%$, o en frutas frescas, $0,1-3,3 \%$. Sin embargo, son las legumbres las que tienen el mayor contenido $9,0-18,7 \%$. Las recomendaciones sobre el consumo de fibra dietética son de entre 30 y $45 \mathrm{~g}$ diarios (Cummings y Frolich, 1993). En este ámbito, es muy importante la algarroba tostada ya que es muy rica en fibra dietética, principalmente fibra insoluble (aproximadamente un $76 \%$ ).

La lisina (ácido diamino caproico) desempeña un papel esencial en la alimentación, particularmente en todos los organismos en fase de crecimiento; por otra parte, este aminoácido está expuesto a bloqueos por los azúcares reductores en los procesos tecnológicos (calentamientos). La reacción de Maillard implica un perjuicio nutricional, afectando selectivamente a la lisina cuando su función $\varepsilon$-amina reacciona con un aldehído o una cetona (generalmente de un azúcar) (Adrián, 2000). La reducción en el valor nutritivo de la proteína debido al tostado no enzimático se ha estudiado intensamente en términos de la pérdida de lisina, por ejemplo, se ha encontrado que el pan pierde de 10 a $12 \%$ durante el tostado (Fox y Cameron, 1992). En la algarroba tostada la lisina liberada cumple en un $44 \%$ los requerimientos de la FAO/WHO (1973) que son de 5,5 (g/100g de proteína).

La mayor parte de los elementos minerales ejercen en el ser humano funciones fisiológicas importantes: regulan el equilibrio osmótico y el potencial celular de membrana, son indispensables para actividades enzimáticas y hormonales diversas, o forman parte de tejidos, como el calcio y el fósforo en los huesos (Primo Yúfera, 1998). Los elementos minerales abundan en casi todos los alimentos. 
La algarroba tostada posee los macronutrientes calcio, fósforo, potasio, sodio, y magnesio, y los micronutrientes (oligoelementos) hierro, zinc, cobre y manganeso. Los contenidos de calcio, fósforo e hierro en la algarroba tostada son superiores a la harina de trigo, a la espinaca y a las manzanas (Fox y Cameron, 1992).

\subsection{Azúcares}

\subsubsection{AZÚCARES TOTALES}

El contenido de azúcares totales determinado en algarroba cruda de Prosopis alba es de 51,14 $\pm 0,9$ (g azúcar/100 g algarroba). La TABLA 23 presenta los valores del contenido de azúcares totales de muestras de algarroba tostada y molida, obtenidas a las distintas temperaturas y tiempos de tostado. Entre $100^{\circ} \mathrm{C} 30 \mathrm{~min}$ y $145^{\circ} \mathrm{C} 60 \mathrm{~min}$ se produce pardeamiento y a partir de los $160^{\circ} \mathrm{C} 30$ min la caramelización ó destrucción de los azúcares de la algarroba, disminuyendo marcadamente el contenido de los mismos. Las ligeras oscilaciones de valores se deben a las variaciones en la muestra por no ser esta sustancia homogénea y a la técnica analítica utilizada.

TABLA 23. Azúcares totales en función de la temperatura y tiempo de tostado

\begin{tabular}{|c|c|c|c|c|c|c|}
\hline \multicolumn{7}{|c|}{ Azúcares totales (g azúcar/100g algarroba) } \\
\hline \multirow{2}{*}{ Tiempo (min) } & 100 & 115 & 130 & 145 & 160 & 175 \\
\cline { 2 - 7 } & $48,28 \pm 0,84$ & $48,28 \pm 0,84$ & $49,13 \pm 0,87$ & $49,41 \pm 0,51$ & $33,15 \pm 0,98$ & $17,21 \pm 0,23$ \\
30 & $47,92 \pm 2,20$ & $50,08 \pm 2,53$ & $47,46 \pm 0,81$ & $47,90 \pm 1,87$ & $31,83 \pm 0,23$ & $12,91 \pm 0,11$ \\
45 & $48,57 \pm 1,30$ & $48,38 \pm 0,95$ & $46,94 \pm 1,21$ & $40,46 \pm 0,26$ & $34,24 \pm 1,35$ & $8,88 \pm 0,08$ \\
60 & valor medio \pm desviación estándar ( $\mathrm{n}=3)$ \\
\hline
\end{tabular}

\subsubsection{AZÚCARES REDUCTORES}

El contenido de azúcares reductores determinado en algarroba cruda de Prosopis alba es de 4,95 \$0,1 (g azúcar/100 g algarroba). Los azúcares reductores en la algarroba tostada a las distintas temperaturas y tiempos, se presenta en la TABLA 24 . Entre $100^{\circ} \mathrm{C} 30 \mathrm{~min}$ y $145^{\circ} \mathrm{C} 60 \mathrm{~min}$ se produce pardeamiento y a partir de los $160^{\circ} \mathrm{C} 30 \mathrm{~min}$ hidrólisis de una parte de la sacarosa (dando fructosa + glucosa), paralelamente a la caramelización o destrucción de los azúcares de la algarroba. Las ligeras oscilaciones de valores se deben a las variaciones en la muestra por no ser esta sustancia homogénea y a la técnica analítica utilizada. 
TABLA 24. Azúcares reductores en función de la temperatura y tiempo de tostado

\begin{tabular}{|c|c|c|c|c|c|c|}
\hline \multicolumn{7}{|c|}{ Azúcares reductores (g azúcar/100 g algarroba) } \\
\hline \multirow{2}{*}{ Tiempo (min) } & \multicolumn{7}{|c|}{ Temperatura $\left({ }^{\circ} \mathrm{C}\right.$ ) } \\
\cline { 2 - 7 } & 100 & 115 & 130 & 145 & 160 & \multicolumn{1}{c|}{175} \\
\hline 30 & $9,33 \pm 0,06$ & $7,56 \pm 0,09$ & $7,07 \pm 0,07$ & $6,82 \pm 0,07$ & $13,46 \pm 1,02$ & $10,55 \pm 0,13$ \\
45 & $5,53 \pm 0,07$ & $5,06 \pm 0,03$ & $6,72 \pm 0,11$ & $6,83 \pm 0,02$ & $15,91 \pm 0,11$ & $7,80 \pm 0,14$ \\
60 & $8,65 \pm 0,09$ & $8,59 \pm 0,20$ & $5,70 \pm 0,10$ & $6,71 \pm 0,22$ & $17,12 \pm 0,68$ & $4,78 \pm 0,04$ \\
\hline
\end{tabular}

\subsubsection{TIPOS DE AZÚCARES POR HPLC}

Los cromatogramas característicos se incluyen en las FIGURAS 26 y 27.

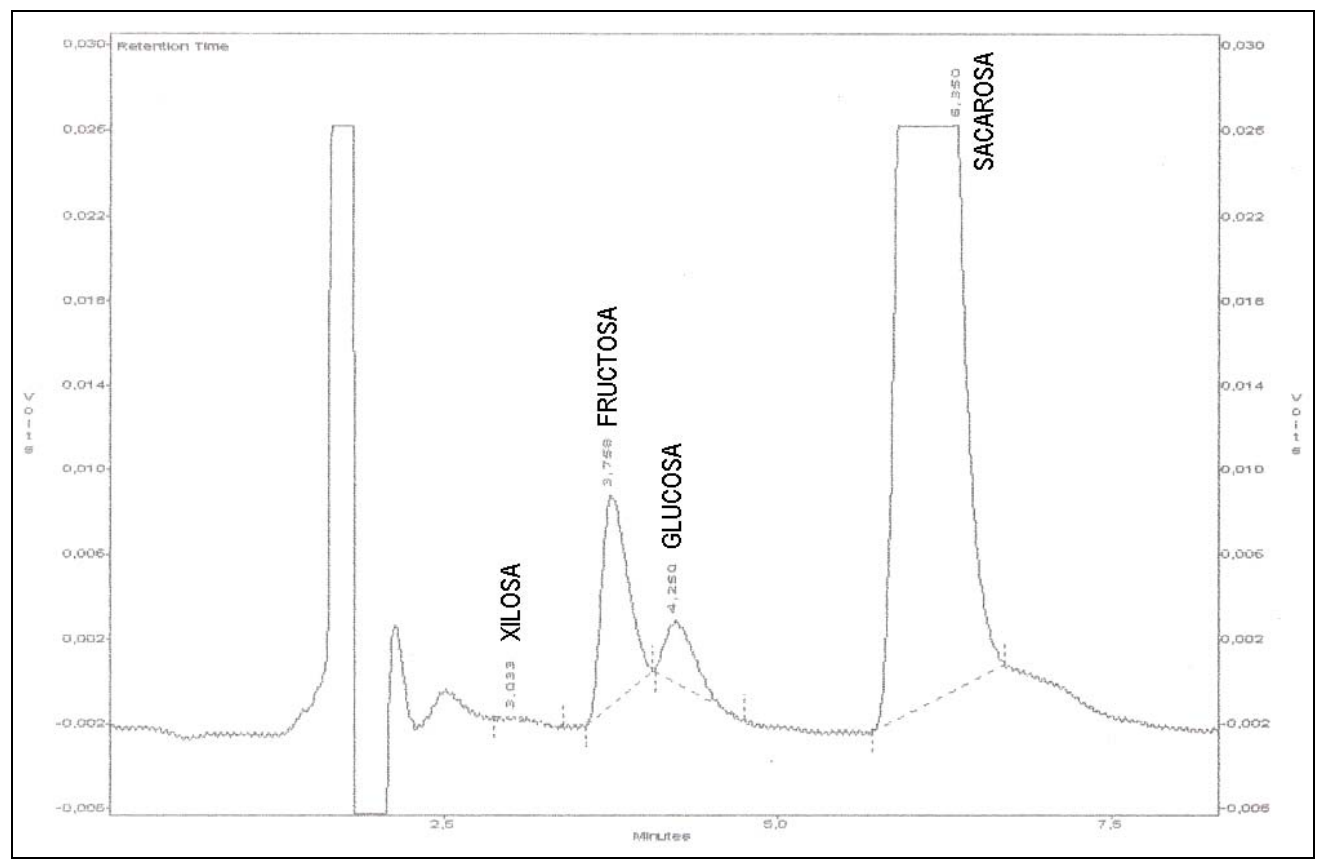

FIGURA 26. Cromatograma de algarroba cruda 


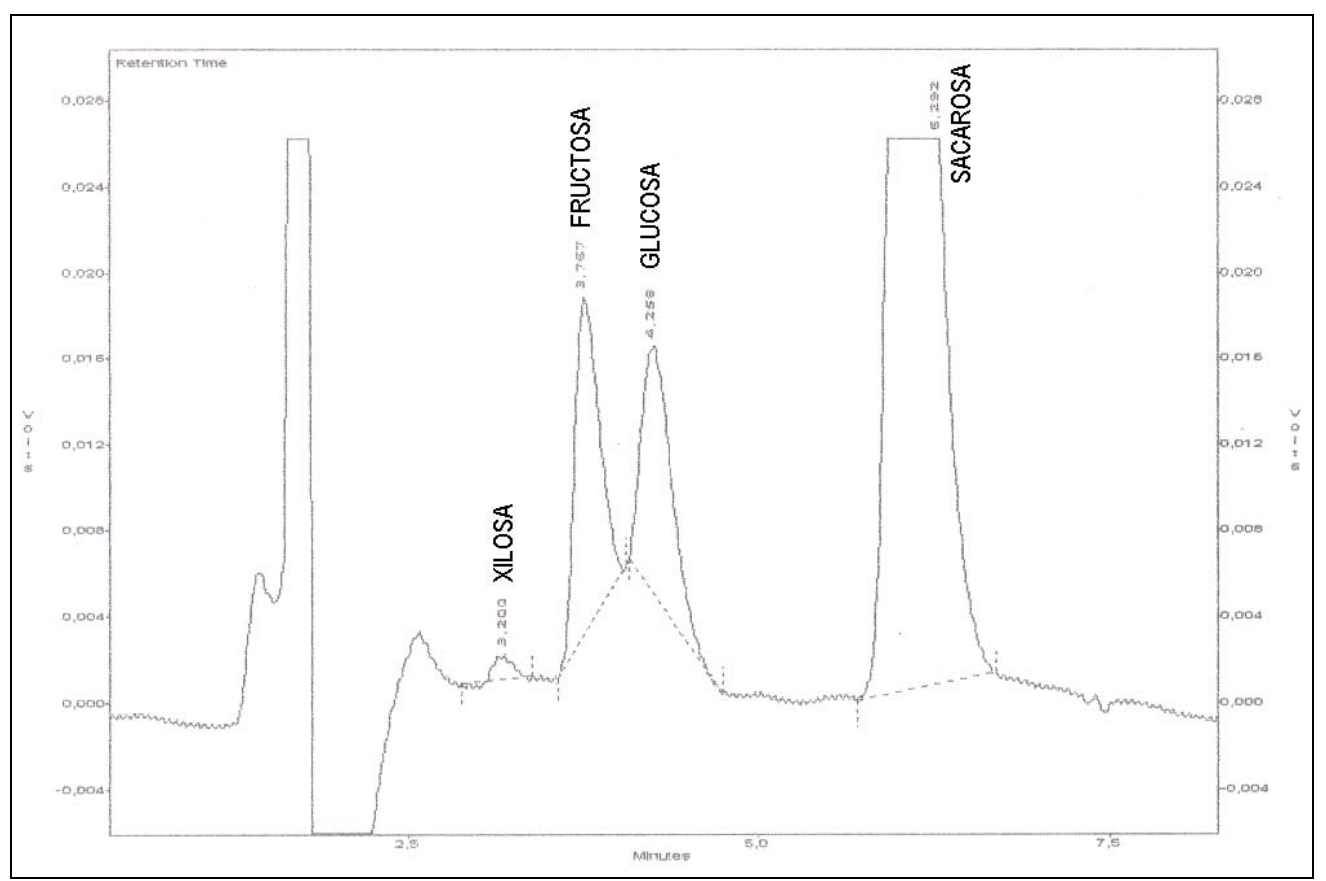

FIGURA 27. Cromatograma de algarroba tostada $\left(160^{\circ} \mathrm{C}, 60 \mathrm{~min}\right)$

En la TABLA 25 se muestra la composición de la fracción de azúcares obtenidas por HPLC.

TABLA 25. Composición de azúcares en algarrobas cruda y tostada

\begin{tabular}{|l|c|c|c|c|}
\hline & \multicolumn{2}{|c|}{ Algarroba cruda } & \multicolumn{2}{c|}{ Algarroba tostada } \\
\hline \multicolumn{1}{|c|}{ Azúcar } & Tiempo retención & $\%^{*}$ & Tiempo retención & $\%^{*}$ \\
\hline xilosa & 3,033 & 0,31 & 3,200 & 0,61 \\
\hline fructosa & 3,758 & 18,13 & 3,767 & 20,99 \\
\hline glucosa & 4,250 & 5,10 & 4,258 & 11,40 \\
\hline sacarosa & 6,350 & 76,46 & 6,292 & 65,34 \\
\hline
\end{tabular}
* porcentaje respecto del total de azúcares

La identificación de los picos de los cromatogramas realizada comparando los tiempos de retención de una mezcla de patrones (xilosa 3,13; fructosa 3,8; glucosa 4,3; sacarosa 6,2) con los de los azúcares presentes en la algarroba cruda y tostada, da como resultado la presencia mayoritaria de xilosa, fructosa, glucosa y sacarosa.

La evolución de los azúcares (xilosa, fructosa, glucosa y sacarosa) depende de la temperatura de tostado.

Los valores de los azúcares reductores creció, lo que podría atribuirse a su hidrólisis por efecto de la temperatura de tostado 0 de otras combinaciones bioquímicas (Serra et al., 1987). 
La reacción de Maillard, que conecta el grupo carbonilo de carbohidratos reductores y el grupo amino de aminoácidos libres también como de residuos de corte de proteínas, puede tener efectos benéficos o perjudiciales. En las primeras etapas de la reacción, generalmente se ha observado una mejora de las propiedades funcionales de proteínas (Handa y Kuroda, 1999), más tarde, la formación de compuestos antioxidantes (Monti et al., 1999) y también de apreciables sabores tostados (Ho, 1996). Sin embargo, también puede ocurrir la pérdida de lisina y la disminución en la digestibilidad de las proteínas (Friedman, 1996) junto con algún efecto antinutritivo (O'Brien et al., 1994; Oste et al., 1987), tóxico (O'Brien y Morrissey, 1989) o mutagénico (Wang et al., 1999). Al mismo tiempo, durante el tostado tiene lugar la caramelización de los azúcares, contribuyendo también a reacciones de pardeamiento no enzimático. En ambas reacciones Maillard y caramelización, se forman compuestos altamente absorbentes de UV e incoloros, en etapas intermedias, y los polímeros marrones aparecen en las etapas finales (Mauron, 1981; Hodge, 1953).

No se ha investigado completamente la reacción de pardeamiento no enzimático de fructosa, como la de glucosa, y usualmente se la ha comparado a esta última. En varios de los primeros estudios (Reynolds, 1965; Hodge, 1953), se encontró que las soluciones de pardeamiento de fructosa acuosa en presencia de aminoácidos en sistemas modelo tenían lugar más rápidamente que la de glucosa, aunque podía ocurrir lo contrario (Baxter, 1995; Bobbio et al, 1981; Ellingson et al., 1954). También se informó que el pardeamiento de las soluciones de fructosa es más o menos extensivo que la de glucosa, dependiendo sobre todo de las condiciones de calentamiento (Wijewickreme et al., 1997; Buera et al., 1987; Kato et al., 1969). Por otro lado, se ha estudiado la influencia del pH sobre la reacción de Maillard de sistemas modelo de aminoácidos con glucosa o fructosa a diferentes escalas de $\mathrm{pH}$ y condiciones de temperatura y concentración de reactantes, específicamente $\mathrm{pH}$ 4-6 (Buera et al., 1987), pH 5-7 (Petriella et al., 1985), pH 5,5-7,5 (Baxter, 1995) y pH 6-12 (Ashoor y Zent, 1984). Cabe mencionar que en la mayoría de estos estudios fue medida solamente la intensidad de pardeamiento de Maillard.

Se ha prestado muy poca atención a la contribución de la caramelización a las reacciones de pardeamiento no enzimático de glucosa o fructosa, aunque el estudio de las reacciones químicas involucradas en la caramelización es un prerrequisito para entender la reacción de Maillard (Mauron, 1981). Sin embargo, se ha establecido claramente que la fragmentación de azúcares ocurre en grado significante en los valores de $\mathrm{pH}$ bajo neutralidad (Buera et al., 1987; O'Beirne, 1986) y aumenta considerablemente a valores altos de $\mathrm{pH}$ y temperaturas, produciendo polímeros de $\mathrm{N}_{2}$ libre coloreados (Clarke et al., 1997; Myers y Howell, 1992). Entonces la reacción de Maillard en alimentos puede sobreestimarse y enfatizarse más los efectos dañinos que los benéficos. 
Cabe destacar el notable contenido de sacarosa la cual, a las temperaturas de tostado, puede hidrolizarse en glucosa y fructosa y, por tanto, aumenta el contenido en azúcares reductores que pueden intervenir en las reacciones de Maillard (Babsky et al., 1986). Teniendo en cuenta los valores de azúcares totales (1.9.1), como era de esperar, el contenido de sacarosa disminuye drásticamente, en un $42,8 \%$, al pasar de algarroba cruda a tostada $\left(160^{\circ} \mathrm{C}, 60 \mathrm{~min}\right)$.

Los antecedentes encontrados señalan que para la pulpa de $P$. pallida el mayor componente es sacarosa $(46,1 \%)$, representando el $94,76 \%$ del total de azúcares solubles (Cruz, 1999). Los azúcares reductores están presentes en muy pequeñas cantidades xilosa $0,27 \%$, fructosa $1,26 \%$ y glucosa $1,02 \%$ (Cruz et al., 1987). La pulpa de $P$. velutina contiene sacarosa, fructosa y glucosa en cantidades de $92 \%, 5 \%$ y $3 \%$ respectivamente (Meyer, 1984). En pericarpio de $P$. juliflora, se reportaron en los azúcares solubles $75 \%$ de sacarosa, además de $12 \%$ de fructosa, $5 \%$ de glucosa, $5 \%$ de inositol y $1 \%$ de rafinosa (Marangoni y Alli, 1988). Un contenido de sacarosa de $30 \%$ y muy bajos contenidos de fructosa, glucosa, inositol y rafinosa han sido encontrados en el pericarpio de $P$. glandulosa y $P$. velutina de Texas y Arizona respectivamente (Becker y Grosjean, 1980).

La mayor parte de la sacarosa de la dieta no procede de vegetales nativos sino del consumo de alimentos modificados que la contienen tras haber sido aislada de la remolacha o la caña de azúcar. Las frutas y hortalizas contienen sólo pequeñas cantidades de sacarosa, fructosa y glucosa (Whistler y Daniel, 1993). Por esto la algarroba se destaca como alimento ya que contiene altas cantidades de sacarosa, fructosa y glucosa.

\section{EVALUACIÓN SENSORIAL}

\subsection{Análisis descriptivos}

Tradicionalmente los aromas inducidos por los procesos térmicos se han considerado, en general, como productos de las reacciones de pardeamiento Estos aromas de pardeamiento se producen por ejemplo en el tostado del café o de los frutos secos (Whistler y Daniel, 1993). Los primeros descubrimientos mostraron el papel que jugaban los azúcares reductores y los compuestos amino en la iniciación de un proceso que finalmente conducía a la formación de pigmentos pardos. Aunque las reacciones de pardeamiento casi siempre están directamente implicadas en el desarrollo del aroma de los alimentos procesados, las interacciones entre a) los productos de degradación de las reacciones de pardeamiento y b) otros constituyentes de los alimentos, son también importantes y ocurren ampliamente (Lindsay, 1993).

$\mathrm{Si}$ bien algunos de los compuestos del aroma de los alimentos procesados son sustancias acíclicas, muchos en cambio son heterocíclicos que tienen como sustituyentes comunes nitrógeno, azufre u oxígeno. 
Estos compuestos del aroma resultantes del tratamiento térmico están presentes en numerosos alimentos y bebidas tales como almendra tostada, cacao y café. Sin embargo, la distribución de los distintos compuestos individuales, dependen de factores como la existencia de precursores, la temperatura, el tiempo y la actividad de agua (Hurrell, 1982).

En las TABLAS 26 y 27 se presentan los atributos y descriptores utilizados para las muestras de referencia y propuestos para la algarroba.

Tabla 26. Atributos y descriptores utilizados para las muestras de referencia

\begin{tabular}{|c|c|c|}
\hline \multicolumn{3}{|c|}{ Material molido } \\
\hline Café & Malta & Cascarilla de cacao \\
\hline $\begin{array}{r}\text { Aroma: genuino } \\
\text { tostado } \\
\text { persistente }\end{array}$ & $\begin{array}{l}\text { Aroma: genuino } \\
\text { cereal tostado } \\
\text { algo dulce } \\
\text { algo persistente }\end{array}$ & $\begin{array}{l}\text { Aroma: genuino } \\
\text { dulce } \\
\text { casi nada persistente }\end{array}$ \\
\hline $\begin{array}{l}\text { Color: marrón oscuro } \\
\text { tostado } \\
\text { opaco }\end{array}$ & $\begin{array}{c}\text { Color: marrón } \\
\text { opaco }\end{array}$ & Color: marrón claro \\
\hline $\begin{array}{l}\text { Aspecto: partículas de tamaño } \\
\text { homogéneo mezcladas con } \\
\text { partículas de color más claro }\end{array}$ & $\begin{array}{l}\text { Aspecto: partículas de } \\
\text { tamaño heterogéneo } \\
\text { mezcladas con partículas } \\
\text { de color más claro }\end{array}$ & $\begin{array}{l}\text { Aspecto: partículas más finas } \\
\text { que las de café, de tamaño } \\
\text { homogéneo }\end{array}$ \\
\hline \multicolumn{3}{|c|}{ Infusión } \\
\hline Café & Malta & Cascarilla de cacao \\
\hline $\begin{array}{l}\text { Aroma: genuino } \\
\text { suave } \\
\text { poco persistente }\end{array}$ & $\begin{array}{l}\text { Aroma: genuino } \\
\text { tostado } \\
\text { dulce } \\
\text { algo persistente }\end{array}$ & $\begin{array}{l}\text { Aroma: dulce } \\
\text { casi imperceptible }\end{array}$ \\
\hline Color: marrón oscuro translúcido & $\begin{array}{l}\text { Color: marrón oscuro algo } \\
\text { verdoso translúcido }\end{array}$ & $\begin{array}{c}\text { Color: marrón claro } \\
\text { ámbar rojizo }\end{array}$ \\
\hline Aspecto: algo oleoso (+) & Aspecto: no oleoso & Aspecto: oleoso (++) \\
\hline $\begin{array}{l}\text { Sabor: genuino } \\
\text { amargo } \\
\text { tostado } \\
\text { persistente }\end{array}$ & $\begin{array}{l}\text { Sabor: genuino } \\
\text { amargo } \\
\text { tostado } \\
\text { poco persistente }\end{array}$ & $\begin{array}{l}\text { Sabor: genuino } \\
\text { poco persistente }\end{array}$ \\
\hline $\begin{array}{l}\text { Sensación al paladar: algo } \\
\text { astringente }\end{array}$ & $\begin{array}{l}\text { Sensación al paladar: algo } \\
\text { astringente }\end{array}$ & $\begin{array}{l}\text { Sensación al paladar: poco } \\
\text { astringente }\end{array}$ \\
\hline
\end{tabular}


Tabla 27. Atributos y descriptores propuestos para la evaluación de algarroba

\begin{tabular}{|c|c|}
\hline Algarroba tostada molida & Infusión de algarroba \\
\hline $\begin{array}{l}\text { Aroma: genuino } \\
\text { tostado } \\
\text { dulce } \\
\text { chocolate }\end{array}$ & $\begin{array}{l}\text { Aroma: genuino } \\
\text { tostado } \\
\text { miel } \\
\\
\text { hierba } \\
\text { chocolate }\end{array}$ \\
\hline Persistencia del aroma & Persistencia del aroma \\
\hline Color: marrón & $\begin{array}{l}\text { Color: marrón } \\
\quad \text { pardo amarillento }\end{array}$ \\
\hline \multirow[t]{5}{*}{$\begin{array}{l}\text { Aspecto: mezcla homogénea } \\
\text { de partículas y fibrillas. }\end{array}$} & $\begin{array}{l}\text { Aspecto: translúcido } \\
\text { oleosidad }\end{array}$ \\
\hline & $\begin{array}{r}\text { Sabor: genuino } \\
\text { tostado } \\
\text { madera } \\
\text { hierba } \\
\text { quemado }\end{array}$ \\
\hline & Gusto: amargo \\
\hline & Sensación al paladar: astringencia \\
\hline & Persistencia del sabor \\
\hline
\end{tabular}

El promedio del puntaje asignado por el panel a cada atributo para cada muestra fue tomado como referencia interna en la evaluación de las muestras de algarroba (TABLA 28). 
Tabla 28. Valores medios asignados por el panel a las muestras de café, malta y cascarilla de cacao

\begin{tabular}{|c|c|c|c|}
\hline \multirow[b]{2}{*}{ Atributos } & \multicolumn{3}{|c|}{ Material molido } \\
\hline & Café & Malta & $\begin{array}{l}\text { Cascarilla } \\
\text { de cacao }\end{array}$ \\
\hline Aroma: genuino & 8,40 & 7,95 & 6,93 \\
\hline tostado & 7,63 & 6,51 & \\
\hline dulce & & 1,51 & 6,17 \\
\hline Persistencia del aroma & 8,42 & 1,15 & 0,92 \\
\hline Color: marrón & 8,16 & 6,68 & 3,02 \\
\hline tostado & 7,70 & 0,00 & \\
\hline brillo & 2,26 & 1,09 & \\
\hline Aspecto: homogeneidad & 7,84 & 4,33 & 6,95 \\
\hline \multirow[b]{2}{*}{ Atributos } & \multicolumn{3}{|c|}{ Infusión } \\
\hline & Café & Malta & $\begin{array}{l}\text { Cascarilla } \\
\text { de cacao }\end{array}$ \\
\hline $\begin{array}{r}\text { Aroma: genuino } \\
\text { tostado }\end{array}$ & 6,95 & $\begin{array}{l}8,00 \\
6,86\end{array}$ & \\
\hline dulce & & 3,74 & 6,13 \\
\hline Persistencia del aroma & 1,07 & 0,73 & 0,25 \\
\hline Color: marrón & 7,53 & 6,92 & 2,37 \\
\hline verdoso & & 0,99 & \\
\hline ámbar & & & 6,89 \\
\hline Aspecto: translúcido & 7,18 & 5,78 & 6,87 \\
\hline oleosidad & 0,64 & 0,00 & 1,05 \\
\hline Sabor: genuino & 7,84 & 7,88 & 7,79 \\
\hline tostado & 7,30 & 7,08 & \\
\hline Gusto: amargo & 7,20 & 7,08 & \\
\hline Persistencia del sabor & 6,19 & 2,61 & 2,22 \\
\hline Sensación al paladar: astringencia & 2,39 & 3,18 & 1,57 \\
\hline
\end{tabular}

Una vez obtenidos los resultados, se analizó la frecuencia relativa porcentual de las respuestas del panel, para cada descriptor, y se encontró que las siguientes respuestas, presentaron frecuencia de respuestas por debajo del $40 \%$ en las tres muestras de algarroba tostada: aroma a cacao, color tostado y brillo para el polvo; y aroma a té de limón, aroma dulce, color ámbar, color verdoso, oleosidad, y sabor a limón para la infusión. Esto indica que la intensidad es muy baja y por ende el panel no lo detecta, razón por la cual los descriptores mencionados fueron eliminados de la lista original.

Las FIGURA 28 muestra el perfil sensorial de algarroba tostada molida para las tres muestras $\left(\mathrm{T} 1: 160^{\circ} \mathrm{C} 60 \mathrm{~min}\right.$; $\mathrm{T} 2$ : $175^{\circ} \mathrm{C} 30 \mathrm{~min}$; y $\mathrm{T} 3: 175^{\circ} \mathrm{C} 45$ min). Se puede observar que la puntuación de todos los descriptores supera 4 , y que el aumento de la temperatura de tostado produce ligeros cambios en el color marrón, en el aroma a chocolate y en la persistencia del aroma. 
La muestra 3 presenta aroma dulce y aroma a chocolate en menor intensidad que las otras dos. El color marrón de esta muestra es más intenso. En cambio la muestra 1 presenta aroma más persistente y color marrón menos intenso que las muestras 2 y 3 . El resto de los descriptores no presentan grandes diferencias entre las tres muestras ensayadas.

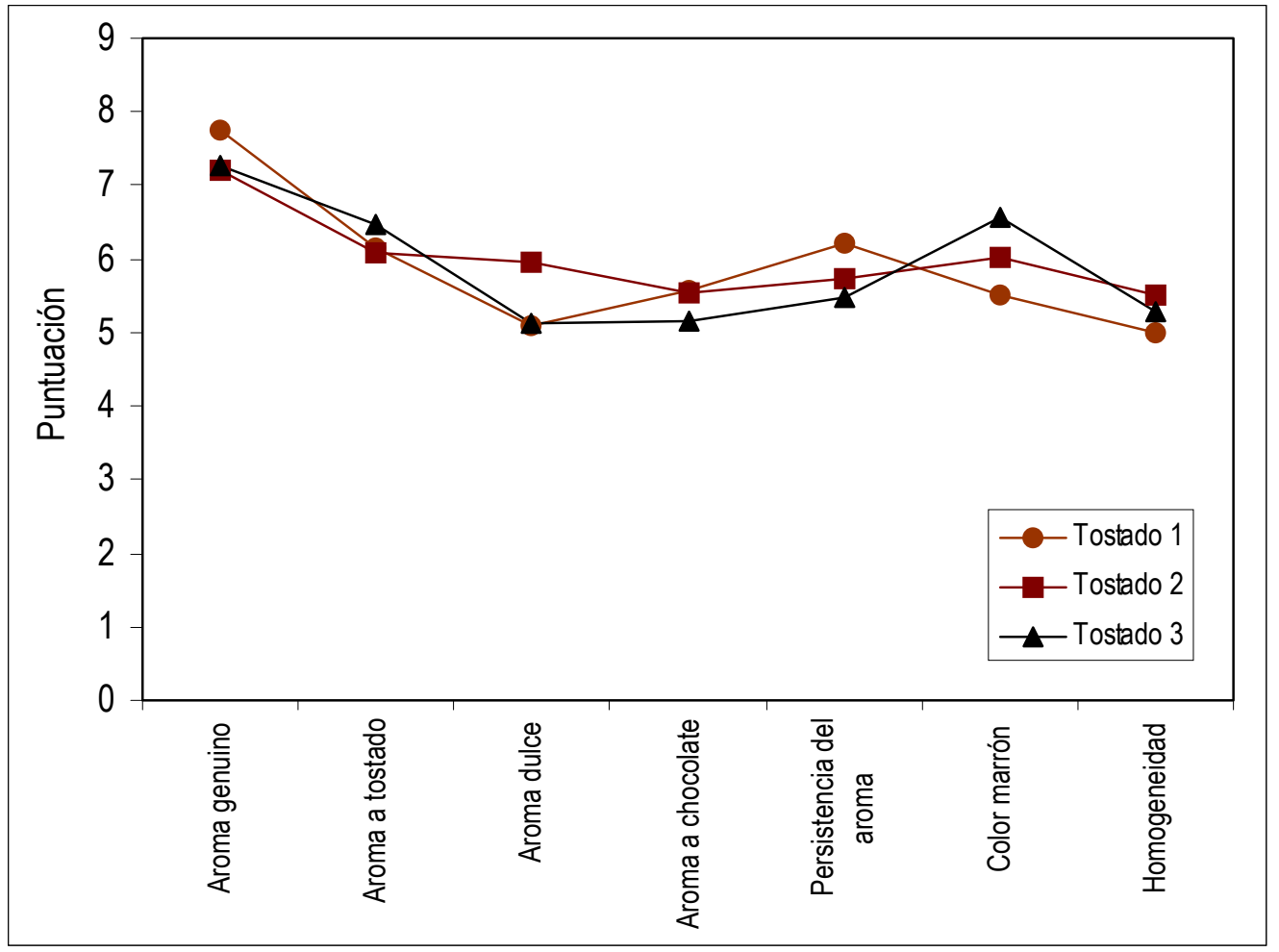

FIGURA 28. Perfil sensorial de algarroba tostada y molida

Las FIGURAS 29, 30 y 31 muestran el perfil sensorial de las infusiones de algarroba tostada a las tres concentraciones ensayadas (3\%, 4,5\% y $6 \%$ ).

El aroma a chocolate y la persistencia del aroma, obtuvieron puntuación promedio por debajo o igual a 3 , tanto para la infusión $3 \%$ como para la de $6 \%$. Por otra parte, el aroma a miel, aroma a hierba, color marrón, color pardo-amarillento y translúcido presentaron puntuación entre 3 y 6 para las tres infusiones ensayadas. En cambio, aroma genuino, aroma a tostado, color marrón, sabor genuino, gusto amargo, sabor a tostado, sabor a hierba y gusto a quemado obtuvieron puntuación igual o superior a 6 . 


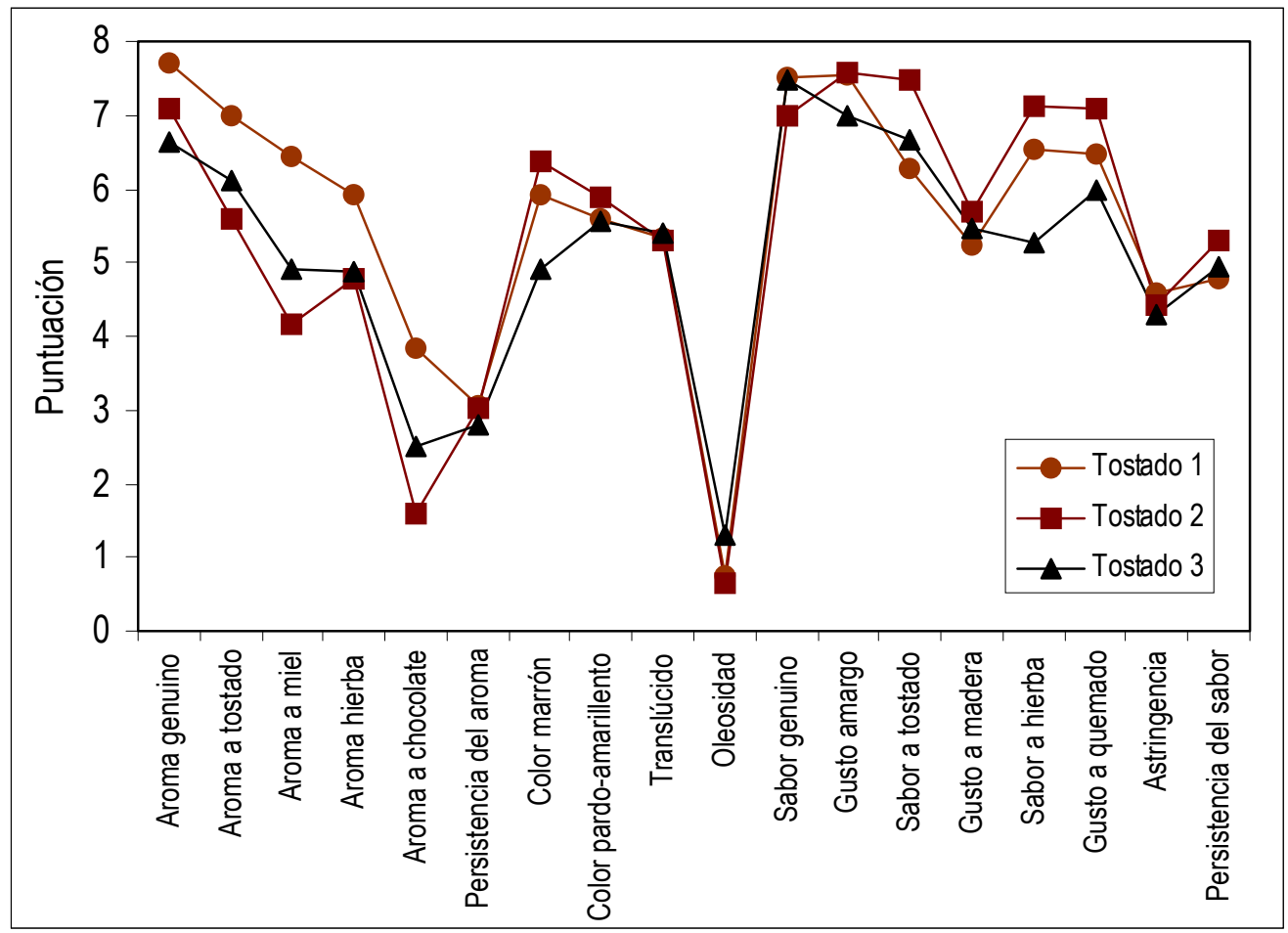

FIGURA 29. Perfil sensorial de algarroba tostada molida en infusión al $3 \%$

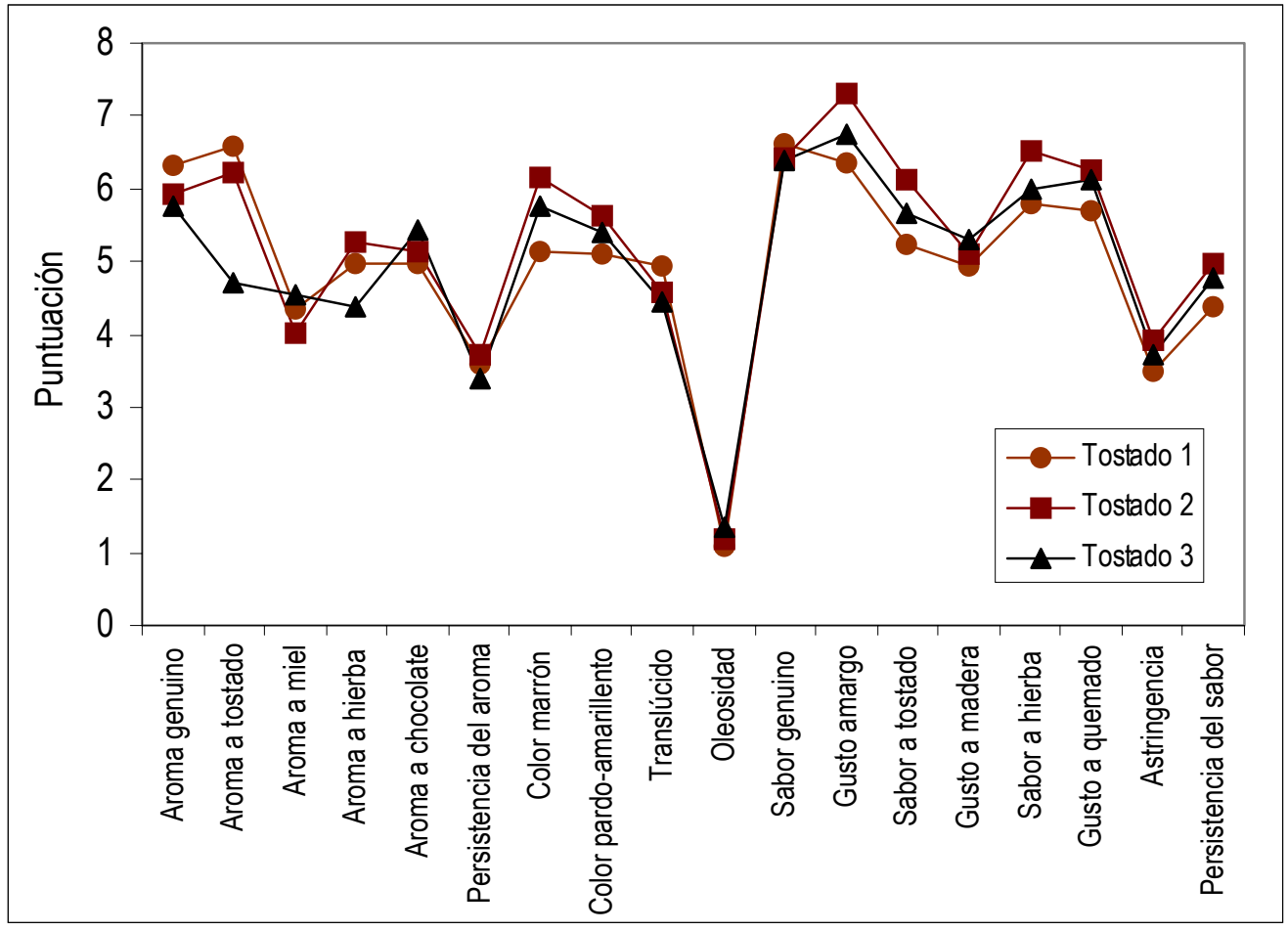

FIGURA 30. Perfil sensorial de algarroba tostada molida en infusión al 4,5\% 


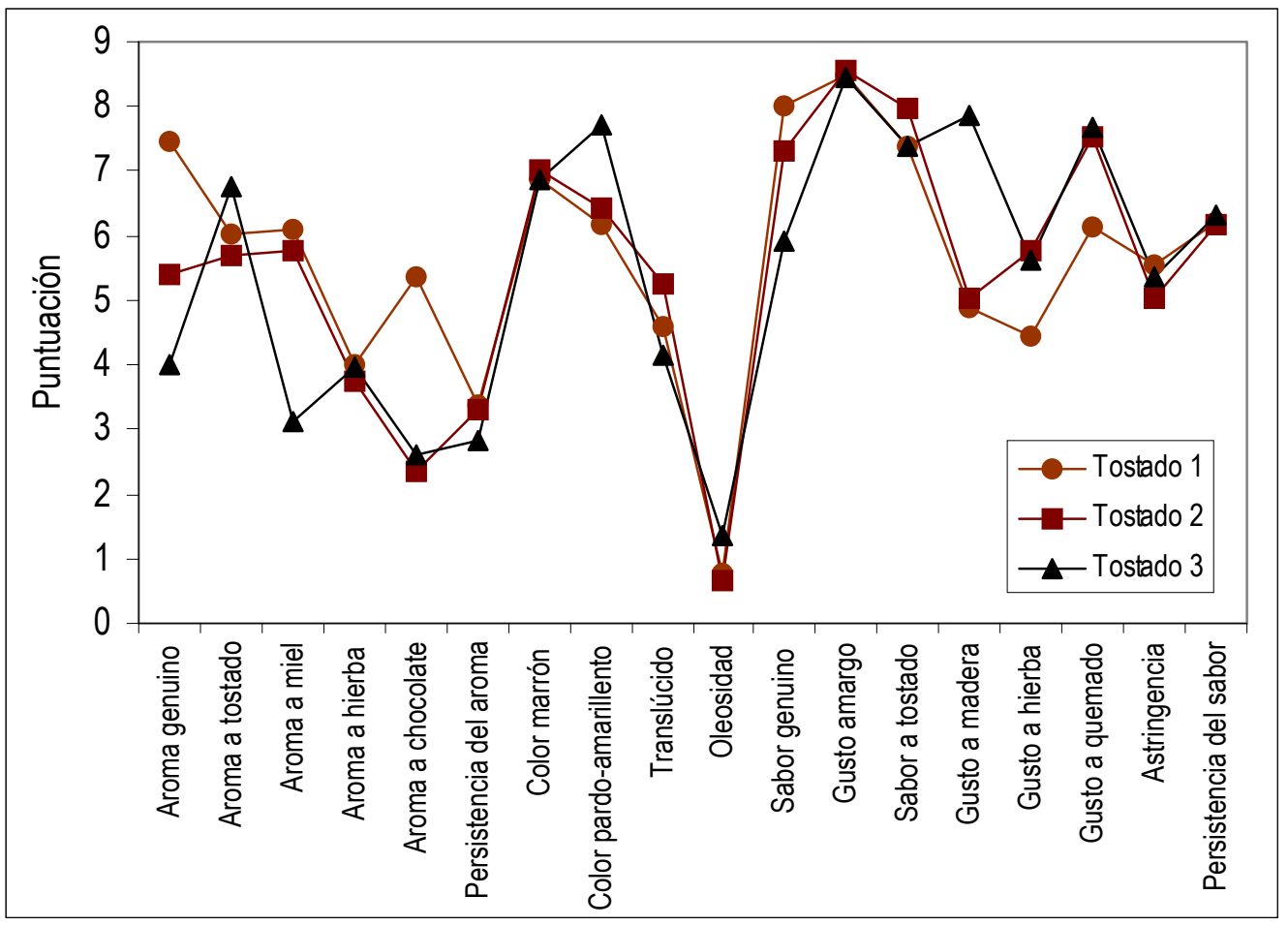

FIGURA 31. Perfil sensorial algarroba tostada molida en infusión al $6 \%$

En la TABLA 29 se presentan los resultados del análisis de variancia obtenidos al nivel $\alpha \leq 0,05$ para la algarroba tostada molida. No se encontraron diferencias estadísticamente significativas en los descriptores aroma, persistencia del aroma y homogeneidad. En cambio hubo diferencias en el color marrón de la muestra 3 respecto de la muestra 1.

Tabla 29. Resultados del análisis de variancia para las muestras de algarroba tostada molida

\begin{tabular}{|l|c|c|c|c|}
\hline \multicolumn{1}{|c|}{ Atributos } & \multicolumn{3}{c|}{ Valor medio } & \multirow{2}{*}{ Muestras } \\
\cline { 1 - 4 } \multicolumn{1}{|c|}{ Tostado 1 } & Tostado 2 & Tostado 3 & \\
\hline Aroma genuino & 7,76 & 7,22 & 7,27 & 1,64 \\
Aroma a tostado & 6,14 & 6,10 & 6,47 & 0,65 \\
Aroma dulce & 5,08 & 5,95 & 5,14 & 1,18 \\
Aroma a chocolate & 5,58 & 5,55 & 5,15 & 1,67 \\
Persistencia del aroma & 6,21 & 5,74 & 5,47 & 0,57 \\
Color marrón & 5,51 & 6,03 & 6,58 & $15,35^{*}$ \\
Homogeneidad & 4,99 & 5,51 & 5,30 & 0,61 \\
\hline
\end{tabular}


En la TABLA 30 se presentan los resultados del análisis de variancia obtenidos al nivel $\alpha \leq 0,05$ para las infusiones de algarroba al 3\%, 4,5\% y $6 \%$. De ella se pueden hacer las siguientes observaciones:

Aroma genuino: la muestra 3 infusión $6 \%$ no difiere de la muestra 2 para la misma infusión, pero si difiere del resto, siendo considerablemente menor. En general, la muestra 1 tiene mejor aroma genuino que el resto.

Aroma a chocolate: la muestra 2 infusión 3\% difiere del resto. Además, se puede observar que las muestras 2 y 3 infusión $6 \%$ presentaron menor intensidad del aroma a chocolate que al 4,5\%; posiblemente, a mayor concentración este descriptor de aroma se encuentre enmascarado por otro de mayor intensidad.

Persistencia del aroma: es relativamente baja en todas las infusiones ensayadas, no encontrándose diferencias entre ellas.

Color marrón: las muestras no difieren para la infusión $6 \%$; en cambio para la infusión $4,5 \%$ las muestras 1 y 3 difieren de la muestra 2 en tanto que, para la infusión $3 \%$, la muestra 3 difiere de las otras dos.

Color pardo-amarillento: la muestra 3 infusión $6 \%$ no difiere de las muestras 1 y 2, para la misma concentración de la infusión pero si difiere del resto.

Translúcido y oleosidad: no se encontraron diferencias significativas. Se puede decir que las muestras son medianamente translúcidas y que tienen poca oleosidad.

Sabor genuino: para cada muestra, no hubo diferencias con la concentración; si difiere la muestra 1 infusión $6 \%$ de las muestras 2 y 3 infusión $4,5 \%$ y de la muestra 3 infusión $6 \%$.

Sabor a tostado: para cada infusión, no hubo diferencias significativas entre las muestras. En cambio, la muestra 2 infusión $6 \%$ difiere de las muestras 1 y 3 infusión 4,5\%.

Gusto a madera: solo la muestra 3 infusión $6 \%$ difiere del resto.

Sabor a hierba y gusto a quemado: no se encontraron diferencias significativas.

Gusto amargo: las infusiones 3\% no difieren entre sí, lo mismo sucede con las infusiones $6 \%$; en cambio la muestra 2 infusión $4,5 \%$ difiere de las otras dos.

Persistencia del sabor: solo la muestra 1 infusión $4,5 \%$ difiere de la muestra 3 infusión $6 \%$.

Astringencia: para todas las muestras, fue de intensidad media y no hubo diferencias significativas entre ellas. 
Tabla 30. Resultados del análisis de variancia para las infusiones obtenidas con las tres muestras de algarroba tostada molida

\begin{tabular}{|c|c|c|c|c|c|c|c|c|c|c|}
\hline Atributos & \multicolumn{9}{|c|}{ Valor medio } & \multirow{3}{*}{$\mathrm{F}$} \\
\hline Muestras & \multicolumn{3}{|c|}{ Tostado 1} & \multicolumn{3}{|c|}{ Tostado 2} & \multicolumn{3}{|c|}{ Tostado 3} & \\
\hline Infusión (\%) & 3 & 4,5 & 6 & 3 & 4,5 & 6 & 3 & 4,5 & 6 & \\
\hline Aroma genuino & 7,71 & 6,34 & 7,45 & 7,08 & 5,94 & 5,38 & 6,64 & 5,78 & 4,00 & $2,54^{*}$ \\
\hline Aroma a tostado & 6,98 & 6,60 & 6,03 & 5,60 & 6,22 & 5,69 & 6,13 & 4,72 & 6,77 & $0,84 \mathrm{NS}$ \\
\hline Aroma a miel & 6,43 & 4,35 & 6,10 & 4,16 & 4,00 & 5,76 & 4,91 & 4,53 & 3,13 & $0,57 \mathrm{NS}$ \\
\hline Aroma a hierba & 5,93 & 4,96 & 4,00 & 4,79 & 5,27 & 3,74 & 4,86 & 4,39 & 3,98 & $0,50_{\mathrm{NS}}$ \\
\hline Aroma a chocolate & 3,83 & 4,96 & 5,35 & 1,60 & 5,14 & 2,37 & 2,50 & 5,43 & 2,63 & $1,53^{*}$ \\
\hline Persistencia del aroma & 3,05 & 3,57 & 3,39 & 3,02 & 3,71 & 3,31 & 2,80 & 3,39 & 2,84 & $0,09_{\mathrm{NS}}$ \\
\hline Color marrón & 5,92 & 5,14 & 6,88 & 6,38 & 6,14 & 7,00 & 4,91 & 5,75 & 6,86 & $5,69^{*}$ \\
\hline Color pardo-amarillento & 5,58 & 5,11 & 6,18 & 5,90 & 5,63 & 6,44 & 5,56 & 5,39 & 7,70 & $1,59 *$ \\
\hline Translúcido & 5,33 & 4,94 & 4,59 & 5,30 & 4,56 & 5,27 & 5,41 & 4,46 & 4,15 & $0,34 \mathrm{NS}$ \\
\hline Oleosidad & 0,73 & 1,10 & 0,77 & 0,67 & 1,20 & 0,67 & 1,30 & 1,35 & 1,38 & $0,53 \mathrm{NS}$ \\
\hline Sabor genuino & 7,53 & 6,61 & 8,03 & 7,00 & 6,43 & 7,30 & 7,49 & 6,38 & 5,92 & $1,27^{*}$ \\
\hline Gusto amargo & 7,54 & 6,37 & 8,49 & 7,57 & 7,31 & 8,54 & 7,00 & 6,74 & 8,44 & $7,24^{*}$ \\
\hline Sabor a tostado & 6,28 & 5,22 & 7,38 & 7,47 & 6,12 & 7,96 & 6,68 & 5,66 & 7,37 & $1,85^{\star}$ \\
\hline Gusto a madera & 5,25 & 4,93 & 4,90 & 5,68 & 5,12 & 5,04 & 5,47 & 5,32 & 7,88 & $0,81^{*}$ \\
\hline Sabor a hierba & 6,55 & 5,78 & 4,45 & 7,12 & 6,53 & 5,75 & 5,27 & 5,98 & 5,62 & $0,57 \mathrm{NS}$ \\
\hline Gusto a quemado & 6,48 & 5,69 & 6,15 & 7,10 & 6,25 & 7,53 & 5,98 & 6,12 & 7,67 & $0,67 \mathrm{Ns}$ \\
\hline Astringencia & 4,60 & 3,48 & 5,55 & 4,42 & 3,93 & 5,04 & 4,30 & 3,71 & 5,38 & $0,81 \mathrm{NS}$ \\
\hline Persistencia del sabor & 4,79 & 4,37 & 6,19 & 5,32 & 4,99 & 6,18 & 4,94 & 4,77 & 6,31 & $1,19^{*}$ \\
\hline
\end{tabular}

\subsection{Aceptabilidad sensorial}

De los 113 consumidores que evaluaron las infusiones al 4,5\% preparadas con las tres muestras de algarroba mezcladas con leche entera en la proporción 1:1 y sin el agregado de azúcar, solo 11 manifestaron desagrado por la muestra $1 ; 7$ por la muestra 2 ; y 23 por la muestra 3 . De igual modo, 2, 7 y 2, respectivamente fue el número de consumidores a quienes las muestras les resultaron indiferentes. En cambio, 100 consumidores mostraron agrado (grado de gusto positivo) para la muestra 1; 99 por la muestra 2; y 88 por la muestra 3. De éstos, el $70,79 \%$ de los consumidores ubicó la muestra 1 entre "me gusta moderadamente" (7) y "me gusta mucho" (8); el 60,18\% ubicó la muestra 2 entre "me gusta poco" (6) y "me gusta moderadamente" (7); y el 41,59\% ubicó la muestra 3 en "me gusta moderadamente" (7) (FIGURA 32). 


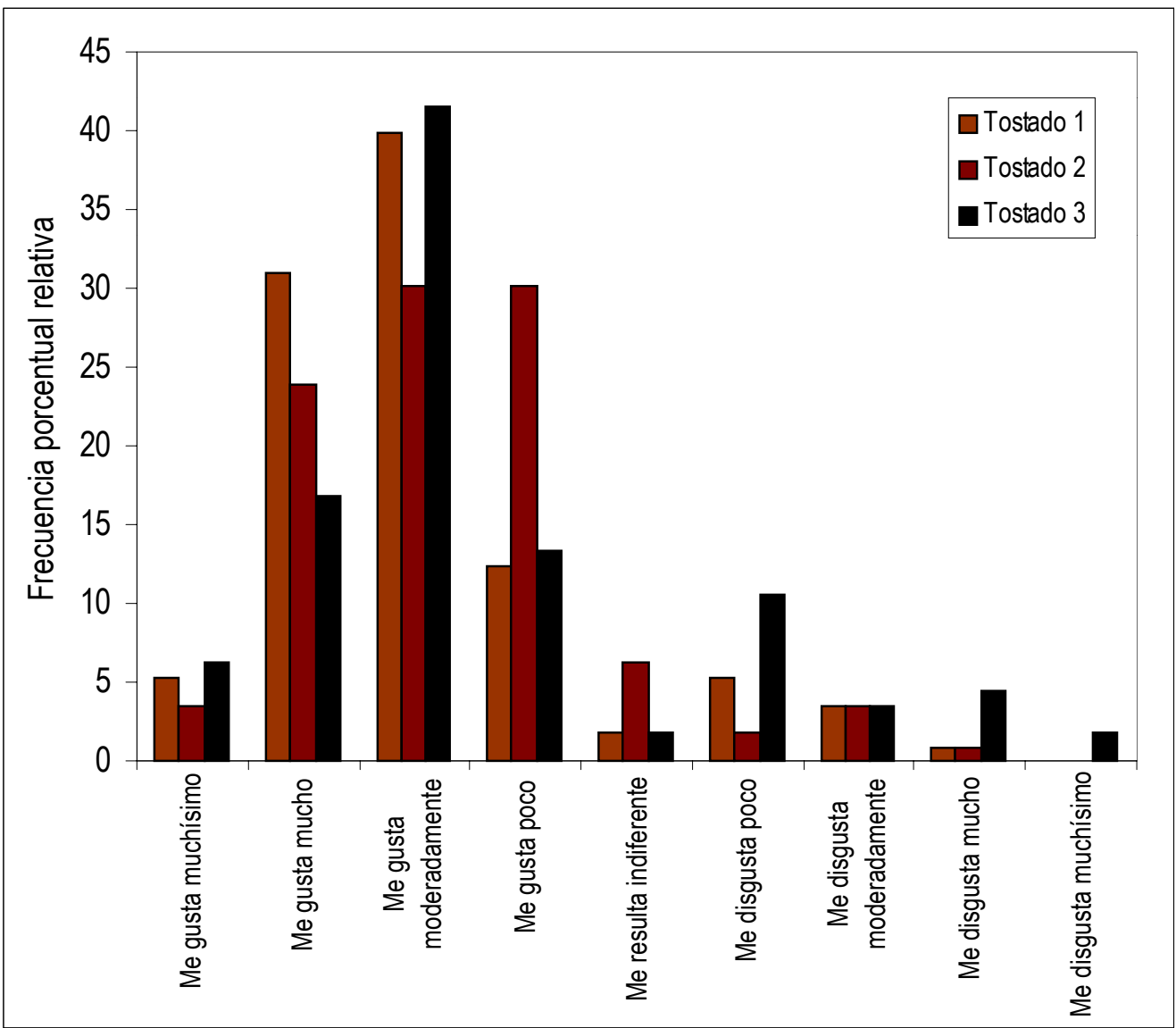

FIGURA 32. Distribución de grados de gusto de infusiones al $4,5 \%$ de algarroba tostada molida mezcladas con leche entera (1:1) 
V. CONCLUSIONES 
El desarrollo de un método de procesado simple de los frutos de Prosopis alba Griseb, resulta importante a fin de lograr una mayor utilización de la algarroba en Argentina como materia prima para la industria alimentaria.

El color de la algarroba está íntimamente relacionado con la temperatura de tueste. Durante el proceso de tostado, el desarrollo de color se presenta inicialmente en la superficie de la algarroba y progresa en forma distinta en el interior en función de la temperatura. Los valores de la energía aparente de activación $\left(E_{a}\right)$ fueron muy similares para las funciones de color: luminosidad $\left(\mathrm{L}^{*}\right)$ e intensidad de color métrico $\left(\mathrm{C}^{*}\right)$, lo cual muestra que son indicadores equivalentes de la evolución del pardeamiento durante el proceso de tostado. En las muestras tostadas a 160 y $175^{\circ} \mathrm{C}$ fue posible obtener valores del tono, croma y luminosidad del producto en el intervalo de los encontrados para café tostado. Las funciones de color presentan valores mayores cuando la temperatura o el tiempo del proceso de tostado también lo hacen. Al estar el color de la algarroba relacionado con ambas variables de proceso, linealmente con el tiempo, aunque no con la temperatura, puede ser un buen parámetro de control de proceso, y puede elegirse el color deseado de producto controlando la temperatura y el tiempo de tostado.

El tostado modificó el comportamiento de la adsorción del agua en la algarroba, disminuyendo la tendencia a la humectación y la capacidad de retención de agua.

Se ha observado que la variación del contenido de glucosa y de fructosa no presenta una tendencia definida con respecto al tiempo y temperatura de tostado. Esto puede deberse a que, si bien desaparecen a través de la reacción de Maillard, aparecen por hidrólisis de la sacarosa, lo que en conjunto no permite ver una evolución clara. Por el contrario, se ha observado que el contenido de sacarosa disminuyó con el tiempo y temperatura de tostado.

Como consecuencia del tostado a $160^{\circ} \mathrm{C}$ durante $60 \mathrm{~min}$, el contenido de azúcares totales se redujo en un $67 \%$, y el contenido de azúcares reductores aumentó en un $345,9 \%$. La sacarosa disminuyó en un $42,8 \%$ con relación a los azúcares totales. El contenido de sólidos solubles disminuyó en un $51,1 \%$.

El aroma de las infusiones ensayadas, presentó matices de tostado, miel, hierba, y chocolate. La muestra tostada a $160^{\circ} \mathrm{C}$ durante 60 min es la que desarrolló aroma más parecido al de café genuino, y tuvo mayor aceptación entre los consumidores consultados.

Se concluye que en este trabajo se logró desarrollar un nuevo producto con tecnología simple, con variables definidas de control de proceso (color, temperatura y tiempo), totalmente natural, sin cafeína, de sabor y aroma agradable, y con alto valor energético para la alimentación humana. 


\section{BIBLIOGRAFÍA}


Abd El-Rashid, A. 1996. Particle size distribution as a way of predicting types of flour and level of flour extraction. Food Science and Technology International, 2: 369-373.

Achi, O. 1992. Microorganisms associated with natural fermentation of Prosopis africana seeds for the production of okpiye. Plant Foods for Human Nutrition, 42: 297-304.

Adrian, J.; Potus, J.; Poiffait, A.; Dauvillier, P. 2000. Análisis nutricional de los alimentos. Editorial Acribia, Zaragoza, España, 91-93, 180-183.

Allen, O.; Allen, E. 1981. The legumes: a sourcebook of characteristics, uses and nodulation. University of Wisconsin Press, Madison, USA.

American Society for Testing and Materials. 1992. Descriptive analysis testing. MNL 13, Philadelphia.

American Society for Testing and Materials. 1981a. Guidelines for the selecting and training of sensory panel members. Special Technical Publication 758, Philadelphia, 5-17.

American Society for Testing and Materials. 1981b. Manual on sensory testing methods. Special Technical Publication 434, Philadelphia, 5-17.

American Oil Chemists Society. 1989. Official and Tentative Methods, Sampling and Analysis of Oilseed by Products, and Sampling and Analysis of Vegetable Oil Source Materials, USA.

Amerine, M.; Pangborn, R.; Roessler, E. 1965. Laboratory studies: quantity quality evaluations. En: Principles of Sensory Evaluation of Food. Academic Press, New York.

Anónimo. 1983. Caffeine. Food Technology, 37(4): 87-91.

Anzaldúa-Morales, A. 1994. La evaluación sensorial de los alimentos en la teoría y la práctica. Editorial Acribia, Zaragoza.

Apostolopoulos, D., Gilbert, S. 1990. Water sorption of coffee soluble by frontal inverse gas chromatography: Thermodynamic Considerations. Journal of Food Science, 55: 475487.

Arenas, P. 1981. Etnobotánica lengua maskoy. Fecic, Buenos Aires.

Ashoor, S.; Zent, J. 1984. Maillard browning in common amino acids and sugars. Journal of Food Science, 49(5): 1206-1207.

Association of Official Analytical Chemists. 1995. Official method of analysis of AOAC international, Arlington, Virginia, USA, $16^{\text {th }}$ Edition, I - II.

Azevedo Rocha, R. 1987. Algarroba na alimentaçâo e farmacopeia do homem rural NorteRiograndense. Revista da Associaçâo Brasileira de Algaroba. Mossoró, 1(1): 67-96.

Aw, T.; Swanson, B. 1985. Influence of tannins of Phaseolus vulgaris protein digestibility and quality. Journal of Food Science, 50: 67-71.

Babsky, N.; Toribio, J.; Lozano, J. 1986. Influence of storage on the composition of clarified apple juice concentrate. Journal of Food Science, 51: 564-567.

Baiâo, V. 1987. Características químicas e nutricionais das sementes de Algaroba (Prosopis juliflora (SW) DC). Revista da Associaçâo Brasileira de Algaroba. Mossoró, 1(3): 19-24.

Barbetti, P.; Chiappini, I. 1978. Gel chromatography of the brown pigments of coffee of different degrees of roasting. Industrie delle Bevande, 7(6): 455-460.

Baxter, J. 1995. Free amino acid stability in reducing sugar systems. Journal of Food Science, 60(2): 405-408.

Becker, R.; Grosjean, O. 1980. A compositional study of pods of two varieties of mesquite (Prosopis glandulosa, Prosopis velutina). Journal of Agricultural and Food Chemistry, 28 : 22-25.

Bender, A. 1994. Diccionario de nutrición y tecnología de los alimentos. Editorial Acribia, Zaragoza, $341 \mathrm{pp}$.

Berger, A.; Bruelhart, M.; Prodolliet, J. 1991. Detection of adulteration in pure soluble coffee by enzymatic sugar determination. Lebensmittel Wissenschaft und Technologie, 24(1): 59-62.

Belitz, H.; Grosch, W. 1997. Química de los alimentos. Editorial Acribia, Zaragoza, 1136 pp.

Biloni, J. 1990. Árboles Autóctonos Argentinos. Tipográfica Editora Argentina, Buenos Aires, 87-99.

Block, E. 1985. The chemistry of garlic and onions. Scientific American, 252(3): 114-119.

Bobbio, F. 1987. Estudo do polissacarídeo da semente de algaroba. Revista da Associaçâo Brasileira de Algaroba. Mossoró, 1(1): 35-39. 
Bobbio, P.; Imasato, H.; De Andrade Leite, S. 1981. Maillard reaction V: preparation and characterization of melanoidins from glucose and fructose with glycine. Anales Academia Brazileira de Ciencias, 53(1): 83-86.

Bravo, L. 1999. Propiedades y aplicaciones de la fibra de algarroba (Prosopis pallida L.). Alimentaria, 13(3): 67-73.

Bravo, L.; Abia, R.; Saura-Calixto, F. 1994a. Polyphenols as dietary fiber associated compounds. Comparative study on in vivo and in vitro properties. Journal of Agricultural and Food Chemistry, 42: 1481-1487.

Bravo, L.; Grados, N.; Saura-Calixto, F. 1998. Characterization of syrups and dietary fiber obtained from mesquite pods (Prosopis pallida L.). Journal of Agricultural and Food Chemistry, 46: 1727-1733.

Bravo, L.; Grados, N.; Saura-Calixto, F. 1994b. Composition and potential uses of mesquite pods (Prosopis pallida L): comparison with carob pods (Ceratonia siliqua L). Journal of the Sciences of Food and Agriculture, 65: 303-306.

Bravo, L.; Saura-Calixto, F.; Goñi, I. 1992. Effects of dietary fibre and tannins from apple pulp on the composition of faeces in rats. British Journal of Nutrition, 67: 463-473.

Bressani, R. 1978. Subproductos del fruto del café. En: Braham, J., Bressani, R. (eds). Pulpa de café: composición, tecnología y utilización. Centro Internacional de Investigaciones para el Desarrollo, Bogotá, Colombia, 9-17.

Brunauer, S.; Emmett, P.; Teller, E. 1938. The adsorption of gases in multimolecular layers. Journal of American Chemical Society, 60: 309-320.

Buera, M.; Chirife, J.; Resnik, S.; Wetzler, G. 1987. Nonenzymatic browning in liquid model systems of high water activity: kinetics of color changes due to Maillard reaction between different single sugars and glycine and compararison with caramelization browning. Journal of Food Science, 52(4): 1063-1067.

Buera, M.; Hough, G.; Martinez, E.; Resnik, S. 1990. Colorimetric, spectrophotometric and sensory color measurements of a dairy product: dulce de leche. Anales de la Asociación Química Argentina, 78: 291-295.

Burkart, A. 1976. A monograph of the genus Prosopis. Journal of the Arnold Arboretum, $\mathbf{5 7}$ (3): 217-249, (4): 450-525.

Burkart, A. 1952. Las leguminosas argentinas, silvestres y cultivadas. Ediciones Acme Agency, Buenos Aires, 126-143.

Carisano, A.; Garibaldi, L. 1964. Gas chromatographic examination of the fatty acids of coffee oil. Journal of the Science of Food and Agriculture, 15: 619-622.

Chiralt, A.; Castañeda, A.; Fito, P.; Giner, J. 1987. Colour Measurement as a Control Variable of Carob Powder Toast Process. En: Fito, P., Mulet, A. (eds). Actas del II Simposium International sobre la Garrofa. Generalitat Valenciana, Valencia, España, 515-529.

CIE. 1976. Oficial recommendations on uniform color spaces. Color difference equations and metric color terms. Colorimetry. Commission Internationale de l'Eclairage, Paris, 15(2).

Clarke, M.; Edye, I.; Eggleston, G. 1997. Sucrose decomposition in aqueous solution and losses in sugar manufacture and refining. Advances in Carbohydrates Chemistry and Biochemistry, 52: 441-470.

Clarke, R. 1987. Roasting and grinding. En: Clarke, R., Macrae, R. (eds). Coffee Technology, Elsevier Applied Science Publishers, London, 2: 73-108.

Clavijo, J. 1991. Uso de la pulpa de algarroba para la obtención de etanol. Tesis de Título Facultad de Ingeniería. Universidad de Piura, Perú.

Código Alimentario Argentino. 1998. Marzocchi Ediciones, Buenos Aires, I - II.

Coirini, R.; Karlín, U. 1999. El fruto del algarrobo en la alimentación animal, en el Chaco argentino: Estudio económico. En: Cuba, A., Silva, A., Cornejo, C. (eds). Bosques Secos y Desertificación. Memorias del Seminario Internacional, Lambayeque, Perú, 203-211.

Cornwell, C.; Wrolstad, R. 1981. Causes of browning in pear juice concentrate during storage. Journal of Food Science, 46: 515-518.

Costell, E.; Durán, L. 1981. El análisis sensorial en el control de calidad de los alimentos. III Planificación, selección de jueces, y diseño estadístico. Revista Agroquímica y Tecnología de Alimentos, 21(4): 454-460. 
Cruz, G. 1988. Evaluation of flour from Prosopis juliflora and Prosopis pallida pods in bakery and extrusion-cooking products. En: Habit, M. (ed). The current state of the knowledge on Prosopis juliflora, FAO, Roma, 425-439.

Cruz, G. 1999. Production and characterization of Prosopis seed galactomannan. PhD Thesis, Dissertation No13153, ETH Zurich.

Cruz, G.; Del Re, B.; Amadò, R. 1987. Contribución al estudio de la composición química de los frutos maduros del algarrobo. En: Resúmenes de la III Jornadas de Fotoquímica, Sociedad Química del Perú, Lima, 122.

Cummings, J.; Frolich, W. 1993. Dietary fibre intakes in Europe. Commission of the European Communities, Luxembourg.

Dalla Rosa, M.; Lerici, C.; Piva, M.; Fini, P. 1980. Procesi di trasformazione del café: aspetti chimici, fisici e tecnologici. Industrie delle Bevande, 466-472.

Del Valle, F. 1988. Evaluation of an industrial process for producing protein enriched mesquite pod (Prosopis sp.) flour. Journal of Food Processing and Preservation, 12: 179-185.

Del Valle, F.; Escobedo, M.; Muñoz, M.; Ortega, R.; Bourges, H. 1983. Chemical and nutritional studies on mesquite beans (Prosopis juliflora). Journal of Food Science, 48: 914-919.

Del Valle, F. Marco, E.; Becker, R.; Saunders, R. 1987. Development and evaluation of a procedure to produce mesquite (Prosopis sp.) pod protein concentrate. Journal of Food Processing and Preservation, 11: 237-246.

Del Valle, F. Marco, E.; Becker, R.; Saunders, R. 1986. Preparation of a mesquite (Prosopis $s p$.$) pod enhanced protein reduced fiber fraction. Journal of Food Science, 51: 1215-$ 1217.

Ellingson, R.; Mueller, A.; Kemmerer, K. 1954. Differences between fructose and glucose in the browning reaction. Fed. Proc., 13: 24 (Abstract).

Escudero, A.; Herraiz, M. 1943. Las bayas de algarrobo (Prosopis alba) como fuente de calcio en la alimentación. Revista de Dietología, 1(4): 266-272.

Espinoza, J. 1987. Tecnología apropiada para la producción de gomas a partir de gomas de semillas de algarroba peruana (Prosopis sp.). En: Fito, P., Mulet, A. (eds). Actas del II Simposium International sobre la Garrofa. Generalitat Valenciana, Valencia, 429-438.

Erize, E. 1960. Diccionario comentado mapuche-español. Universidad Nacional del Sur, Argentina.

Fagg, C.; Stewart, J. 1994. The value of Acacia and Prosopis in arid and semi-arid environments. Journal of Arid Environments, 27: 3-25.

FAO/WHO. 1973. Energy and protein requirements. Ad Hoc Committee, World Health Organization Technical, Reports Serie $\mathrm{N}^{\circ} 522$, Roma.

Feather, M.; Harris, J. 1972. Dehydration reaction of carbohydrates. Advances in Carbohydrates Chemistry, 28: 161-170.

Felger, R. 1977. Mesquite in Indian cultures of southwestern North America. En: Simpson B (ed). Mesquite: its biology in two desert ecosystems. Dowden, Hutchinson and Ross, Stroudsburg, Pennsylvania, USA, 150-176.

Felker, P. 1999. Oportunidades de Inversiones en el Algarrobo (Prosopis alba). Secretaría de Producción y Medio Ambiente. Santiago del Estero, Argentina, 13 pp.

Felker, P. 1981. Uses of tree legumes in semiarid regions. Economy Botany, 35: 174-186.

Felker, P.; Bandursky, R. 1977. Protein and amino acid composition of tree legume seeds. Journal of the Sciences of Food and Agriculture, 28: 791-797.

Felker, P.; Grados, N.; Cruz, G.; Prokopiuk, D. 2003. Economic assessment of production of flour from Prosopis alba and Prosopis pallida pods for human food applications. Journal of Arid Environments, 53(4): 517-528.

Fernandes, P.; Figueiredo, A. 1995. Effect of mesquite seed gum addition to kappa carrageenan or xanthan gum mixed systems. Food Hydrocolloids, 9: 251-255.

Figueiredo, A. 1975. Lebensmittelchemisch relevante Inhasltstoffe der Schoten der Algarobeira (Prosopis juliflora DC). Ph.D. Thesis, University of Würzburg, Alemania.

Figueiredo, A. 1983. Extraçâo, identificaçâo e características do polissacarídeo da semente de algarobeira (Prosopis juliflora DC). Ciência e Tecnologia de Alimentos. 3(1): 82-89. 
Figueiredo, A. 1987. Industrializaçâo das vagens de algaroba (Prosopis juliflora SW DC) visando a produçâo a goma da semente. Revista da Associaçâo Brasileira de Algaroba. Mossoró, 1(1): 7-34.

Figueiredo, A. 1990. Mesquite: history, composition and food uses. Food Technology, 44: 118-128.

Figueiredo, A.; Price, R. 1990. Chemical structure of mesquite (Prosopis juliflora DC) seed polysaccharide. Ciência e Tecnologia de Alimentos. 10(2): 287--300.

Folstar, P. 1985. Lipids. En: Coffee. Elsevier Applied Science Publishers, London and New York, I: 203-222.

Fox, B.; Cameron, A. 1992. Ciencia de los alimentos, nutrición y salud. Editorial Limusa, México, $457 \mathrm{pp}$.

Freyre, M.; Baigorria, C.; Rozycki, V.; Bernardi, C.; Martínez-Navarrete, N.; Camacho, M. 2001. Composición y propiedades de semillas de vinal (Prosopis ruscifolia L.). En: Fito, P., Chiralt, A., Andrés, A., Martínez, N. (eds). Series de Ciencia e Ingeniería de Alimentos, Investigación del Postgrado del Instituto de Alimentos para el Desarrollo, Departamento de Tecnología de Alimentos. Editorial de la Universidad Politécnica de Valencia, Valencia, II: 229-240.

Friedman, M. 1996. Food browning and its prevention: an overview. Journal of Agricultural and Food Chemistry, 44(33): 631-653.

Gal, S. 1983. The need for, and practical applications of, sorption data. En: Physical Properties of Foods. Jowitt, R., Escher, F., Hallström, B. Meffert, H., Spiess, W., Vos, G. (eds). Applied Science Publishers, London and New York, 13-25.

Galera, F.; Trevisson, M.; Bruno, S. 1992. Prosopis in Argentina: Initial Results on Cultivation in Greenhouses and Orchards, and Pod Quality for Food or Feed of Five Native Prosopis Species of Cordoba Province. En: Dutton, R. (eds). Prosopis species. Aspects of their Value, Research and Development. Proceedings of the Prosopis Symposium, Centre for Overseas Research and Development, University of Durham, UK, 145-156.

Grados, N.; Cruz, G. 1994. La algarroba, Perspectivas de utilización industrial. Universidad de Piura, Perú, Serie de Química N², 22 pp.

Grados, N.; Cruz, G. 1996. New approaches to industrialization of algarrobo (Prosopis pallida) pods in Peru. En: Felker, P.; Moss, J. (eds). Proceedings of the workshop: "Prosopis: semiarid fuelwood and forage tree, building consensus for the disenfranchised". 13-15 de Marzo. Washington DC. Texas A. and M. University, Kingsville, Texas, USA, 3.25-3.42.

Greenspan, L. 1977. Humidity fixed points of binary saturated aqueous solutions. Journal of Research of the National Bureau of Standards - A. Physics and Chemistry, 81A: 89-96.

Good, H. 2002. Measurement of color in cereal products. Cereal Foods World, 47(1): 5-6.

Habit, M.; Contreras D.; González, R. 1981. Prosopis tamarugo: arbusto forrajero para zonas áridas. FAO, Roma, 25.

Hall, C. 1972. Processing equipment for agricultural products. En: Food grinding and mixing. Westport, Connecticut, AVI Publishing, 3.

Handa, H.; Kuroda, N. 1999. Functional improvements in dried egg white through the Maillard reaction. Journal of Agricultural and Food Chemistry, 47(5): 1845-1850.

Hart, F.; Fisher, H. 1984. Análisis Modernos de Alimentos. Editorial Acribia, Zaragoza, 118,123-124.

Ho, C. 1996. Thermal generation of Maillard Aroma. En: Ikan, R. (ed). The Maillard reaction: consequences for the chemical and life science. John Wiley \& Sons, New York, 27-53.

Hodge, J. 1967. Origin of flavors in foods - non-enzymatic browning reactions. En: Schultz, H. Day, E. Libbey, L. (eds). Symposium on Foods: The Chemistry and Physiology of Flavors. AVI Publishing Co., Westport, Connecticut, 465-491.

Hodge, J. 1953. Dehydrated foods: Chemistry of browning reactions in model systems. Journal of Agricultural and Food Chemistry, 1(15): 928-943.

Holmquist-Donquis, I.; Ruiz de Rey, G. 1997. Functional properties of mesquite bean protein (Prosopis juliflora). Archivos Latinoamericanos de Nutrición, 47(4): 343-351.

Horigome, T.; Kumar, R.; Okamoto, K. 1988. Effects of condensed tannins prepared from leaves of fodder plants on digestive enzymes in vitro and in the intestine of rats. British Journal of Nutrition, 60: 275-286. 
Hough, G.; Buera, M.; Martinez, E.; Resnik, S. 1991. Effect of composition on nonenzymatic browning rate in dulce de leche-like systems. Anales de la Asociación Química Argentina, 79: 31-40.

Hurrell, R. 1982. Maillard reaction in flavour. En: Morton, I.; Macleod, A. (eds). Food Flavours, Elsevier Scientific, Ámsterdam, 399-437.

Ibarz, A.; Navés, J. 1995. Efecto de la temperatura y contenido en sólidos solubles sobre la cinética de pardeamiento no enzimático de zumos clarificados de manzana. Food Science and Technology International, 1: 29-34.

Iglesias, H.; Chirife, J. 1976. Prediction of effect of temperature on water sorption isotherms of food material. Journal of Food Technology, 11: 109-118.

Jimenez, B.; Vergara, A. 1977. Estudio sobre la composición química y posibilidades de industrialización de la algarroba. Tesis de Título Facultad de Ingeniería. Universidad de Piura, Perú.

Jones, J. 2000. Update on defining dietary fiber. Cereal Foods World, 45(5): 219-220.

Kanade, P.; Pai, J. 1988. Moisture sorption method for hygroscopic samples using a modified proximity equilibration cell. Journal of Food Science, 53(4): 1218.

Kanzaria, M.; Varshney, A. 1998. Prosopis juliflora its uses. En: Prosopis species in the arid and semiarid zones of India. Tewari, J.; Pasiecznik, L.; Harsh, L.; Harris, P. (eds). Prosopis Society of India and the Henry Doubleday Research Association, Coventry, UK, 113-115.

Karel, M. 1984. Chemical effects in food stored at room temperature. Journal of Chemical Education, 61(4): 335-339.

Kato, H.; Yamamoto, M.; Fujimaki, M. 1969. Mechanisms of browning degradation of Dfructose in special comparison with D-glucose-glycine reaction. Agricultural and Biological Chemistry, 33(6): 939-948.

Kuster, B., Temmink, H. 1977. The influence of $\mathrm{pH}$ and weak-acid anions on the dehydration of D-fructosa. Carbohydrates Research, 54: 185-192.

Labuza, T. 1984. Moisture sorption: practical aspects of isotherm, measurement and use. American Association of Cereal Chemists, St. Paul, MN, 149.

Labuza, T. 1972. Nutrient losses during drying and storage of dehydrated foods. CRC. Critical Review, Food Technology, 3: 217.

Labuza, T. 1980a. Temperature/enthalpy/entropy compensation in food reactions. Food Technology, 34(2): 67.

Labuza, T. 1980b. The effect of water activity on reaction kinetics of food deterioration. Food Technology, 34(4): 36-51, 59.

Labuza, T.; Baisier, W. 1992. The kinetics of nonenzymatic browning. En: Physical Chemistry of Foods. Schwartzberg H., Hartel, R. (eds). IFST, New York, 602, 622-625.

Labuza, T.; Kaaname, A.; Chen, J. 1985. Effect of temperature on the moisture sorption isotherms and water activity shift of two dehydrated foods. Journal of Food Science, 50: 385-391.

Lamarque, A.; Maestri, D.; Grosso, N.; Zygadlo, J.; Guzmán, C. 1994. Proximate Composition and Seed Lipid Components of some Prosopis (Leguminosae) from Argentina. Journal of the Sciences of Food and Agriculture, 66: 323-326.

La Torre, P. 1990. Polvo soluble instantáneo a partir de algarroba. Tesis de Título Facultad de Ingeniería. Universidad de Piura, Perú.

Lee, S. 1979. Caramel considered being a key component of coffee. Tea and Trade Journal, 151(9): 6-10.

Leino, M.; Lapveteläinen, A. 1991. Characterization of stored arabica y robusta coffee by headspace-GC and sensory analyses. Food Quality and Preference, 3(2): 115-125.

Leung, H. 1986. Water activity and other colligative properties of foods. En: Physical and chemical properties of foods. Okos, M. (ed). American Society of Agricultural Engineers, 138-185.

Lindsay, R. 1993. Flavor. En: Fennema, O. (ed). Química de los alimentos. Editorial Acribia, Zaragoza, (9): 659-707.

López Hernández, J.; Adris, J.; Fernández, E.; Monserrat, S. 1985. Obtención de mucílago a partir de algarrobo (Prosopis alba). La Alimentación Latinoamericana, 155: 62-64.

Lozano, R. 1978. El color y su medición. Editorial AméricaLee, Buenos Aires, 188-189. 
Mabrouk, R.; Deatherage, F. 1956. Organic acids in brewed coffee. Food Technology, 10: 194-197.

Madrid, A. 1991. Manual de Industrias Alimentarias. AMV Ediciones, Madrid, 504-508.

Maga, J. 1982. Pyrazines in foods: an update. Food Science and Nutrition, 16(1): 1-48.

Maga, J. 1981. Pyrroles in foods. Journal of Agricultural and Food Chemistry, 29(4): 691693.

Maga, J. 1975. The role of sulfur compouns in food flavor. Food Science and Nutrition, 6(2): 153-176.

Maier, H. 1985. On the composition of fast roasted coffees. En: $11^{\text {th }}$ International Colloquium on the Chemistry of Coffee, ASIC, Paris.

Marangoni, A.; Alli, I. 1988. Composition and properties of seeds and pods of the tree legume Prosopis juliflora (DC). Journal of the Sciences of Food and Agriculture, 44: 99110.

Martínez, N.; Andrés, A.; Chiralt, A.; Fito, P. 1998. Termodinámica y cinética de sistemas alimento entorno. Universidad Politécnica de Valencia, Servicio de Publicaciones, 375 pp.

Martínez, N.; Chiralt, A. 1996. Influence of roasting on the water sorption isotherms of nuts. Food Science and Technology International, 2(6): 399-404.

Martínez Crovetto, R. 1964. Estudios etnobotánicos. Nombres de plantas y su utilidad según los indios tobas del este del Chaco. Bonplandia, Corrientes, Argentina, I: 279-333.

Mauron, J. 1981. The Maillard reaction in food. A critical review from the nutritional standpoint. Progress in Food Nutrition and Science, 5(1): 5-35.

Meilgaard, M.; Civille, G.; Carr, V. 1991. Sensory evaluation techniques. CRC Press Inc., Boca Ratón, Florida, 187-200.

Métraux, A. 1944. Estudios de etnografía chaquense. Anales del Instituto de Etnografía Americana, V: 263-314.

Meyer, D. 1984. Processing, utilization and economics of mesquite pods as a raw material for the food industry. PhD Thesis, Dissertation No. 7688, ETH Zurich.

Meyer, D.; Becker, R.; Gumbmann, M.; Vohra, P.; Neukom, H.; Saunders, R. 1986. Processing, composition, nutritional evaluation, and utilization of mesquite (Prosopis $s p$.) pod as a raw material for the food industry. Journal of Agricultural and Food Chemistry, 34: 914-919.

Meyer, D.; Becker, R.; Neukom, H. 1982. Milling and separation of Prosopis pod components and their application in food products. En: Mesquite utilization. Parker, $\mathrm{H}$. (ed). Symposium proceedings, College of Agricultural Sciences, Texas Tech University, Lubbock, Texas, USA, L1-L12.

Montes, A. 1981. Bromatología. Editorial Universitaria Buenos Aires, Argentina, II: 315-316.

Monti, S.; Ritieni, A.; Graziani, G.; Randazzo, G.; Manzanina, L.; Segre, A.; Fogliano, V. 1999. LC/MS analysis and antioxidative efficiency of Maillard reaction products from lactose-lysine model system. Journal of Agricultural and Food Chemistry, 47(4): 15061513.

Myers, D.; Howell, J. 1992. Characterization and specification of caramel colours: an overview. Food Chemistry and Toxicology, 30(4): 356-363.

Nachmedov, F.; Kuljasova, N. 1990. Chicory-apple juice as coffee substitute. Pishchevaya Promyshlennost, USSR, 6: 20-21.

O'Beirne, D. 1986. Effect of $\mathrm{pH}$ on nonenzymatic browning during storage in apple juice concentrate prepared from bramley's seedling apples. Journal of Food Science, 51(4): 1073-1074.

O'Brien, J.; Morrissey, P. 1989. Nutritional and toxicological aspects of the Maillard browning reaction in foods. Critical Review Food Science and Nutrition, 25(3): 211-248.

O'Brien, J.; Morrissey, P.; Flynn, A. 1994. Alteration of mineral metabolism and secondary pathology in rats fed Maillard reaction products. En: Labuza, T.; Reineccius, G.; Monnier, V.; O'Brien, J.; Baynes, J. (eds). Maillard Reactions in Chemistry, Food and Health. The Royal Society of Chemistry, Cambridge, UK, 397-401.

Oduol, P.; Felker, P.; Mckinley, C.; Meier, C. 1986. Variation among selected Prosopis families for pod sugar and pod protein contents. Forest Ecology and Management, 16: 423-431. 
Ortega-Nieblas, M.; Vásquez-Moreno, L. 1995. Caracterización fisicoquímica de los aceites crudos de algunas semillas de leguminosas del desierto sonorense. Grasas y aceites, 46: $1-5$.

Ortega-Nieblas, M.; Vásquez-Moreno, L.; Robles-Burgueño, M. 1996. Protein quality and antinutritional factors of wild legume seeds from the sonoran desert. Journal of Agricultural and Food Chemistry, 44: 3130-3132.

Oste, R.; Miller, R.; Sjostrom, H.; Noren, O. 1987. Effects of Maillard reaction products on protein digestion. Studies on pure compounds. Journal of Agricultural and Food Chemistry, 35(6): 938-942.

Pak, M.; Arraya, H.; Villalon, R.; Tagle, M. 1977. Analytical study of Tamarugo, an autochthonous Chilean feed. Journal of the Sciences of Food and Agriculture, 28: 59.

Pasiecznik, N.; Felker, P.; Harris, P.; Harsh, L.; Cruz, G.; Tewari, J. Cadoret, K.; Maldonado, L. 2001. The Prosopis juliflora - Prosopis pallida complex: a monograph. Henry Doubleday Research Association, Coventry, UK, 162 pp.

Pérez, I. 1995. Estudio de algunos cambios químicos y microestructurales producidos en el proceso de elaboración del turrón de Jijona. Tesis Doctoral, Universidad Politécnica de Valencia.

Petriella, C.; Resnik, S.; Lozano, R.; Chirife, J. 1985. Kinetics of deteriorative reactions in model food systems of high water activity: Color changes due to nonenzymatic browning. Journal of Food Science, 50(3): 622-625.

Phillips, R.; Chinnan, M.; Branch, A.; Miller, J.; Mcwatters, K. 1988. Effects of pretreatment on functional and nutritional properties of Cowpea sp. meal. Journal of Food Science, 53: 805.

Pilosof, A. 2000. Propiedades de hidratación. En: Pilosof, A., Bartholomai, G. (eds). Caracterización funcional y estructural de proteínas. Editorial Universitaria de Buenos Aires, 17-29.

Poisson, J. 1977. Aspects chimiques et biologiques de la composition du café vert. En: 8th International Colloquium on the Chemistry of Coffee, ASIC, Paris, 219-234.

Primo Yúfera, E. 1998. Química de los alimentos. Editorial Síntesis. España, 23-24, 64-71.

Prokopiuk, D.; Cruz, G.; Grados, N.; Garro, O; Chiralt, A. 2001. Estudio Comparativo entre Algarroba Argentina (Prosopis alba) y Algarroba Peruana (Prosopis pallida). En: Fito, P., Chiralt, A., Andrés, A., Martínez, N. (eds). Series de Ciencia e Ingeniería de Alimentos, Investigación del Postgrado del Instituto de Alimentos para el Desarrollo, Departamento de Tecnología de Alimentos. Editorial de la Universidad Politécnica de Valencia, Valencia, II: 545-554.

Rajaram, N.; Janardhanan, K. 1991. Studies on the underexploited tree pulses, Acacia catechu Willd., Parkinsonia aculeata L. and Prosopis chilensis (Molina) Stunz: Chemical composition and antinutritional factors. Food Chemistry, 42: 265-273.

Ragonese, A.; Martínez Crovetto, R. 1947. Plantas indígenas de la Argentina con frutos o semillas comestibles. Revista de Investigación Agrícola, I: 147-216.

Reynolds, T. 1965. Chemistry of nonenzymatic browning. Advances in Food Research, II(14): 167-283.

Roig, F. 1993a. Informe Nacional para la Selección de Germoplasma en Especies de Prosopis de la República Argentina. En: Instituto Argentino de Investigaciones de las Zonas Áridas (eds). Conservación y Mejoramiento de Especies del Género Prosopis. Quinta Reunión Regional para América Latina y el Caribe de la Red de Forestación del Centro Internacional de Investigaciones para el Desarrollo, Mendoza, Argentina, 1-36.

Roig, F. 1993b. Aportes a la Etnobotánica del Género Prosopis. En: Instituto Argentino de Investigaciones de las Zonas Áridas (eds). Conservación y Mejoramiento de Especies del Género Prosopis. Quinta Reunión Regional para América Latina y el Caribe de la Red de Forestación del Centro Internacional de Investigaciones para el Desarrollo, Mendoza, 99-119.

Roig, F.; Dalmasso, A. 1986. Cartilla del algarrobo. Comité Ecológico, Mendoza, 16-17.

Romeo, M.; Vásquez, M.; Escobar, B.; Baeza, G. 1989. Viscosidad de soluciones de mucílago de algarrobo (Prosopis chilensis (Mol.) Stunz). I. Efecto del pH y de los iones sodio y calcio. Alimentos, Chile, 14: 23-27. 
Rozycki, V.; Baigorria, C.; Bernardi, C.; Zannier, M.; Osella, C. 1998. Optimización de Molienda de Frutos de Prosopis alba y Ensayos de Panificación. En: Instituto Nacional de Investigación y Tecnología Agraria y Alimentaria (eds). Simposio Iberoamericano sobre Proteínas para Alimentos (Buenos Aires, 1996), Madrid, 113-127.

Ruiz, W.; Cruz, G.; Grados, N. 1999. Aprovechamiento integral de la algarroba (Prosopis sp.) como medio para impulsar y promover el desarrollo sostenible de los bosques secos de la Región Grau. En: Cuba, A., Silva, A., Cornejo, C. (eds). Bosques Secos y Desertificación. Memorias del Seminario Internacional, Lambayeque, Perú, 91-106.

Rusconi, C. 1958. Acerca del pan de patay. Revista del Museo de Historia Natural de Mendoza, Argentina, XI: 193-208.

Sáenz, G.; Serra, J.; Escriche, I. 1987. Composición química de la algarroba peruana (Prosopis sp.). En: Fito, P., Mulet, A. (eds). Actas del II Simposium International sobre la Garrofa. Generalitat Valenciana, Valencia, 419-427.

Salazar, I. 1993. Cuantificación de taninos en cada una de las fracciones del fruto del algarrobo. Tesis de Título Facultad de Ingeniería. Universidad de Piura, Perú.

Sanz Pedrero, P. 1992. Fisicoquímica para farmacia y biología. Masson-Salvat Medicina, Barcelona, 596-601.

Saravia, R. 1995. La algarrobeada. Procesos tradicionales e intervención externa. Desarrollo Agroforestal y Comunidad Campesina, Salta, 3(14): 16-18.

Saunders, R.; Becker, R.; Meyer, D.; Del Valle, F.; Marco, E.; Torres, M. 1986. Identification of commercial milling techniques to produce high sugar, high fiber, high protein, and high galactomannan gum fractions from Prosopis pods. Forest Ecology and Management, 16: 169-180.

Saura, F.; Clavijo, J.; Abia, R. 1991. Características químicas del endocarpio del fruto del algarrobo piurano. Boletín de la Sociedad Química del Perú, 57: 245-250.

Schär, W.; Rüegg, M. 1985. The evaluation of GAB constants from water vapor sorption data. Lebensmittel Wissenschaft und Technologie, 18: 225-229.

Serra, J.; Escriche, I.; Fito, P.; Lluch, M. 1987. Evolución del comportamiento de los azúcares de la algarroba en distintas experiencias de tostado. En: Fito, P., Mulet, A. (eds). Actas del II Simposium International sobre la Garrofa. Generalitat Valenciana, Valencia, 541-550.

Shimoda, M.; Shibamoto, T. 1990. Isolation and identification of headspace volatiles from brewed coffee with an on-column GC/MS method. Journal of Agricultural and Food Chemistry, 38: 802-804.

Silva, S. 1988. Prosopis juliflora (Sw) DC in Brazil. En: Habit M. (ed). The current state of the knowledge on Prosopis juliflora. FAO, Roma, 29-55.

Simpson, B. (ed). 1977. Mesquite: its biology in two desert ecosystems. Dowden, Hutchinson and Ross, Stroudsburg, Pennsylvania, USA.

Singleton, V. 1981. Naturally occurring food toxicants: phenolic substances of plant origin common in foods. Advances in Food Research, 27: 149-242.

Singleton, V.; Rossi, J. 1965. Colorimetry of total phenolics in grapes and wine with phosphomolybdic-phosphotungstic acid reagent. American Journal of Enological Viticultural, 16: 144-158.

Sivetz, M. 1972. How acidity affects coffee flavor. Food Technology, 26: 70-77.

Sivetz, M. 1983. Tecnología aplicada al café y el té. En: Desrosier, N. (ed). Elementos de Tecnología de Alimentos. Compañia Editorial Continental, México, 607-619.

Smith, C. 1967. Plant remains. En: Byers, D. (ed). The prehistory of the Tehuacan Valley. Environment and Subsistence, I: 220-255.

Speer, K.; Sehat, N.; Montag, A. 1993. Fatty acids in coffee. En: $15^{\text {th }}$ International Colloquium on the Chemistry of Coffee, ASIC, Montpellier, 583-592.

Spiess, W.; Wolf, W. 1987. Critical evaluation of methods to determine moisture sorption isotherms. En: Water activity: Theory and Applications to Food. Rockland, L., Beuchat, L. (eds). Marcel Dekker, New York.

Spiess, W.; Wolf, W. 1983. The results of the Cost 90 Project on water activity. En: Physical properties of food. Jowitt, R.; Escher, F.; Hallström, B.; Meffert, h.; Spiess, W.; Vos, G. (eds). Applied Science Publishers, London and New York, 65-91.

Stone, H.; Sidel, J.; Oliver, S.; Woolsey, A.; Singleton, R. 1974. Sensory evaluation by quantitative descriptive analysis. Food Technology, 28(11): 2. 
Subsecretaría de Recursos Naturales y Medio Ambiente. 1999. Plan provincial de expansión forestal. En: Ministerio de la Producción (ed), Chaco, Argentina, 23.

Theander, O. 1981. Novel developments in caramelization. Progress in Food Nutrition and Science, 5: 471-478.

Tomasik, P.; Zawadzki, W. 1998. Reaction of the plant material with biogenic amino acids. Polish Journal of Food and Nutrition Sciences, 7/48(1): 29-34.

Toribio, J.; Lozano, J. 1987. Formation of 5-hydroxy methylfurfural in clarified apple juice during heating at elevated temperatures. Lebensmittel Wissenschaft und Technologie, 20: $59-64$.

Toribio, J.; Lozano, J. 1986. Heat induced browning in apple juice at high temperatures. Journal of Food Science, 51: 172.

Tressl, R.; Grünewald, K.; Koppler, H.; Silwar, R. 1978. Phenols in roasted coffees of different varietes. Zeitschrift für Lebensmittel Untersuchung und Forschung, 167(2): 108110.

Tressl, R.; Kossa, T.; Renner, R.; Koppler, H. 1976. Gas chromatographic-mass spectrometric investigations on the formation of phenolic and aromatic hydrocarbons in food. Zeitschrift für Lebensmittel Untersuchung und Forschung, 162: 123-130.

Tressl, R.; Silwar, R. 1981. Investigation of sulphur-containing components in roasted coffee. Journal of Agricultural and Food Chemistry, 29(5): 1078-1082.

Trevisson, M. 1992. Evaluación nutricional de frutos de tres especies de algarrobos: Prosopis alba, Prosopis chilensis y Prosopis nigra procedentes del noroeste de Córdoba. Tesina de Título Facultad de Biología. Universidad Nacional de Córdoba, Argentina.

Van Den Berg, C. 1985. Development of BET - like models for water of food. Theory and relevance. En: Properties of water in foods. Simatos, D., Multon, J. (eds). Martinus Nijhoff Publishers, Dordrecht, Netherlands, 119.

Van Den Berg, C.; Bruin, S. 1981. Water activity and its estimation in food systems: theoretical aspects. En: Water activity: Influences on food quality. Rockland, L.; Stewart, G. (eds). Academic Press, London and New York, 1-55.

Vásquez, M.; Carbonell, E.; Costell, E. 1988. Comportamiento reológico de soluciones acuosas de la goma de algarrobo (Prosopis chilensis). Comparación con el de las gomas de guar y garrofín. Revista de Agroquímica y de Tecnología de Alimentos, 28: 251-260.

Vieira, R.; Guerra, N.; Freitas, E. 1986. A contribution to the study of alternative sources of food: coffee-substitute from Prosopis juliflora pods. En: Habit M. (ed). The current state of the knowledge on Prosopis juliflora. FAO, Rome, 419-421.

Vieira, R.; Guerra, N.; Freitas, E. 1995. Sucedáneo do café a partir de Prosopis juliflora. D.C. Pesquisa Agropecuaria Brasileira, Brasilia, 30(1): 121-124.

Vijayakumari, K.; Siddhuraju, P.; Janardhanan, K. 1997. Effect of domestic processing of the levelsof certain antinutrients in Prosopis chilensis (Molina) Stunz seeds. Food Chemistry, 59: 367-371.

Wang, M.; Jin, Y.; Li, J.; Ho, C. 1999. Two novel betacarboline compounds from the Maillard reaction between xylose and tryptophane. Journal of Agricultural and Food Chemistry, 47(1): 48-50.

Whistler, R.; Daniel, J. 1993. Carbohidratos. En: Fennema, O. (ed). Química de los alimentos. Editorial Acribia, Zaragoza, (3): 81-156.

Wijewickreme, A.; Kitts, D.; Durance, T. 1997. Reactions conditions influence the elementary composition and metal chelating affinity of nondialyzable model Maillard reaction. Journal of Agricultural and Food Chemistry, 45(12): 4577-4583.

Wolf, W.; Spiess, W.; Joung, G. 1985. Standardization of isotherm measurements (COST Project 90 and 91 bis). En: Properties of water in foods. Simatos, D., Multon, J. (eds). Martinus Nijhoff Publishers, Dordrecht, Netherlands, 661.

Wong, D. 1995. Química de los alimentos, mecanismos y teoría. Editorial Acribia, Zaragoza, $476 \mathrm{pp}$.

Zamora, M.; Calviño, A. 1996. A comparison of methodology applied to the selection of a panel for sensory evaluation of instant coffee. Journal Sensory Studies, 11: 211-226.

Zolfaghari, R.; Harden, M. 1985. Analytical study of green and mature pods of mesquite (Prosopis glandulosa). Lebensmittel Wissenschaft und Technologie, 18: 186-191. 
Zolfaghari, R.; Harden, M. 1982. Nutritional value of mesquite beans (Prosopis glandulosa). En: Mesquite utilization. Parker, H. (ed). Symposium proceedings, College of Agricultural Sciences, Texas Technology University, Lubbock, Texas, USA, K2-K16.

Zolfaghari, R.; Harden, M.; Huffman, L. 1986. Some physical and chemical properties of honey mesquite pod (Prosopis glandulosa) and applications in food products. Cereal Chemistry, 63: 104-108.

Zuloaga, F; Morrone, O. 1996. Catálogo de las plantas vasculares de la República Argentina. Pteridophyta, Gymnospermae, Angiospermae (Monocotyledoneae). Missouri Botanical Garden Press, USA, I: 323 pp. 